\title{
Technical and economic effectiveness for repair with FRP of concrete T-beam bridges: Case study for PennDOT-District 3
}

Daniel A. Brayack

West Virginia University

Follow this and additional works at: https://researchrepository.wvu.edu/etd

\section{Recommended Citation}

Brayack, Daniel A., "Technical and economic effectiveness for repair with FRP of concrete T-beam bridges: Case study for PennDOT-District 3" (2006). Graduate Theses, Dissertations, and Problem Reports. 3243. https://researchrepository.wvu.edu/etd/3243

This Thesis is protected by copyright and/or related rights. It has been brought to you by the The Research Repository @ WVU with permission from the rights-holder(s). You are free to use this Thesis in any way that is permitted by the copyright and related rights legislation that applies to your use. For other uses you must obtain permission from the rights-holder(s) directly, unless additional rights are indicated by a Creative Commons license in the record and/ or on the work itself. This Thesis has been accepted for inclusion in WVU Graduate Theses, Dissertations, and Problem Reports collection by an authorized administrator of The Research Repository @ WVU. For more information, please contact researchrepository@mail.wvu.edu. 


\title{
Technical and Economic Effectiveness for Repair with FRP of Concrete T-Beam Bridges: Case Study for PennDOT-District 3
}

\author{
Daniel A. Brayack \\ Thesis submitted to the \\ College of Engineering and Mineral Resources \\ at \\ West Virginia University \\ in partial fulfillment of the requirements \\ for the degree of \\ Master of Science \\ in \\ Civil and Environmental Engineering \\ Julio F. Davalos, Ph D., Chair \\ Karl E. Barth, Ph D., Co-Chair \\ Indrajit Ray, Ph. D. \\ Department of Civil and Environmental Engineering \\ Morgantown, West Virginia \\ 2006
}

Keywords: fiber reinforced polymer (FRP), concrete t-beam bridge, cost-benefit, economic feasibility 


\title{
Technical and Economic Effectiveness for Repair with FRP of Concrete T-Beam Bridges: Case Study for PennDOT-District 3
}

\section{Daniel Brayack}

\section{Advisor: Dr. Julio F. Davalos}

\begin{abstract}
:
The bridge inventory of the Pennsylvania Department of Transportation - District 3 (PennDOT-D3) includes 128 concrete T-Beam bridges built in 1920 to 1960. Due to deterioration over time, a significant number of these bridges are in need of repair or replacement. Traditional methods of repair require temporary bridge-closures and do not provide long-term effective solutions. Moreover, the cost of replacement is not financially viable. Thus, PennDOT D-3 sponsored this project to investigate the technical and economic suitability of a relatively new technology, widely used for seismic retrofit, consisting of externally bonded Fiber-Reinforce Polymer (FRP) for repair and retrofit of concrete T-Beam bridges in particular, but applicable to other bridge structures in PA.
\end{abstract}

This thesis discusses a case-study project for innovative rehabilitation of cast-inplace concrete T-Beam bridges in PennDOT-D3. The 128 bridges considered are simplysupported structures of 20 to 60-ft span that provide much needed service throughout the District. Although specific to PennDOT-D3 this study presents a general prescription for the possible adoption of FRP for bridge repair and retrofit.

This study describes a method for cataloging candidate bridges from an inventory based on suitability and favorability for repair with externally bonded FRP composites. The rationale for the classification of a set of characteristics is described. This classification is based on inspection data (photographical indication of damage and field verification for representative bridges) and age, span, and ADT/ADTT. From these characteristics, three suitable levels are identified: Class 1 (high), Class 2 (moderate) and Class 3 (low). Correspondingly, 3 repair protocols are recommended: Major (repair contracted out through competitive bid), Moderate (repair performed as a joint effort 
between state engineers and contractors), and Minor (repair performed entirely by an inhouse crew). Comparisons are given for both cost-benefit (future worth) and construction methods for both FRP and conventional repair for these 3 levels. Also, from a synthesis of classification characteristics and repair levels, a prescription for the selection of candidate bridges for trial repair is presented, to implement the technology on Phase II of this project currently underway. 


\section{Acknowledgements}

First of all, I would like to express my dear thanks to my Advisor Dr. Julio F. Davalos for his continuing support and guidance throughout my time here at WVU. I really enjoyed my time here and am glad that I could have been a part of all of the projects that we worked on together. Also, I really enjoyed all of your classes. Because of my Junior level Structural Analysis class, I am pursing structures for my life-long career. Also, from the connections that I have gained through my experiences as a graduate student, I have been able to land my dream job, working for the DOH main office in Charleston. My sincere appreciation also goes to Dr. Karl Barth for the encouragement, the difficult classes and all of the fun and exciting balderdash discussions we had together. Also, thanks to Dr. Indrajit Ray. I really enjoyed working with you and have learned quite a lot from my classes with you. To Dr. Chunfu Lin, thanks for helping me and providing me with excellent knowledge in class and throughout the projects.

I would like to thank Lauren, Andy, Lora, Jennifer, Yi, and Zhiguo for the time we spent together in the graduate office and the fun that we had together in classes.

I gratefully acknowledge the financial support from West Virginia University and my advisor, Dr. Davalos.

Also, I would like to thank my Dad, my Grandpa and my Grandma for their endless support. Finally, I would like to thank the Campus Lutheran Ministry, and my Pastor, Matthew Riegel, for providing a healthy and moral environment from which I was able to grow into a responsible and well-manner person. 


\section{Table of Contents}

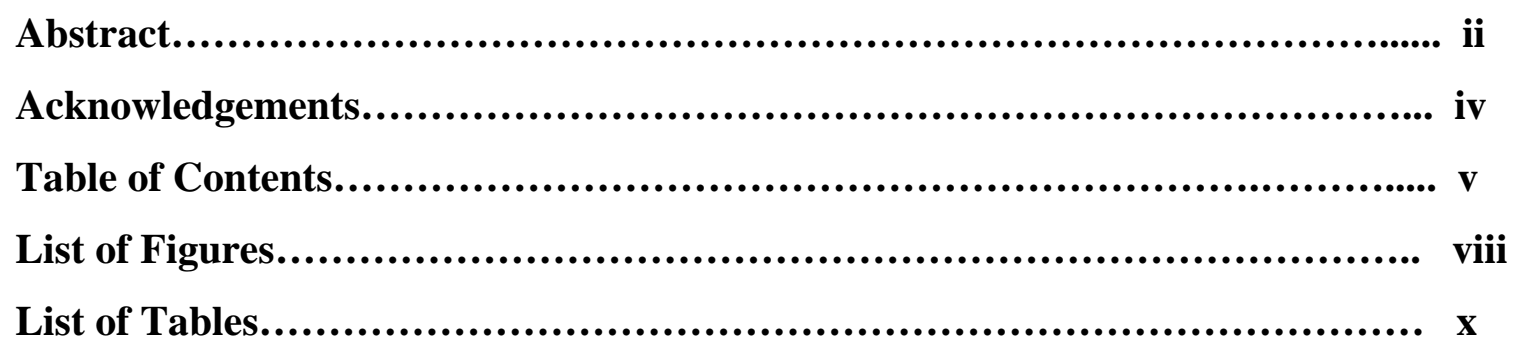

Chapter 1 Introduction........................................................ 1

$1.1 \quad$ Background....................................................... 1

1.2 Development of FRP for Rehabilitation............................... 2

1.3 Advantages of Repair with FRP.................................. 3

1.3.1 Applicability of FRP for Repair............................. 3

1.3.2 Versatility of FRP...................................... 3

$1.4 \quad$ Objectives and Scope of Work.................................... 4

Chapter 2 Overview of Conventional and FRP Repair Methods................ 7

2.1 Overview of Conventional Repair Methods............................ 7

2.2 Overview of Repair using the FRP technology ....................... 7

2.3 Example Repair from Missouri Department of Transportation............ 9

$2.4 \quad$ Summary and Conclusions..................................... 10

Chapter 3 Classifications of Bridges................................ 15

3.1 Defining Characteristics Classifications........................... 15

3.2 Application of Characteristics Classifications to PennDOT D-3....... 17

3.2.1 Overview of Inventory of PennDOT-D3.................... 18

3.2.2 Application of Characteristics Classification................. 18

3.2.3 Examples of Classification............................... 20

3.2.4 Weight Values for Characteristics Classification.............. 20 
3.2.5 Overall Classification of the PennDOT-D3 Inventory......... 21

3.3 Recommendations for General Classification...................... 22

3.3.1 General Characteristic Classifications........................ 22

3.3.2 Localized Damage Classifications.......................... 23

3.3.3 Weighted Averages..................................... 23

3.4 Grouping based on Overall Damage.............................. 24

3.4.1 Repair Level-1 (Major).................................... 24

3.4.2 Repair Level-2 (Moderate) $\ldots \ldots \ldots \ldots \ldots \ldots \ldots \ldots \ldots \ldots \ldots \ldots .25$

3.4.3 Repair Level-3 (Minor).................................. 25

3.5 Conclusions.................................................. 26

Chapter 4 Recommendations for Selecting Ideal Candidate Bridges............ 41

4.1 Considerations for Selection of Candidate Bridges................. 41

4.1.1 Suitable Candidates....................................... 41

4.1.2 Preliminary Analysis.................................... 42

4.1.3 Detailed Analysis....................................... 43

4.2 Selection of Candidate Bridges for Different Levels of Repair........ 44

4.2.1 Major Candidate Bridges (Repair - Level 1).............. 45

4.2.2 Moderate Candidate Bridges (Repair - Level-2).............. 45

4.2.3 Minor Candidate Bridges (Repair - Level 3)................ 46

4.3 Suggested Implementation Strategy........................... 47

4.4 Conclusions.............................................. 47

Chapter 5 Comparison of Methods Based on Costs \& Construction........... 51

5.1 Design Assumptions........................................... 51

5.2 Repair-Example 1: Cost Comparison for Level 1 repair............ 52

5.2.1 Design and Cost Assumptions for Repair-Example 1......... 52

5.2.2 Cost Assumptions for Replacement........................ 53

5.2.3 Comparison of Costs for Repair-Example 1................ 54 
5.3 Repair-Example 2: Cost comparison for Level 2 repair.............. 54

5.3.1 Cost-Benefit Comparison for Repair-Example 2.............. 55

5.3.2 Repair Scenarios Repair-Example 2...................... 55

5.3.3 Design and Cost Estimate for Repair-Example 2............. 56

5.3.4 Present Worth of Scenario 1 for Repair-Example 2........... 58

5.3.5 Cost Comparison for Repair-Example 2.................. 58

5.4 Repair-Example 3: Cost Comparison for a Level 3 repair............ 58

5.4.1 Design and Cost Estimate for Repair-Example 3............. 59

5.5 Learning Curve Approach...................................... 61

5.6 Comparison of Construction Methods........................... 61

5.7 Detour-Driving Mileage Costs for Repair Example 2 ................. 62

Chapter 6 Recommendations for Implementation............................. 72

6.1 Various Approaches to Implementation........................ 72

6.2 PennDOT-D3 Implementation............................... 72

6.3.1 Castlewood Canyon Arch Bridge....................... 73

Chapter 7 Conclusions and Recommendations................................ 80

7.1 Concluding Remarks....................................... 80

7.2 Recommendations for Future Work............................. 82

References....................................................................... 84

Appendix A Details of Characteristics Classifications.......................... 85

Appendix B Classification Based on Local Damage............................. 91 


\section{List of Figures}

Figure 1.1 Typical damage to a Reinforced Concrete T-beam. PennDOT-D3:

Bridge\#12-54-2013-0010-0000................................. 6

Figure 2.1 A Typical Formwork Diagram for Repair Using the Conventional Method, Provided by PennDOT-D3.................................. 11

Figure 2.2 Bridge X-0596 of MODOT (Galati et al., 2004)..................... 11

Figure 2.3 Condition of Exterior Girder of Bridge X-0596-MDOT

(Galati et al., 2004)............................................... 12

Figure 2.4 Cutting of FRP sheets (Galati et al., 2004)....................... 12

Figure 2.5 Manual Lay-up FRP Sheet Installation (Galati et al., 2004)............ 13

Figure 3.1 An example of Damage Class-3 local damage. Damaged area extends above the rebar...................................... 28

Figure 3.2 Another example of Damage Class-3 local damage. Damaged area extends above the rebar......................................... 28

Figure 3.3 Examples of Damage Class-2 local damage. ........................ 29

Figure 3.4 Example of a Damage-Class 1 local damage......................... 29

Figure 3.5 Bradford County \#08-4034-0140-1580 ............................ 30

Figure 3.6 Union County \#59-0045-0310-2011_............................... 31

Figure 3.7 Bradford County \#08-4013-0250-1496............................ 32

Figure 3.8 Union County \#59-1001-0110-2058............................. 33

Figure 3.9 Snyder County \#54-0522-0090-1932_............................... 34

Figure 3.10 Columbia County \#19-3008-0100-0039........................... 35

Figure 3.11 Tioga County \#58-1002-0050-0000 .............................. 36

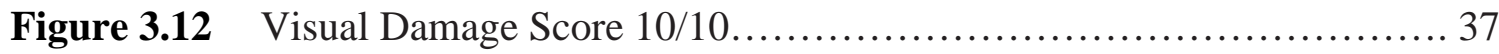

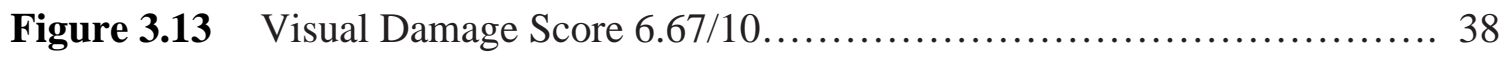

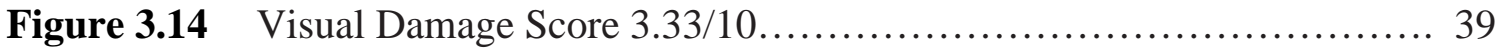

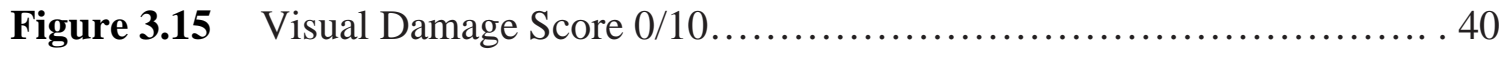


Figure 4.1 Major Candidate Bridge (Repair Level-1)........................ 48

Figure 4.2 Moderate Candidate Bridge (Repair Level- 2)....................... 49

Figure 4.3 Minor Candidate Bridge (Repair Level-3)......................... 50

Figure 5.1 Standard T-Beam Section for Design Assumptions

for the FRP Repair......................................... 65

Figure 5.2 Standard T-Beam Section for Design Assumptions for

the Conventional Repair........................................ 65

Figure 5.3 Bridge \#41-0118-0230-0644, PennDOT-D3 Inventory............... 66

Figure 5.4 Photographical Indication of Damage to the Center Pier of

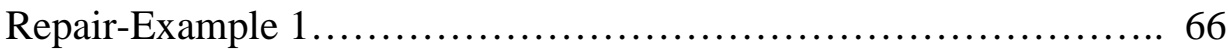

Figure 5.5 Bridge \#59-0045-0310-2011................................ 67

Figure 5.6 A Cross-Sectional Diagram of the Bridge \#59-0045-0310-2011,

Provided by PennDOT-D3......................................6 67

Figure 5.7 Cost Comparisons Between Conventional and FRP

Methods for Example 2, Scenarios 1 and 2.................... 68

Figure 5.8 Bridge \#41-0118-0020-1109................................. 69

Figure 5.9 Typical Learning Curve (Xanthakos, 1995)........................ 70

Figure 5.10 Gantt Chart for Conventional Repair (obtained with

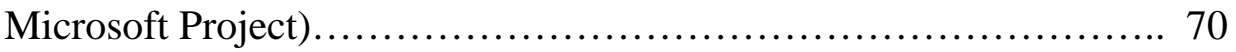

Figure 5.11 Gantt Chart for Surface-Bonded FRP Technology

(obtained with Microsoft Project)............................ 70

Figure 5.12 Open Traffic Plans for Example Bridge 2 (distance $=600$ yards)..... 71

Figure 6.1 Castlewood Canyon Arch Bridge FRP Repair. (ASCE).............. 77

Figure 6.2 Typical Damage to the Castlewood Canyon Arch

Bridge. (Fafach, Shing, Chang and Xi, 2004).................. 78

Figure 6.3 FRP repair applied by (Hag-Elsafi, Alampalli, Kunin, 2001)

and (Hag-Elsafi, Alampallil, Kunin, 2003)..................... 79

Figure 6.4 Damaged Beam-Cap repaired by (Hag-Elsafi, Lund,

Alampalli, 2002)........................................... 79 


\section{List of Tables}

Table 2.1. Summary of Information of Repair of Bridge X-0596

(Galati et al., 2004).............................................14

Table 3.1: Classification of Bridges in PennDOT D-3.........................22

Table 3.2: Local Damage Levels of Bridges in PennDOT D-3...................22

Table 3.3: Example of Application of an Importance Factor to Bridge Classification for Bridge \#49-1039-0020-0000........................27 


\section{Chapter 1}

\section{Introduction}

This thesis ties closely to a portion of a report presented to PennDOT District 3 (PennDOT D-3) as part of a project to investigate an alternative method for the rehabilitation of deteriorating concrete T-Beam bridges. This report (Davalos, Barth, Ray, et al. 2005), as well as this thesis, answer a series of questions posed by PennDOT D-3. This thesis expands upon the project report by proposing a general scheme for the selection of bridges for rehabilitation; the PennDOT D-3 project is used to develop this scheme and then is presented as an example. This Chapter reviews the background for the repair of deteriorating concrete structures with externally bonded Fiber-Reinforced Polymer (FRP) Composites. Concrete deterioration is first discussed, followed by FRP repair as an alternative to conventional rehabilitation methods. An "under-water" example repair is presented to demonstrate the versatility and advantages of FRP. Finally, the scope of work for this thesis is presented.

\subsection{Background}

Concrete structures and particularly concrete highway bridges are continuously exposed to the deleterious effects of environmental attacks, leading to degradation of the material and corrosion of the reinforcing steel. Such degradation is exacerbated by the application of deicing salts on highway bridges as well as the freeze-thaw and dry-wet cyclic exposures causing accelerated ageing of structures over time. In the United Sates nearly one-third of the highway bridges are in need of repair or replacement, and a significant percentage of these bridges include concrete either partially or totally. Figure 1.1 shows a common result of these deteriorating mechanisms. The US infrastructure rehabilitation cost is estimated at 1.3 trillion dollars over the next five years, with corrosion deterioration costs due to deicing and sea salts effects estimated at $\$ 150$ billion (Davalos, Barth, Ray, et al. 2005.) Similarly in the United Kingdom over 10,000 concrete bridges are in need of structural strengthening. In Europe, the cost of the repair of reinforced concrete structures because of steel corrosion is estimated to be over $\$ 600$ million 
annually. In Canada, it is estimated that the required repair costs for parking garages alone is about $\$ 6$ billion (Neville, 1996).

As an illustration of structural deterioration of concrete highway bridges, consider a recent bridge collapse in Washington Pennsylvania that has roused concerns about the condition of concrete bridges in PA and the United States of America. A paraphrase (Time, 29 December 2005): “On 27 December, 2005 a 45-year old overpass (SR-1014) that had been rated 'structurally deficient' and has been hit repeatedly by trucks collapsed under its own weight. PennDOT inspects bridges every two years; this bridge was due for inspection in two months. Its deck and superstructure had been rated a 4 out of 10 , with 10 being the best in March 2004. Still the bridge was not posted with load limits. It would have been categorized as 'structurally deficient' along with 25 percent of all 25,000 bridges the state owns. Three people were injured, a 45-year old woman, her 6month old daughter and her 22-month old son.” Several weeks later, several other bridges were closed; a paraphrase (Time, 29 December 2005): “Two bridges over I-70 in Washington County were closed. The bridges that were closed were similar in design to the one that collapsed. 'We are applying lessons learned from the recent incident and looking even more intently at bridges of this type that span the highways' said PennDOT Secretary Allen D. Biehler. The cause of failure was sited as deterioration of reinforced strands."

\subsection{Development of Fiber-Reinforced Polymer/Plastic for Rehabilitation}

Concrete deterioration worldwide has motivated the development of new and innovative materials and methods for structural rehabilitation, since replacement of structures would be very costly. One solution to overcome steel corrosion in concrete for new construction is to use Fiber-Reinforced Polymer or Plastic (FRP) materials instead of steel. More importantly is the beneficial application of FRP for structural rehabilitation of deteriorated concrete structures. FRP composite materials in the form of fabrics and laminates have been externally bonded to concrete structures to increase structural capacity and provide longer service-life. The application of this technology in practice has been highly successful (Davalos, Barth, Ray, et al. 2005). 


\subsection{Advantages of Repair with FRP}

This Section discusses the advantages and applications of FRP repair, specifically applicability and versatility. An example is presented to demonstrate these advantages.

\subsubsection{Applicability of FRP for Repair}

FRP repair is a simple way to increase both the strength and design life of a structure. Because of its high strength to weight ratio and resistance to corrosion, this repair method is ideal for deteriorated concrete structures due to exposure to de-icing salts and other environmental factors. By encasing concrete members, FRP protects existing steel and concrete from deleterious effects. It was noted that in many bridges the majority of corrosive damage occurred on exterior girders. This indicates that deleterious effects may be a direct result of surface exposure to spray of water and de-icing agents. Encasement of these girders not only increases design life, but also protects the members from surface attacks.

\subsubsection{Versatility of FRP}

FRP is a versatile material. Though this thesis focuses on concrete T-Beam bridges, FRP can be applied to a wide range of structures. FRP sheets can be cut and easily bonded to any concrete member. The next Section presents an example of a wide-scale repair of pier structures where due to site conditions and cost, FRP repair was well suited.

\subsubsection{Example: Issues Related to FRP Wrap of Corroded Piers}

Sen and Mullin's, (2004) investigated the application of FRP to piers in a harsh, corrosive environment, and demonstrated the cost-effectiveness and versatility of FRP. The 2.6mile Friendship Trails Bridge is the world's longest over-the-water recreational trail. Located in Florida, this bridge contains 254 piers. About seventy percent of these piers needed to be repaired; hence, an inexpensive means was sought. Through this project, it was found that FRP was an easy and cost-effective method for rehabilitation. "The research team was pleasantly surprised at the ease with which the underwater wrapping was carried out.” Figure 1.2 shows piers and application of the FRP. 


\subsection{Objectives and Scope of Work}

The specific objective of this thesis is to investigate the technical and economical feasibility of using “surface-bonded FRP-wrap repair” (FRP repair/method) for widescale bridge rehabilitation. This thesis uses a project performed with PennDOT D-3 as case study to present bridge-classification and the selection of candidate bridges from an inventory for FPR repair. An interesting note is that most applications of FRP in the past have been concerned with only one or several large repairs to "highlight" or “demonstrate” FRP innovation. In contrast, the scope of the PennDOT D-3 project includes a District-wide “and possibly State-wide” replacement of a conventional repair method with the FRP repair. Specifically this thesis intends to answer a serious of questions posed by PennDOT D-3.

Chapter 2 poses an answer to the question: "Is FRP a valid repair method for bridges in the PennDOT D-3 inventory?” This Chapter presents both the conventional and FRP methods for repair of reinforced concrete T-Beam bridges. The repair procedure for the FRP method is presented in detail using both a repair protocol from a materials provider and an example repair from the Missouri Department of Transportation (MODOT). From this example repair, it is shown that MODOT has successfully implemented FRP repair on bridges similar to those in the PennDOT D-3 inventory. Also, a typical formwork diagram is used to illustrate the conventional method and to provide a contrast between these two repair methods.

To answer the following question: "Which bridges are suitable and favorable for repair using FRP?” and “Which bridges are ideal candidates for a trial repair program?”, Chapter 3 groups bridges in two ways. The first group involves classification based on bridge characteristics (3.1). These characteristics include type and extent of local damage (Damage-Class), and bridge data such as age, span-length, and traffic levels. This classification is designed to rank bridges accordingly for suitability and favorability for repair with FRP. 
The second grouping includes classification based on overall damage (3.2). Three levels of repair are defined and presented to indicate the overall level of repair. This is important for a transition from conventional repair methods to FRP repair. We recommended that first, a large-scale (Repair-Level 1) project be carried out, which would be contracted out through competitive bid. This would provide PennDOT D-3 with a good training experience. The end-goal of this technology transfer is to allow PennDOT D-3 to implement FRP autonomously with a blend of "in-house" forces and competitive bids based on the required level of repair.

The characteristic classifications described above are applied to the PennDOT D-3 inventory in 3.3 as an example. Using the classifications developed for PennDOT D-3, a prescription for general classifications is suggested in 3.4.

To answer the question posed in Chapter 3: "Which bridges are ideal candidates for a trial repair program?”, a synthesis of the two groupings from Chapter 3 is used to define "ideal candidate bridges" in Chapter 4. These bridges are later used in Chapter 5 to answer the question: "Is the FRP technology economically feasible and competitive with the conventional repair method?” In Chapter 5, comparisons are given for both costs and construction requirements for both methods.

After answering technical and economic questions and selecting candidate bridges, the final question posed is: "What are the implementation steps for FRP repair of the selected bridge(s)?” This question is answered in Chapter 6 by a series of suggested steps. Several selected examples are presented from numerous of projects to illustrate the implementation steps. Finally, conclusions and recommendations for future work are presented in Chapter 7. 


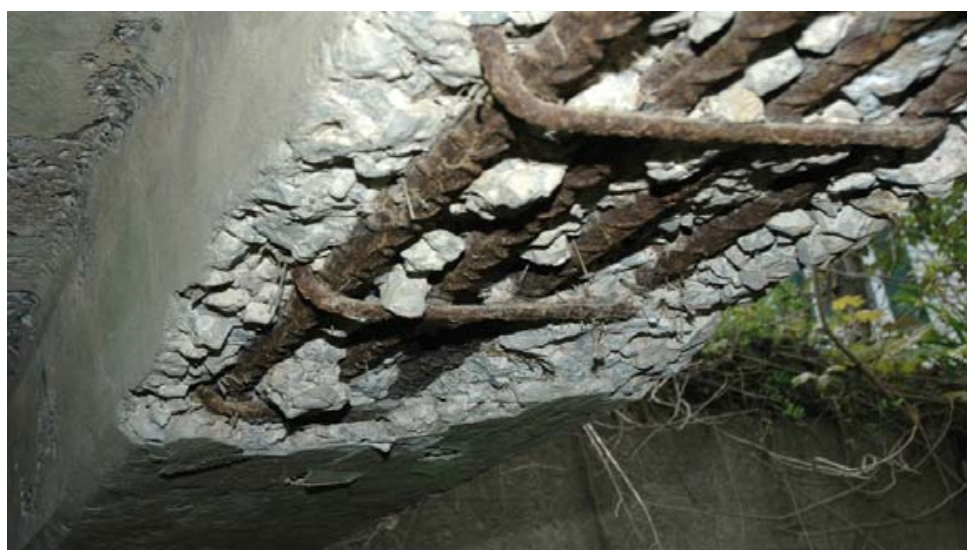

Figure 1.1: Typical damage of a Reinforced Concrete T-beam. PennDOT-D3: Bridge\#12-54-2013-0010-0000.
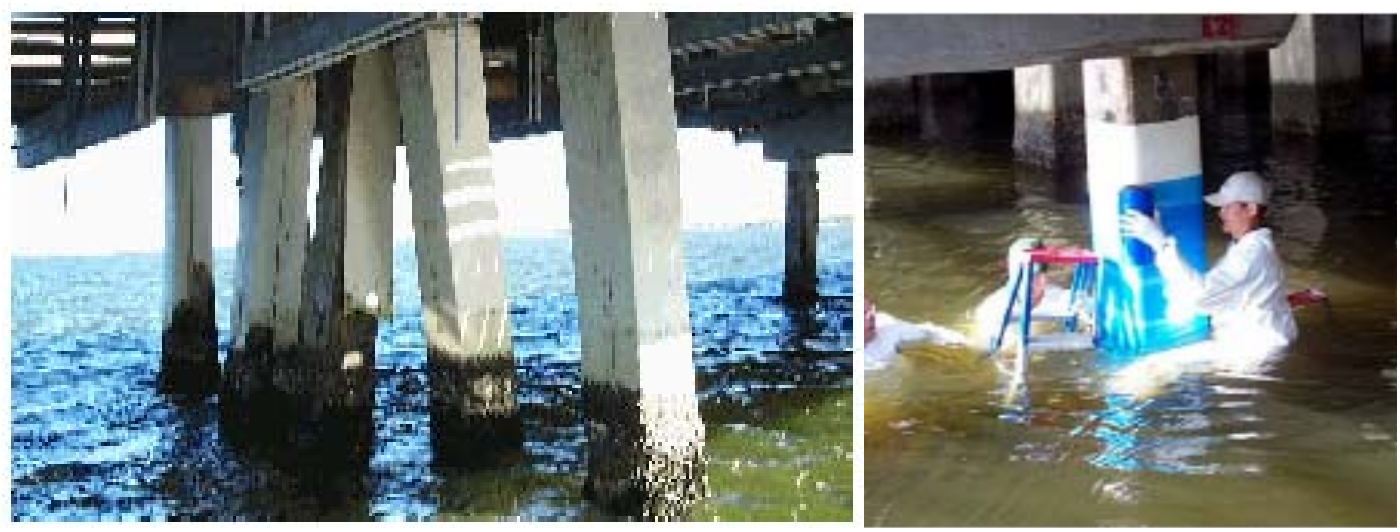

Figure 1.2: $\quad$ Corroded piers and application of FRP (Sen and Mullins, 2004). 


\section{Chapter 2}

\section{Overview of Conventional and FRP Repair Methods}

This Chapter answers the question: "Is FRP a valid repair method for bridges in the PennDOT D-3 inventory?” To provide background on the existing method, an overview of the conventional repair method employed by PennDOT D-3 is presented (2.1). To provide insight, an overview of the application of surface-bonded FRP to concrete bridges is provided in (2.2). The FRP repair method is discussed by using both a typical installation procedure from Fyfe CO, a technology provider (2.2), and a sample repair performed in Missouri (2.3). An answer to the posed question and a summary of this chapter are provided in (2.4).

\subsection{Overview of Conventional Repair Methods}

In an effort to prevent further corrosion of steel rebar and deterioration of reinforced concrete T-Beam bridges, a conventional repair technique has been developed and employed by PennDOT D-3. This method involves: removal of all loose and unsound concrete, replacement and/or additional placement of rebar, and placement of formwork to cast a concrete cover or "jacket." Though this process seems quite simple, formwork and repair of rebar requires significant effort. Figure 2.1 shows an example of suggested formwork for a conventional T-Beam repair. This figure was provided by PennDOT-D3.

\subsection{Overview of Repair using the FRP technology}

The behavior of concrete members retrofitted with FRP systems is highly dependent on a sound concrete substrate, as well as proper preparation and profiling of the concrete surface. Surface preparation of the substrate is essential to achieve a good bond. The surface must be clean of all laitance, dust, dirt, oil, curing compound and existing coatings by appropriate means (Davalos, Lin, Ray, et al. 2005). Other irregularities should be filled or ground smooth in order to provide an acceptable surface. Once the surface is prepared, the FRP is applied using the manufacture's specifications. To 
provide an overview of the FRP surface-bonded repair process, a typical installation procedure prescribed by Fyfe Co., a supplier of this technology, is as follows:

1. Prepare surface to receive the composite laminate strips by abrasive blasting or grinding to achieve a 1/16" minimum aggregate amplitude (International Concrete Repair Institute CSP 5 - Guideline No.03732).

2. Broom or air-clean surface per specification.

3. Apply primer coat of $\mathrm{TYFO}^{\circledR} \mathrm{S}$ or $\mathrm{TYFO}^{\circledR}$ WS (propriety designation for carbon composite laminate strips) to the prepared substrate.

4. Apply a thick coat (approximately $1 / 16$ ”) of $\mathrm{TYFO}^{\circledR} \mathrm{TC}$ to the primed substrate for bond.

5. Clean the abraded side of the laminate (side without lettering) with acetone or other similar solvent to remove all foreign materials - allow complete evaporation of solvents prior to proceeding with the installation.

6. Apply TYFO ${ }^{\circledR}$ TC epoxy adhesive (approximately $1 / 16$ ”) to the cleaned laminate surface using a trowel or by similar method. Note - The TYFO ${ }^{\circledR} \mathrm{TC}$ is not to be applied to the cleaned strip for a minimum of 30 minutes to allow complete evaporation of the Acetone or other solvent.

7. Allow sufficient time for the epoxy adhesive to become tacky as required.

8. Apply strips to surface by hand placement. The laminate shall then be pressed to the substrate using a hard roller (rubber or steel) to assure both proper bond and uniform elevation. Excess extruded epoxy may be removed by trowel or similar method.

9. Clean excess epoxy from installed laminate and adjacent areas.

10. Finish: Refer to architectural specification for final finish. Use system as directed by manufacturer.

11. Cure: The composite shall be protected from contact by moisture for a period of a minimum of three days. Curing is complete after seven days.

An example repair from the Missouri Department of Transportation is presented next to illustrate surface preparation and the installation of eternally bonded FRP. 


\subsection{Example Repair from Missouri Department of Transportation}

To illustrate the application and process of FRP repair, an example repair of two bridges is provided. The repairs were performed by the Missouri Department of Transportation (MODOT) in conjunction with the University of Missouri-Rolla (UMR), and under the direction of Dr. Nestore Galati (Galati et al., 2004). These bridges (Bridge X-0596 and Bridge T-0530) are similar in design and have experience a similar level and type of damage as the bridges in the PennDOT-D3 inventory. Figures 2.2, 2.3 and Table 2.1 show photos of Bridge X-0596 and a summary of information. The MODOT repairs were targeted for both rehabilitation and strengthening. Although strength gain may not be a primary objective in projects, it is an added benefit of repair using FRP. The implementation steps of MODOT's FRP repair are summarized next, and include: (1) substrate repair, (2) surface preparation, (3) application of FRP, and (4) traffic control.

1. Substrate Repair: The performance of the composite system not only depends on the strength and quality of the concrete substrate, but also on the bond between the composite and substrate. Unsound concrete was removed and patched. Also, holes were filled (Galati et al., 2004).

2. Surface Preparation: To promote continuous and intimate contact between the substrate and FRP, concrete irregularities were removed and smoothed to less than $1 \mathrm{~mm}$. Also, all corners were rounded to reduce stress concentrations. Finally, abrasive sandblasting was used to clean the concrete surfaces of dust, dirt, laitance, oil and any curing substances. Concrete surface roughness was equivalent to CSP 3 (Concrete Surface Profile number 3) as defined by the "International Concrete Repair Institute” (Galati et al., 2004).

3. External Bonding of Composite Reinforcement: Three spans of Bridge X-0596 were bonded with manual lay-up laminates. The installation process is described next. 
Epoxy primer was used to fill voids in the concrete surface. All surfaces, which were to be bonded with FRP, were primed with a penetrating primer. Primer was mixed in accordance with the manufacturer's specified ratio and applied using brushes and rollers.

The carbon fiber sheets were cut (see Figure 2.4, photos from Bridge T-0530) before placement into prescribed sizes. Next, the sheets were installed by manual lay-up methods. The sheets were saturated using rollers (Figure 2.5). After appropriate time (10 minutes), a second saturant application was applied to complete impregnation. The saturant was applied in strict accordance with the manufacturer's recommendations. (Galati et al., 2004)

4. Traffic Control: One of the benefits of the application of this technology is that the bridge does not need to be closed during installation. However, in order to avoid vibrations on Bridge T-0530 during the installation, traffic control was used. Speed of vehicles was limited to $15 \mathrm{mph}$.

\subsection{Summary and Conclusions}

This chapter has presented an overview of both the conventional repair method employed by PennDOT D-3 and the innovative FRP repair method. Specifications from Fyfe Co. were summarized to show the steps for performing an FRP repair. Also, an example for MODOT brides in collaboration with UMR was provided to show details of FRP repair. From these specifications and example repairs from MODOT (for bridges similar to those in the PennDOT D-3 inventory), it is inferred that the FRP method is potentially applicable to the repair of PennDOT D-3's bridges. 


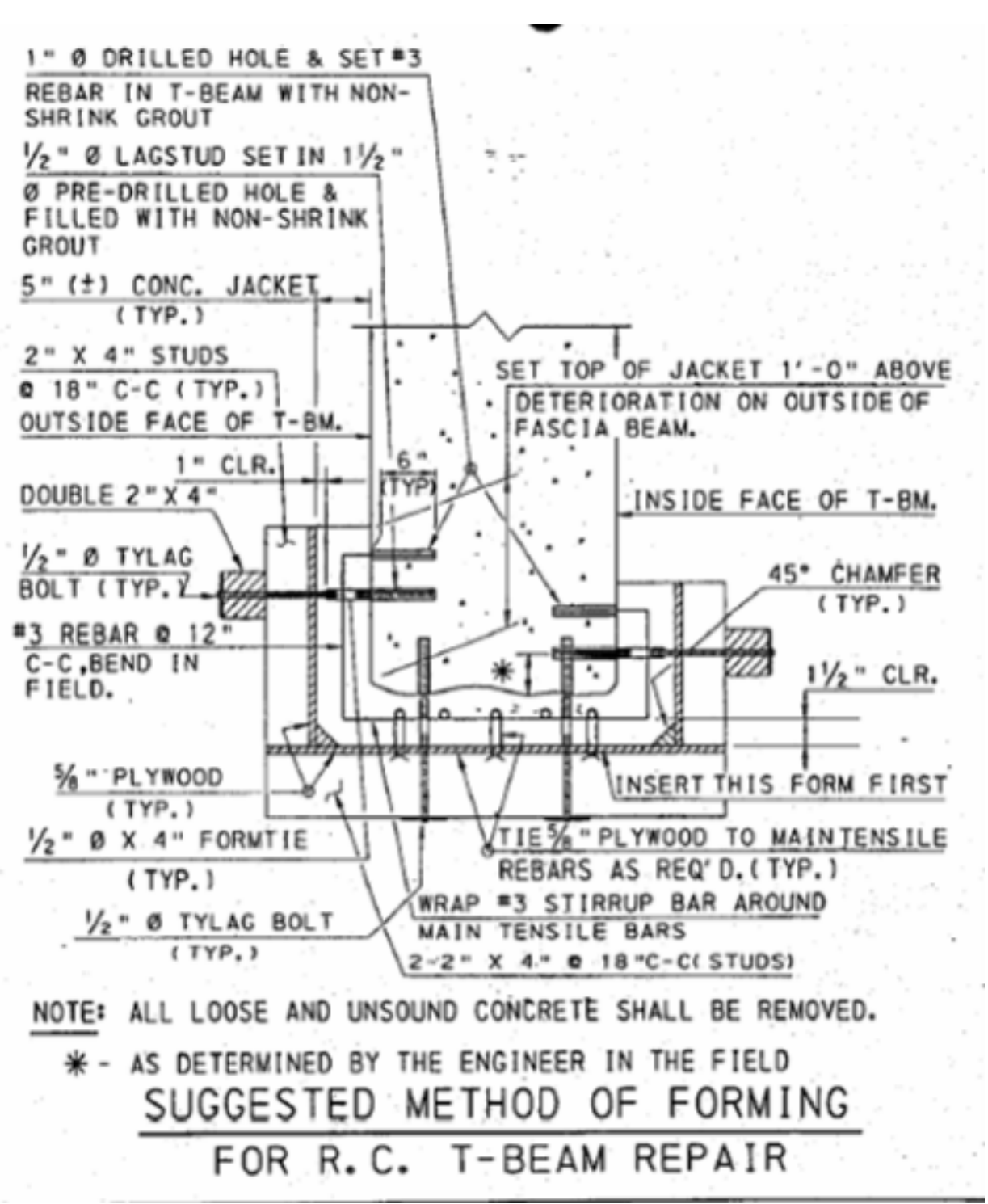

Figure 2.1: A Typical Formwork Diagram for Repair Using the Conventional Method, Provided by PennDOT-D3.

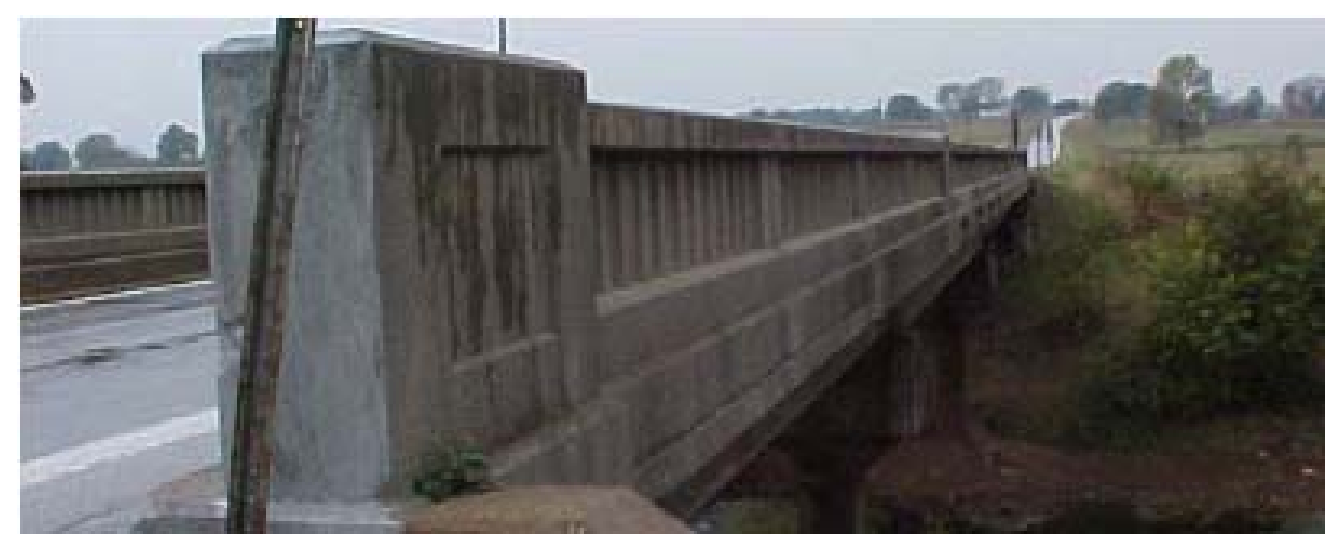

Figures 2.2. Bridge X-0596 of MODOT (Galati et al., 2004). 


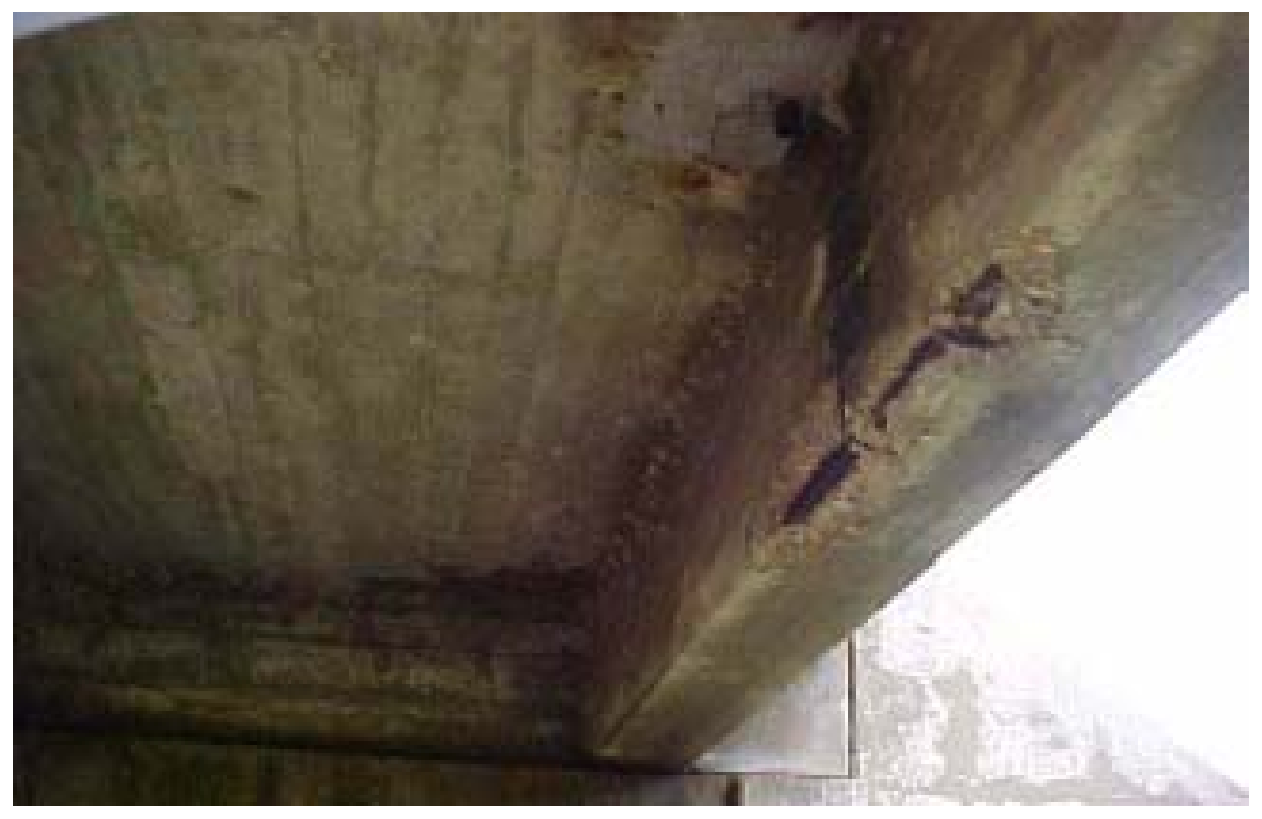

Figure 2.3. Condition of Exterior Girder of Bridge X-0596-MDOT (Galati et al., 2004).

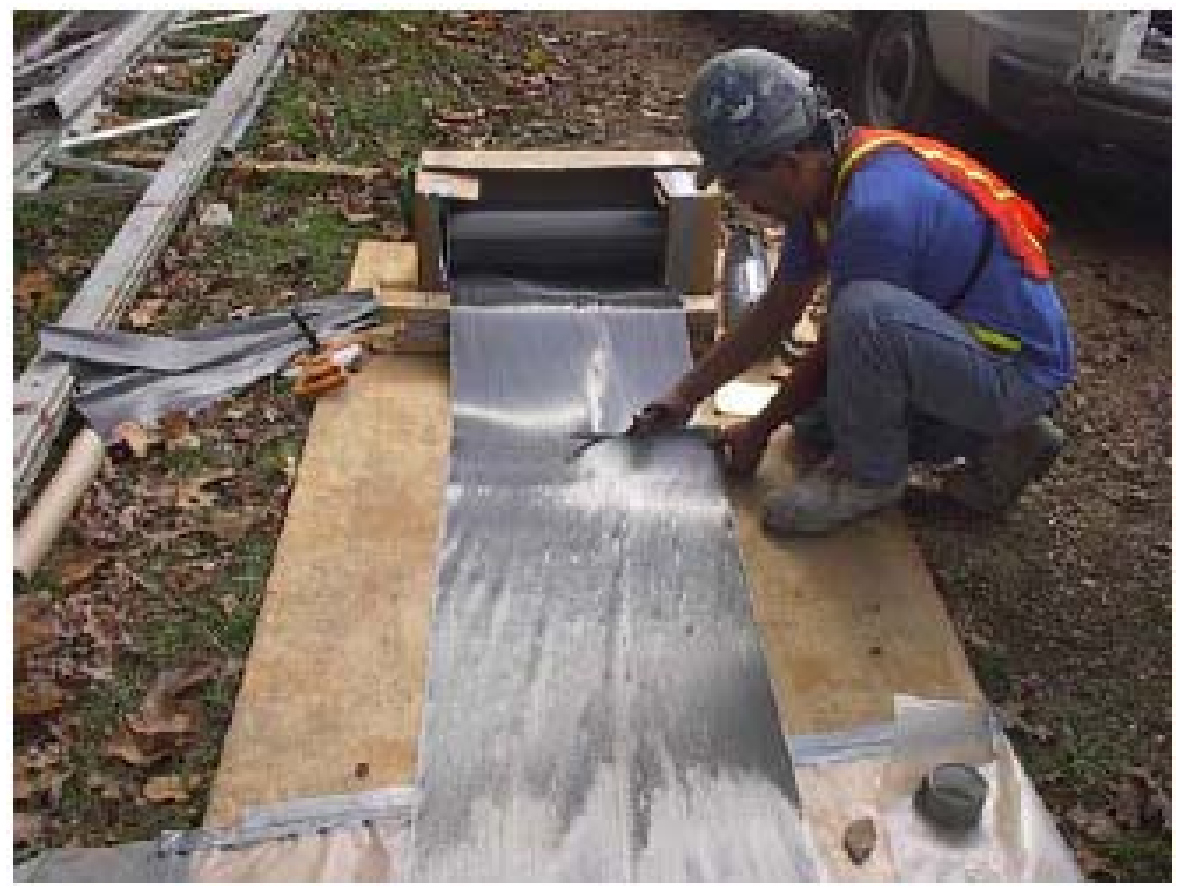

Figure 2.4. Cutting of FRP sheets (Galati et al., 2004). 


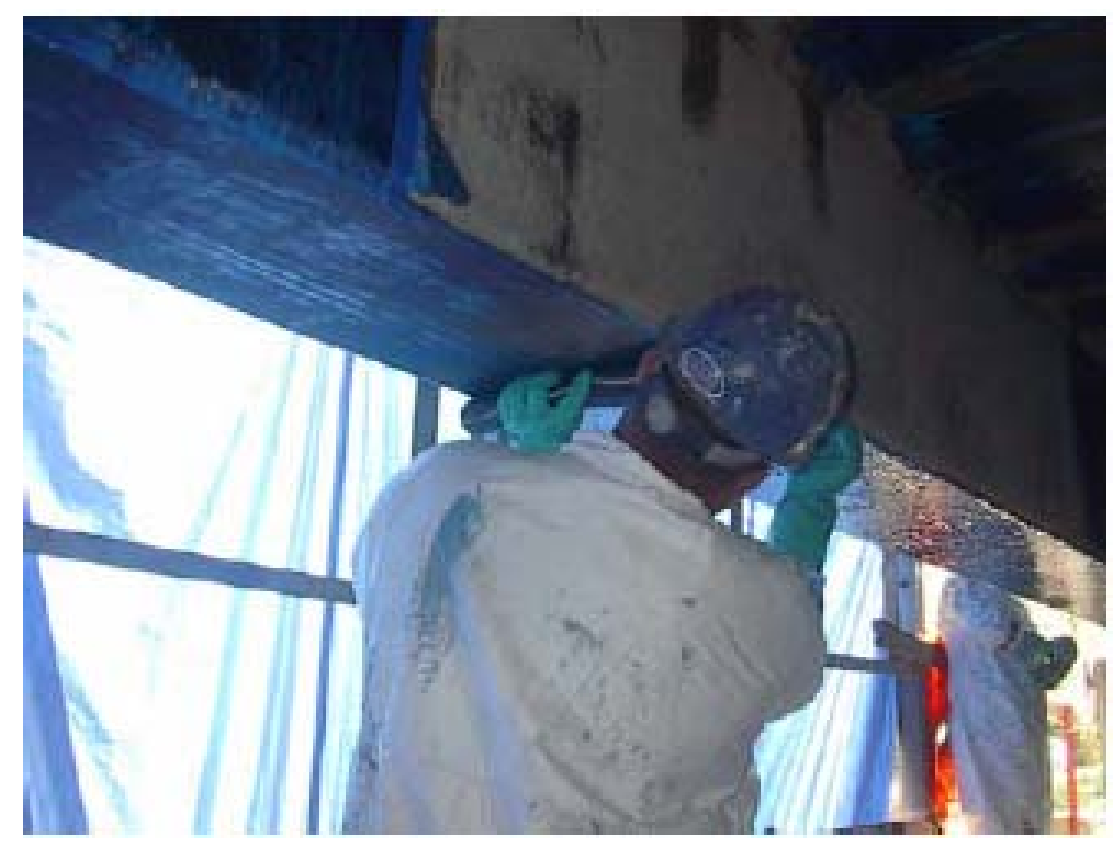

Figure 2.5. Manual Lay-up FRP Sheet Installation (Galati et al., 2004). 
Table 2.1. Summary of Information of Repair of Bridge X-0596 (Galati et al., 2004).

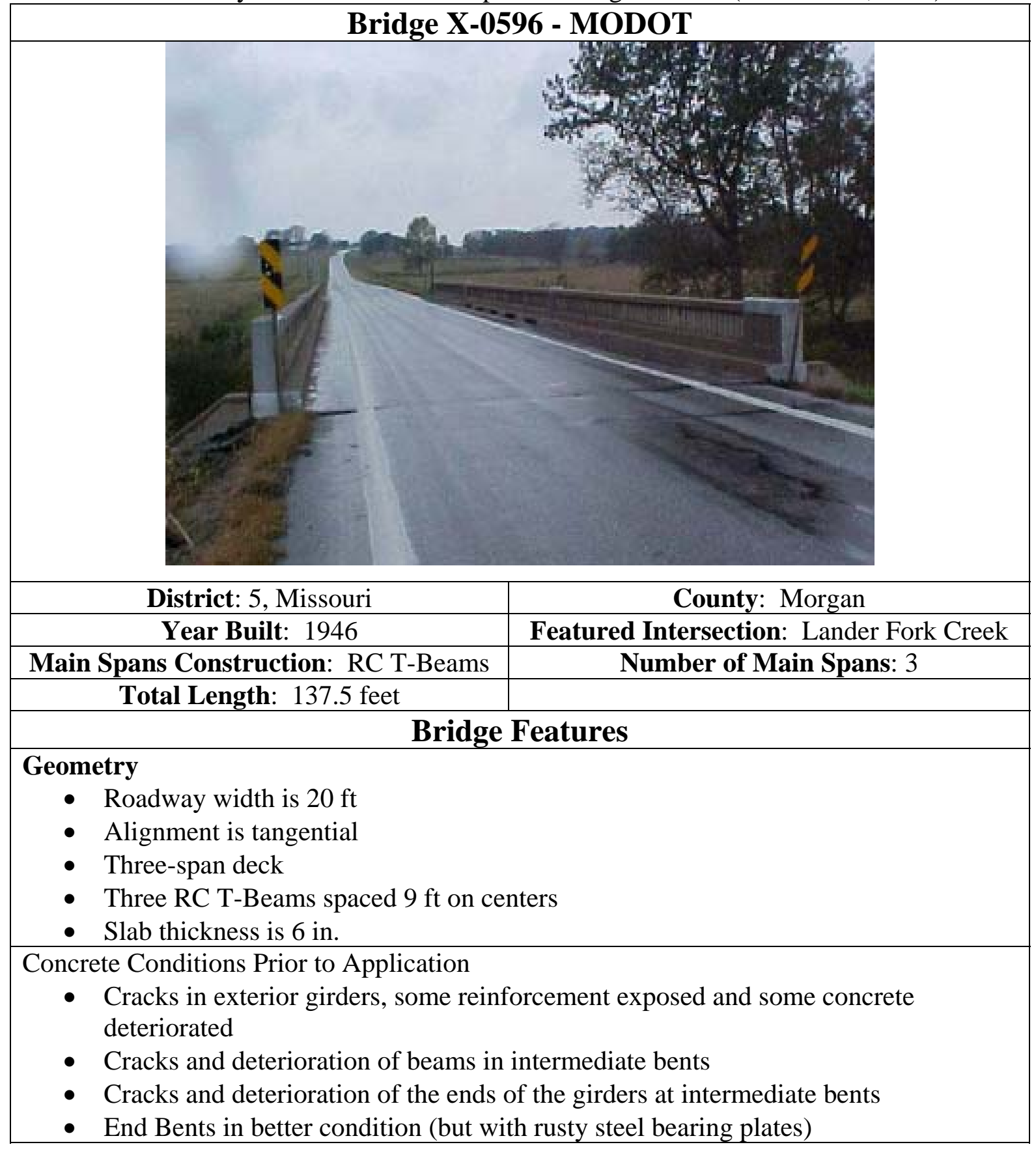




\section{Chapter 3}

\section{Classifications of Bridges}

This chapter answers the question: "Which bridges are suitable and favorable for repair using FRP?” and addresses the question: "Which bridges are ideal candidates for a trial repair program” which is answered in Chapter 4. A set of groupings is proposed to select bridges that are good candidates for FRP repair. Using a weighted average of bridge characteristics (characteristics classifications as defined in Section 3.1), three classes are proposed: Class 1 (high favorability), Class 2 (moderate favorability), and Class 3 (low favorability). Bridges from the PennDOT D-3 inventory are used as an example to illustrate this grouping. Details of individual characteristic classifications, respective scores and overall bridge classifications of PennDOT D-3 bridges are found in 3.2.

Though these classifications were developed for PennDOT D-3 (as shown in 3.2), general classifications can be extrapolated to fit any inventory. Details of this are presented in (3.3).

To select candidate bridges for a trial repair program, three overall damage levels are defined (3.4). These levels allow grouping of bridges according to the overall project size. This ranges from: Repair Level-1 (Major repair effort, contracted out through competitive bid) to Repair Level-3 (Minor repair effort, performed entirely by “in-house” employees), with a Repair Level-2 being a middle ground (combination of both contractors and "in-house" forces). These repair levels will be used later to suggest a trial program to train state employees (Chapter 4). Also, these repair levels will be used in Chapter 5 to compare cost-benefit between conventional and FRP repair. Finally, in section (3.5), conclusions are presented.

\subsection{Defining Characteristics Classifications}

The purpose of this and the next section is to calculate weighted averages to classify bridges in the PennDOT D-3 inventory according to favorability for repair. 
Characteristic classifications are first defined (this Section). Next (Section 3.3), these classifications are applied to the PennDOT D-3 inventory

To identify bridges which would most benefit from the FRP repair, the PennDOT D-3 inventory is classified based on a weighted average of the four characteristics and scores presented next. Other factors may be included to tailor this classification to a partial inventory or other inventories.

1. $\quad$ Age (1-10)

2. Span Length (1-10)

3. ADT/ADTT (1-10)

4. Localized Damage-Class (Initially photographical indications from inspection teams) (Class 0 to 3; Score for each corresponding class 0 to 10)

For the first three characteristics, 10 represents most favorable for repair. For Localized Damage-Class, 0 represents least suitable for repair whereas 3 represents most suitable for repair. In order to classify bridges based on the above characteristics, a weighted average is calculated from these for ranking the bridges according to favorability for repair. Details of this can be found in (3.3). An explanation of each characteristic and rationale for scoring is presented next.

1. Age of Bridge: Older bridges received a lower score because these bridges are generally closer to their design life. Also, due to global deterioration, replacement may be the most economical alternative. Newer bridges are scored higher.

2. Span Length: Because of general similarities in cross-sections and beam spacing in the inventory, span length is an important category. Because bridges with larger spans will likely experience more critical loads, these are scored higher.

3. ADT/ADTT: A bridge that carries more traffic is more favorable for repair than bridges that do not carry much traffic at all. Because of limited resources, it is more sensible to repair bridges that are used more frequently. Also, with 
increased truck traffic, bridges are likely to experience more critical stresses and fatigue loads.

\section{Localized Damage-Class (Visual Inspection/Photographical Indication):}

Visual indication of damage is the most subjective characteristic. Classification in this category is based on past experience with repair and/or comparison to damage repaired by others. This Section will provide several figures to illustrate the type/extent of local damage most prevalent in T-Beam bridges and their respective class.

Bridges with more extensive local damage are rated higher because repair of these bridges is more critical.

Damage classes are as follows:

- Damage-Class-3: First layer of reinforcement completely exposed. Damage generally extends above the rebar. (Figure 3.1 and 3.2)

- Damage Class-2: Broader, this level of damage encompasses most levels of partial rebar exposure. (Figure 3.3)

- Damage Class-1: Minor exposure of rebar (Figure 3.4)

- Damage Class-0: No visible damage

\subsection{Application of Characteristics Classifications to PennDOT D-3}

This Section provides examples of the application of the classifications presented in the previous Section. This classification was performed on an inventory of 128 Reinforced Concrete T-Beam bridges in District 3, Pennsylvania. First, (3.2.1) reviews the inventory of District 3's bridges. Then, (3.2.2) tailors the characteristic classifications (defined in 3.1) to these bridges and provides scorings based on general characteristics (Age, Span Length, ADT and ADTT) as well as the local damage-class. 
Section (3.2.3) goes further to explain and provide examples of each local damage-class scoring, whereas Section (3.2.4) explains and applies weighted averages, placing each bridge in a specific characteristic category which is provided in (3.2.5).

\subsubsection{Overview of Inventory of PennDOT-D3}

Shown next is the range of characteristics of PennDOT-D3's 128-bridge inventory.

Specific details for each bridge can be found in Appendix A.

\begin{tabular}{|c|c|}
\hline Year Built & 1919 to 1973 \\
\hline Span Length (ft) & 15 to 174 \\
\hline ADT & 70 to 12300 \\
\hline ADTT & 2 to 2100 \\
\hline
\end{tabular}

From Appendix A, it is evident that most bridges are single-span (non-continuous multispans are specifically noted), short bridges (20-60ft), built between 1920-1960. The ADT and ADTT vary greatly amongst the population.

\subsubsection{Application of Characteristics Classification}

The following tables show the characteristic classifications described in (2.1) applied to the PennDOT-D3 inventory.

\section{Age:}

\begin{tabular}{|c|c|c|}
\hline Age Category & Score & Bridges in Category \\
\hline $1955-1973$ & 10 & 12 \\
\hline $1950-1954$ & 9 & 8 \\
\hline $1944-1949$ & 8 & 3 \\
\hline $1942-1945$ & 7 & 8 \\
\hline $1940-1941$ & 6 & 14 \\
\hline $1935-1939$ & 5 & 21 \\
\hline $1930-1934$ & 4 & 29 \\
\hline $1925-1929$ & 3 & 21 \\
\hline $1920-1924$ & 2 & 9 \\
\hline Older than 1920 & 1 & 3 \\
\hline & Total $=$ & 128 \\
\hline
\end{tabular}




\section{Span Length:}

\begin{tabular}{|c|c|c|}
\hline Span (ft) & Score & Bridges in Category \\
\hline $80+$ & 10 & 5 \\
\hline $60-79$ & 9 & 5 \\
\hline $50-59$ & 8 & 7 \\
\hline $45-49$ & 7 & 9 \\
\hline $40-44$ & 6 & 10 \\
\hline $35-39$ & 5 & 16 \\
\hline $30-34$ & 4 & 24 \\
\hline $25-29$ & 3 & 33 \\
\hline $20-24$ & 2 & 15 \\
\hline Less than 20 & 1 & 4 \\
\hline & Total $=$ & 128 \\
\hline
\end{tabular}

\section{ADT/ADTT:}

\begin{tabular}{|c|c|c|}
\hline ADT & Score & Bridges in Category \\
\hline $10,000+$ & 10 & 6 \\
\hline $5,000-9,999$ & 9 & 14 \\
\hline $3,000-4,999$ & 8 & 19 \\
\hline $2,500-2,999$ & 7 & 9 \\
\hline $1,500-2,499$ & 6 & 14 \\
\hline $1,000-1,499$ & 5 & 13 \\
\hline $500-999$ & 4 & 11 \\
\hline $300-499$ & 3 & 17 \\
\hline $150-299$ & 2 & 11 \\
\hline Less than 150 & 1 & 14 \\
\hline & Total $=$ & 128 \\
\hline
\end{tabular}

\begin{tabular}{|c|c|c|}
\hline ADTT & Score & Bridges in Category \\
\hline $1,000+$ & 10 & 3 \\
\hline $500-999$ & 9 & 7 \\
\hline $400-499$ & 8 & 7 \\
\hline $300-399$ & 7 & 11 \\
\hline $200-299$ & 6 & 8 \\
\hline $100-199$ & 5 & 18 \\
\hline $75-99$ & 4 & 14 \\
\hline $50-74$ & 3 & 15 \\
\hline $25-49$ & 2 & 13 \\
\hline Less than 25 & 1 & 32 \\
\hline & Total $=$ & 128 \\
\hline
\end{tabular}




\section{Local Damage-Class:}

\begin{tabular}{|c|c|c|}
\hline Class & Score & Bridges in Category \\
\hline 3 & 10 & 30 \\
\hline 2 & 6.67 & 36 \\
\hline 1 & 3.33 & 17 \\
\hline 0 & 0 & 45 \\
\hline & Total $=$ & 128 \\
\hline
\end{tabular}

\subsubsection{Examples of Classification}

Bridges in the PennDOT-D3 inventory showed similar damage. Generally the exterior beams experienced a wide range of damage while the interior beams and deck experience less or not damage. The classification based on localized damage does not consider the overall damage, but rather the extent of damage indicated by photographical evidence.

Sample bridges and their corresponding classifications are provided in Figures 3.5-3.11. Also, Figures 3.12-3.15 show photographical indication of local damage and respective local damage-class ratings.

\subsubsection{Weight Values for Characteristics Classification}

In order to aid in the selection of bridges for further evaluation, the scores assigned for each characteristic are tabulated and averaged based on weighted averages. These weighted averages can be tailored to meet the specific goals of any DOT.

The age of the bridge is considered because of both economic and repair concerns. Older bridges are more likely to reach their design life sooner. Also, older bridges will generally have concrete of lesser quality (due to deterioration), which will be important in the implementation of the FRP technology.

The span length of the bridges is an important parameter. Because most of these bridges in the inventory are of similar designs, longer spans will equate to more critical load conditions. Hence, it will likely be more economical to apply the technology to bridges with longer span lengths. 
An important factor in the classification of bridges is the ADT and ADTT. Larger traffic volumes will result in increased probability of critical loading, and it is more cost effective to repair bridges that are used more often.

Finally, the most important classification is based on the type and extent of local damage. The PennDOT D-3 inventory is scored based on visitation of a small sample of bridges and primarily existing photographical inspection data.

For the PennDOT-D3 inventory, characteristics were weighted as follows:

1. Age (15\%)

2. $\quad$ Span Length $(10 \%)$

3. ADT/ADTT (35\%) (17.5\% \& $17.5 \%)$

4. Local Damage Class (40\%)

Note: These weighted averages are subjective. Engineering judgment or a statistical approach may be used to determine the best weighted averages for a particular inventory.

\subsubsection{Overall Classification of the PennDOT-D3 Inventory}

Based on the weighted averages and scores provided in this chapter, the following classes have been defined for the PennDOT-D3 inventory:

Class 1: Prime Candidate for Repair (Score of 68-100\%). This set of bridges is likely a prime candidate for the FRP technology. Field investigation is suggested for the following purpose: On some of these bridges, the damage may be so severe that the most economical course of action may be to replace these structures.

Class 2: Moderate Candidate for Repair (Score of 50-68\%). These bridges are likely candidates for repair. However, field investigation of these bridges is suggested to closely examine the type and extent of damage, as well as the cost-benefit of applying the FRP technology to these bridges.

Class 3: Low Candidate for Repair (Score of 0-50\%). Because of age, size, level of traffic, damage type or lack of damage, these bridges are not the prime focus for the 
FRP technology. Some of these bridges may benefit from FRP-repair technology, but other bridges may be better candidates for conventional repair.

Table 3.1 shows the rating class, score, number of bridges, and percentage of total inventory. It should be noted that many of the bridges in the inventory have no visual damage. Table 3.2 shows local damage level scoring and the number of bridges in each of these categories. Characteristic classification and details of the inventory are found in Appendix A. Classification of bridges based solely on damage is found in Appendix B.

Table 3.1: Classification of Bridges in PennDOT D-3

\begin{tabular}{|l|l|l|l|}
\hline Rating Class & Score & No of Bridges & Percentage of Total \\
\hline 1 & $68-100$ & 13 & 10.2 \\
\hline 2 & $50-67$ & 44 & 34.4 \\
\hline 3 & $0-49$ & 71 & 55.5 \\
\hline
\end{tabular}

Table 3.2: Local Damage Levels of Bridges in PennDOT D-3

\begin{tabular}{|l|l|l|}
\hline $\begin{array}{l}\text { Damage } \\
\text { Ranking }\end{array}$ & $\begin{array}{l}\text { No of } \\
\text { Bridges }\end{array}$ & $\begin{array}{l}\text { Percentage } \\
\text { of Total }\end{array}$ \\
\hline 3 & 15 & 11.7 \\
\hline 2 & 44 & 34.4 \\
\hline 1 & 29 & 22.7 \\
\hline 0 & 40 & 31.3 \\
\hline
\end{tabular}

\subsection{Recommendations for General Classification}

This section prescribes general guidelines for the classification of bridges. These guidelines, as well as engineering judgment, can help determine which bridges in an inventory are most suitable for FRP repair. From these "suitable” bridges, a candidate bridge can be selected for a trial program.

\subsubsection{General Characteristics Classification}

Because of limited resources, one must rank an inventory based on favorability for repair. For bridges in a particular inventory that are generally similar in design, distinguishing characteristic factors such as: age, span length, ADT, and ADTT can be used to rank the structures considered. 
Though each inventory is different and should be evaluated accordingly, ADT\&ADTT are good factors to consider while ranking bridges for favorability. It makes sense to repair bridges that are used more often. Also, these bridges have a higher probability of experiencing critical design loads. Though this factor is given a higher importance level than age/span-length, etc., the suggested approach can be modified and tailored to classify any inventory.

Actual data, however, may not be exclusively used to classify bridges. Other social factors may play a significant role in the importance of a bridge. Though a particular bridge may have a low ADT or ADTT, a school bus may pass over this bridge every day; or perhaps a bridge may provide an essential connection for a community. To account for this, an optional importance factor can be applied to the characteristic classifications. Naturally, this importance factor is independent of damage classification. This importance factor can be applied while calculating weighted averages as illustrated in (3.4.3).

\subsubsection{Localized Damage Classification}

Type and extent of damage is generally the most important factor in the classification of a bridge. Many State DOTs perform yearly/bi-yearly inspection which includes photographical documentation. From these photographs, an inventory can be classified without visitation. It is, however, strongly suggested that a sample of the inventory be physically examined to gauge photographical evidence and assess suitability for repair.

An effective method of damage classification is to first examine the type of damage in the inventory and then compare this type of damage to samples from PennDOT-D3 (Figures 3.12-3.15)

\subsubsection{Weighted Averages}

Based on the particular goals of a DOT and distinguishing characteristics of an inventory, a weighted average of each characteristic and damage score can be calculated to rank bridges according to favorability for repair. From this classification, candidate bridges 
can be selected for a trial repair program. If accepted, the FRP method can then be applied to the rest of the suited bridges in the inventory.

Presented in Table 3.3 is an example from PennDOT D-3 with an applied importance factor. Without the importance factor, this bridge is considered a moderate candidate for repair (Class 2). However, if this bridge was identified as an “important” bridge as discussed in (3.4.1), an importance factor of " 2 " can be applied to this bridge. From Table 3.3, it is shown that, with this importance factor, this bridge moves from Class 2 to Class 1 (prime candidate for repair). Note: this importance factor does not affect the visual damage score.

\subsection{Grouping based on Overall Damage}

The purpose of this section is to group bridges based on overall repair-levels. This classification will indicate the overall project size. A large scale repair (Repair Level-1) is most likely contracted out to a $3^{\text {rd }}$ party company, whereas a smaller repair (Repair Level-3) could be performed by a trained, “in-house” work force. Bridges that fall between these two ranges (Repair Level-2) could be repaired via a joint effort between a contractor and state employees. This grouping will help identify a candidate or several candidates which are suitable for an introductory repair/training experience for state employees. Once trained, state employees could continue the implementation of the FRP technology independently.

Also, these repair levels are used later in Chapter 5 to compare cost-benefit for the FRP and conventional repair methods.

\subsubsection{Repair Level-1 (Major)}

This level requires extensive repair, including most or all of the beams along the entire length. At this level, the engineering work is most likely performed by a consultant and the actual repair is contracted out through competitive bid.

At this level, all of the preparatory concrete work and application of surface bonded FRP would be performed per project specifications and construction drawings. It is expected 
that the overall scope of work may include other pay items such as abutment repair, bearing repair, and possibly expansion joint repair. While the application of the FRP may represent a smaller portion of the overall project cost, the scale of the project can offer sufficient opportunities for developing expertise with FRP technology (Davalos, Barth, Ray, et al. 2005).

\subsubsection{Repair Level-2 (Moderate)}

This level of repair requires a significant effort; however, this level of damage is not as extensive as a Level 1 repair. Typically, this level of repair will include several beams, including generally the entire length of exterior girders.

At this level, some field activities can be accomplished by state employees. However, because of technical complexities and scope of work, some aspects of the project would be performed by outside contractors. Several possibilities could be explored, such as: (1) retaining a consultant for the engineering portion and using state forces for labor (possibly in phases); (2) performing the engineering in-house and contracting out the specialty items (crack injection or application of the FRP), with state forces acting as a general contractor; finally (3), performing the engineering in-house and contracting out all of the field work (Davalos, Barth, Ray, et al. 2005).

\subsubsection{Repair Level-3 (Minor)}

This level of repair requires a less effort compared to levels 1 and 2. Typically, this level of repairs includes either one or several partial beams. This type of repair can be completed entirely by a trained "in-house” work force.

From a field assessment, the expected scope of work could include removing loose concrete, cleaning existing reinforcing steel, measuring the current area of steel, estimating the compressive strength of the concrete, forming and casting new concrete or mortar to re-establish the beam section, then application of surface bonded FRP after appropriate surface preparation. To expedite the project, final design to determine the quantities of the FRP can be performed while preparatory work is being completed. At this level the anticipated scope of work, although detailed, is small and it is realistic to 
assume that the state could accomplish this using in-house engineering and state forces. Funding for this type of maintenance construction is realistically within the limits of a state force account.

\subsection{Conclusions}

In this chapter, we discussed a set of characteristics classifications to determine which bridges in the PennDOT D-3 inventory are suitable and favorable for repair using FRP. These classifications were based on distinguishing bridge characteristics such as age, span length, traffic level, and type of damage. Also, a grouping based on overall damage, or repair levels, was presented. This grouping will be used in Chapter 4 to suggest candidate bridges and a trial repair program. Also, this grouping will be used in Chapter 5 to compare cost-benefit for three repair examples.

From classifications developed for PennDOT D-3, a set of general classifications is prescribed. The intent of these prescriptions is to propose general guidelines for the adoption of FRP for any bridge inventory. 
Table 3.3: Example of Application of an Importance Factor to Bridge Classification for Bridge \#49-1039-0020-0000

\begin{tabular}{|c|c|c|c|c|c|c|c|c|c|c|c|}
\hline Span & $\begin{array}{c}\text { Span } \\
\text { SC }\end{array}$ & Yr & $\begin{array}{c}\text { Age } \\
\text { SC }\end{array}$ & ADT & $\begin{array}{c}\text { ADT } \\
\text { SC }\end{array}$ & ADTT & $\begin{array}{c}\text { ADTT } \\
\text { SC }\end{array}$ & Visual & V SC & Imp. & Rank \\
\hline 30 & 4 & 30 & 4 & 500 & 4 & 50 & 3 & 3 & 10 & 1 & 62.25 \\
\hline 30 & 4 & 30 & 4 & 500 & 4 & 50 & 3 & 3 & 10 & 2 & 84.5 \\
\hline
\end{tabular}

\begin{tabular}{|l|r|}
\hline $\begin{array}{l}\text { Weighted } \\
\text { Values }\end{array}$ & Percent \\
\hline Span & 10 \\
\hline Age & 15 \\
\hline ADT & 17.5 \\
\hline ADTT & 17.5 \\
\hline Visual & 40 \\
\hline Sum & 100 \\
\hline
\end{tabular}

Note: each score is out of 10 , characteristic classes are in yellow and damage classifications are in green.

Sample Calculation:

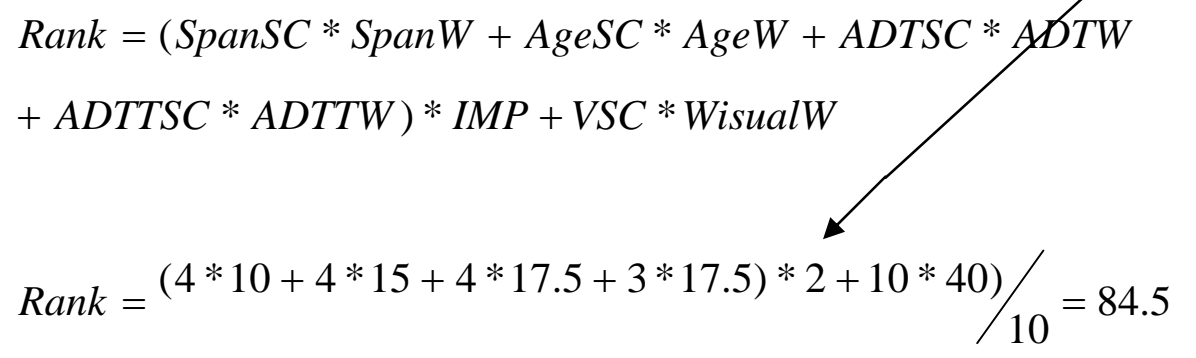

Note: Span SC = Span-Score (=4); Span W = Span-Weight $(=10)$. Similar rotation of other parameters 


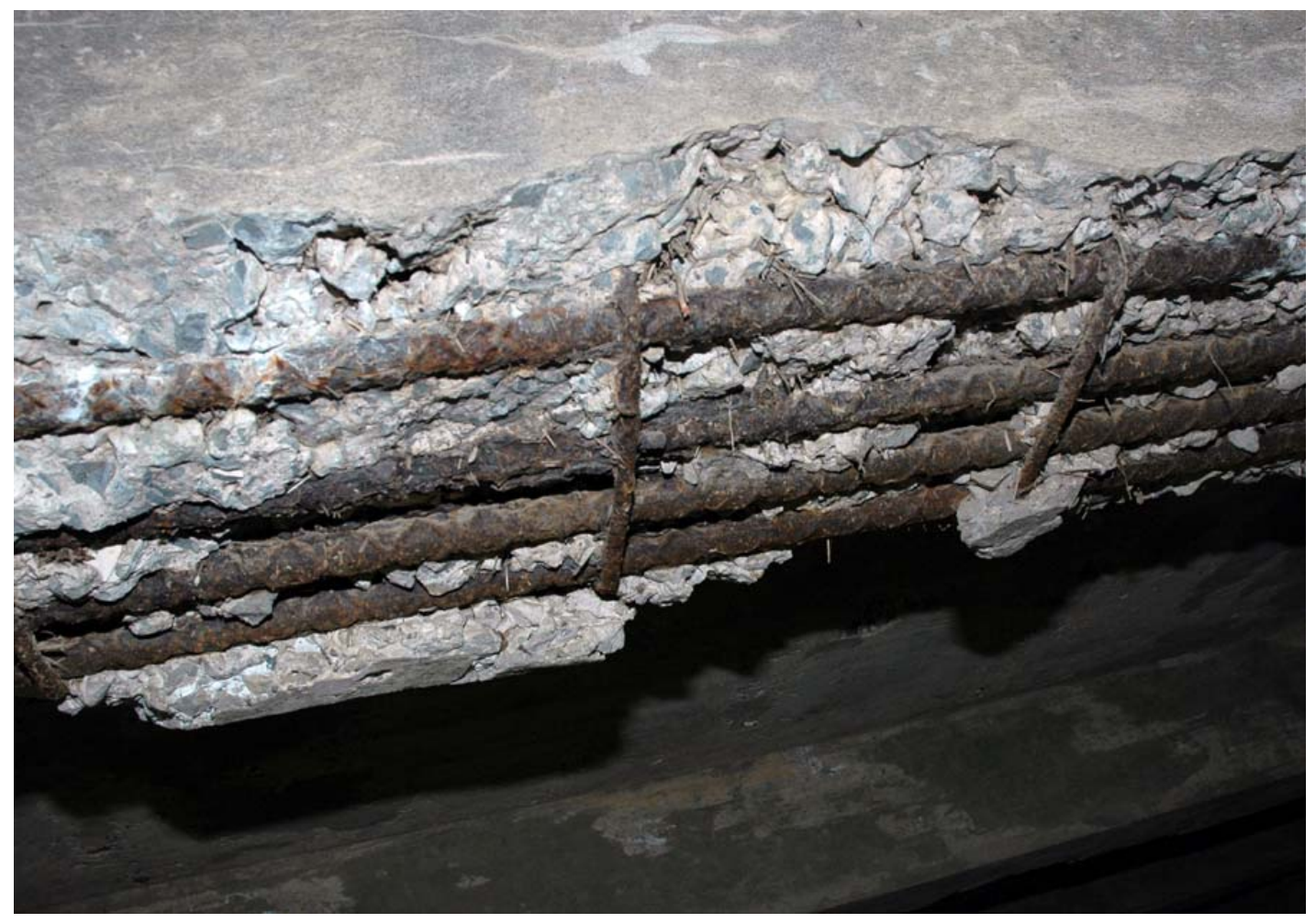

Figure 3.1: An example of Damage Class-3 local damage. Damaged area extends above the rebar.

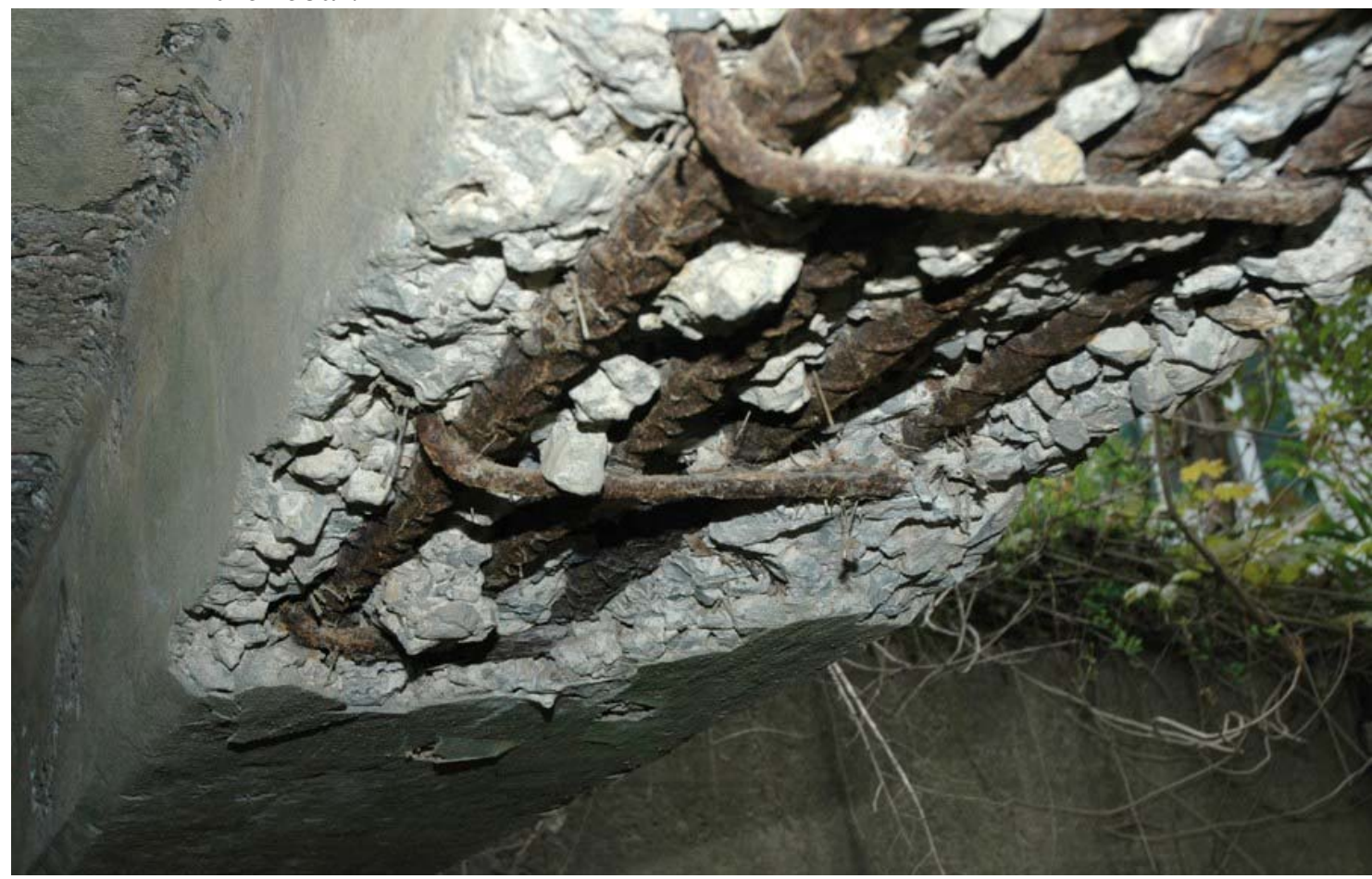

Figure 3.2: Another example of Damage Class-3 local damage. Damaged area extends above the rebar. 

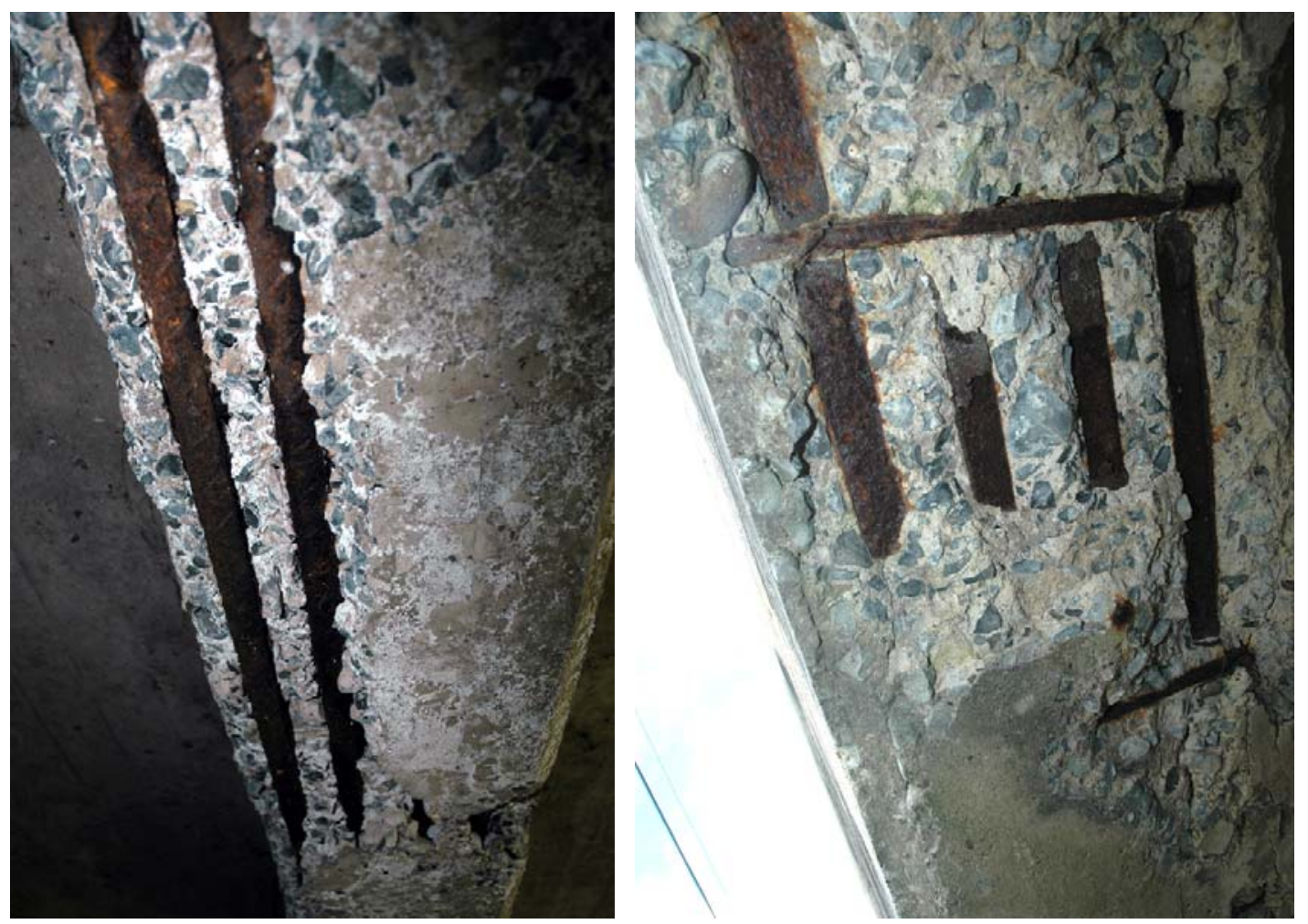

Figure 3.3: Examples of Damage Class-2 local damage. Partial exposure of rebar.

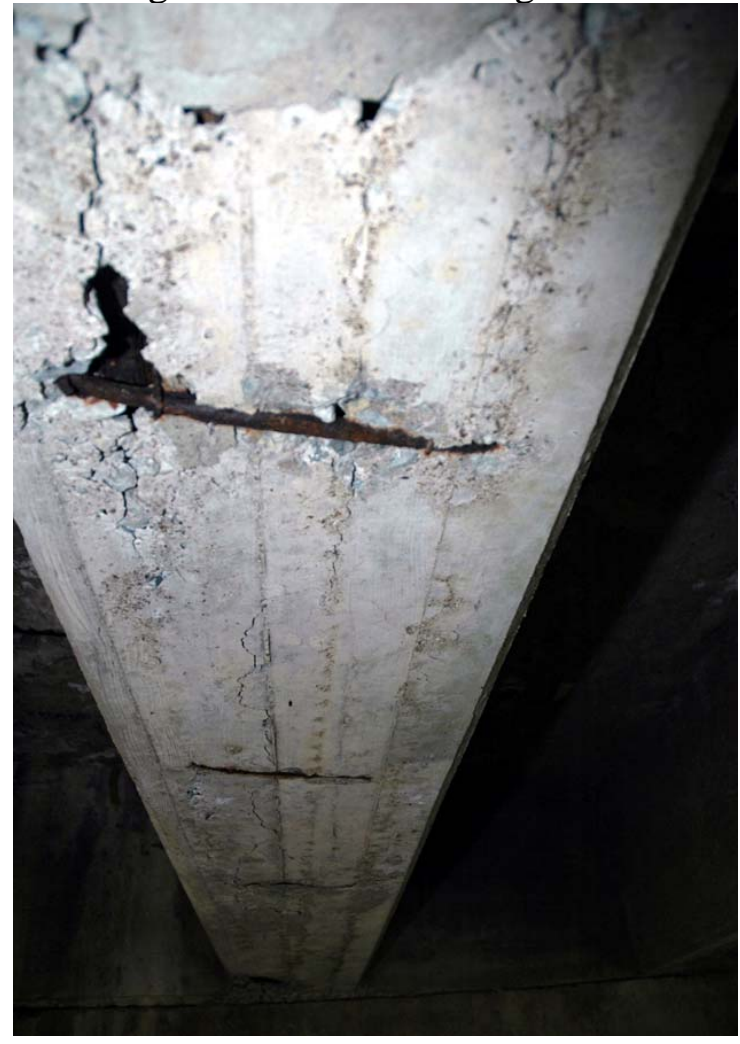

Figure 3.4: Example of a Damage-Class 1 local damage. Minor exposure of rebar. 

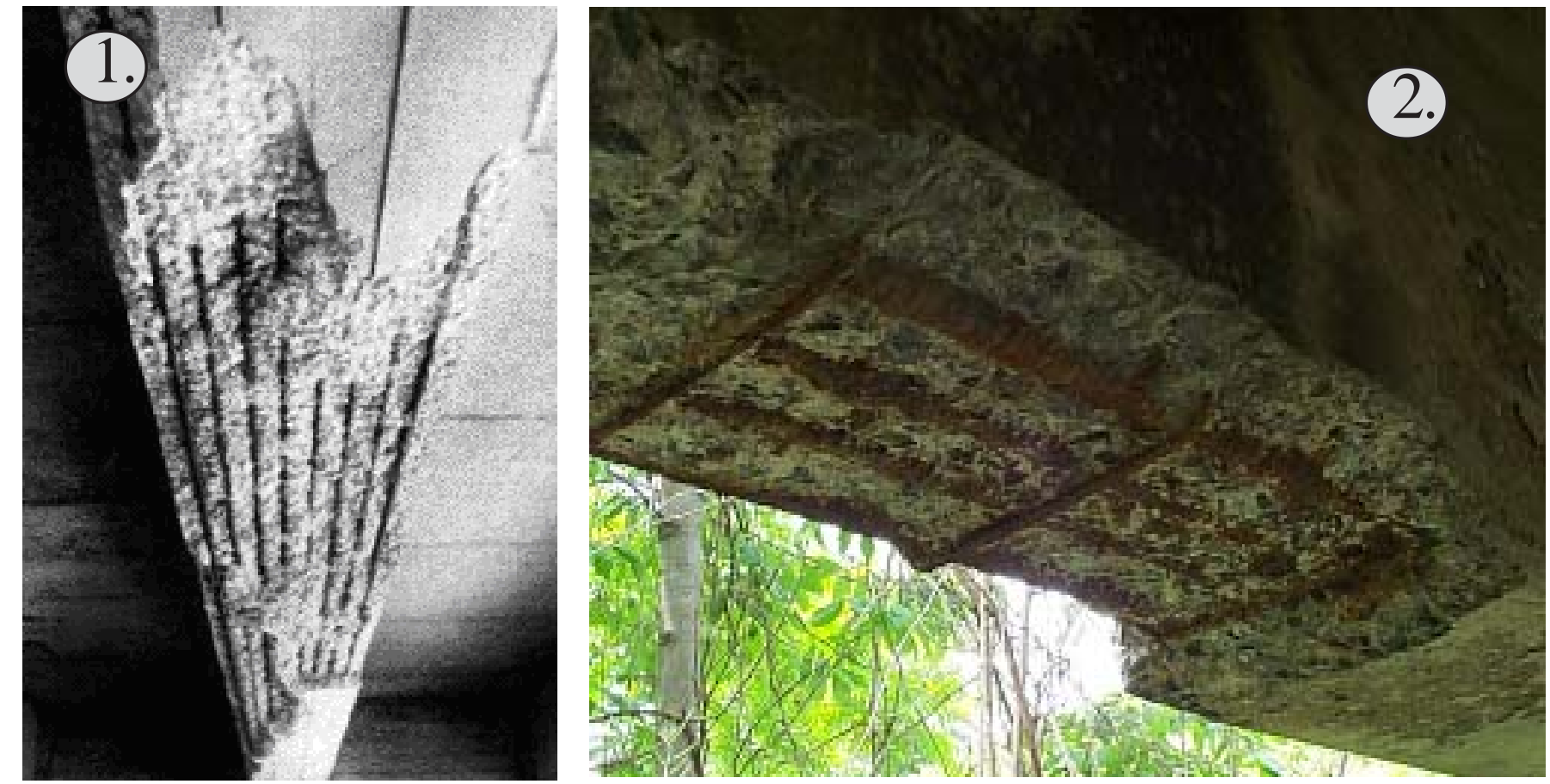

Photos 1 and 3: NCHRP Report 514, examples of a T-beam suitable for FRP repair techonology

Photo 2: Provided by PennDOT for bridge \#08-4034-0140-1580

Note: This bridge carries low traffic volume. But the combination of span, age and visual damage resulted in a ranking of about 70 out of 100 , or the lower end of the population of Class \#1 bridges.

\section{Details:}

Span(ft): 50

Ranking: 8/10

Year Built: 1952

Ranking: 9/10

ADT: 354

Ranking: 3/10

ADTT: 35

Ranking: 2/10

Visual Damage:

Ranking 10/10

Number of Spans: 1

Status: Open

Road: SR 4034

Figure 3.5. Bradford County \#08-4034-0140-1580. Class\#1: Overall Score (70.3/100). 


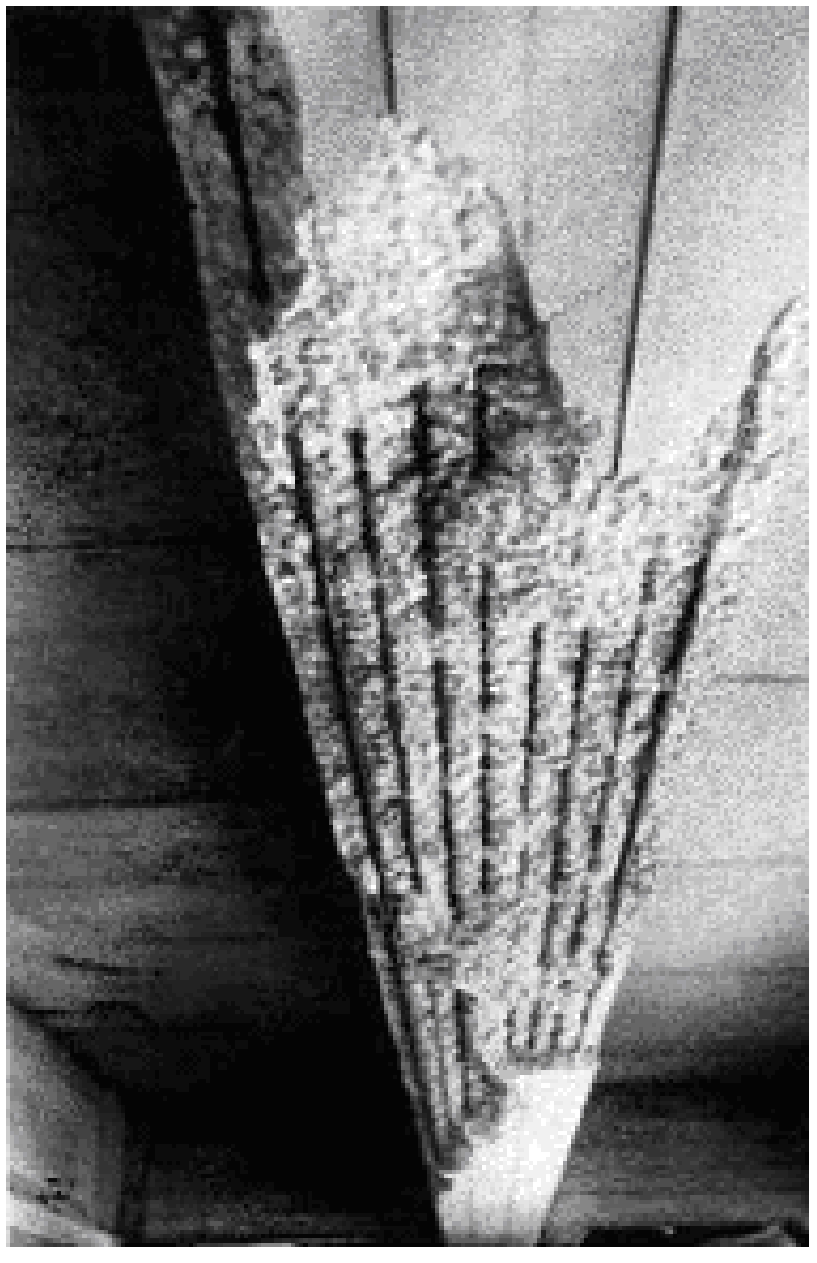

Photo on left: NCHRP Report 514, an example of a T-beam suitable for FRP repair techonology

Photo on right: Provided by PennDOT for bridge \#59-0045-0310-2011

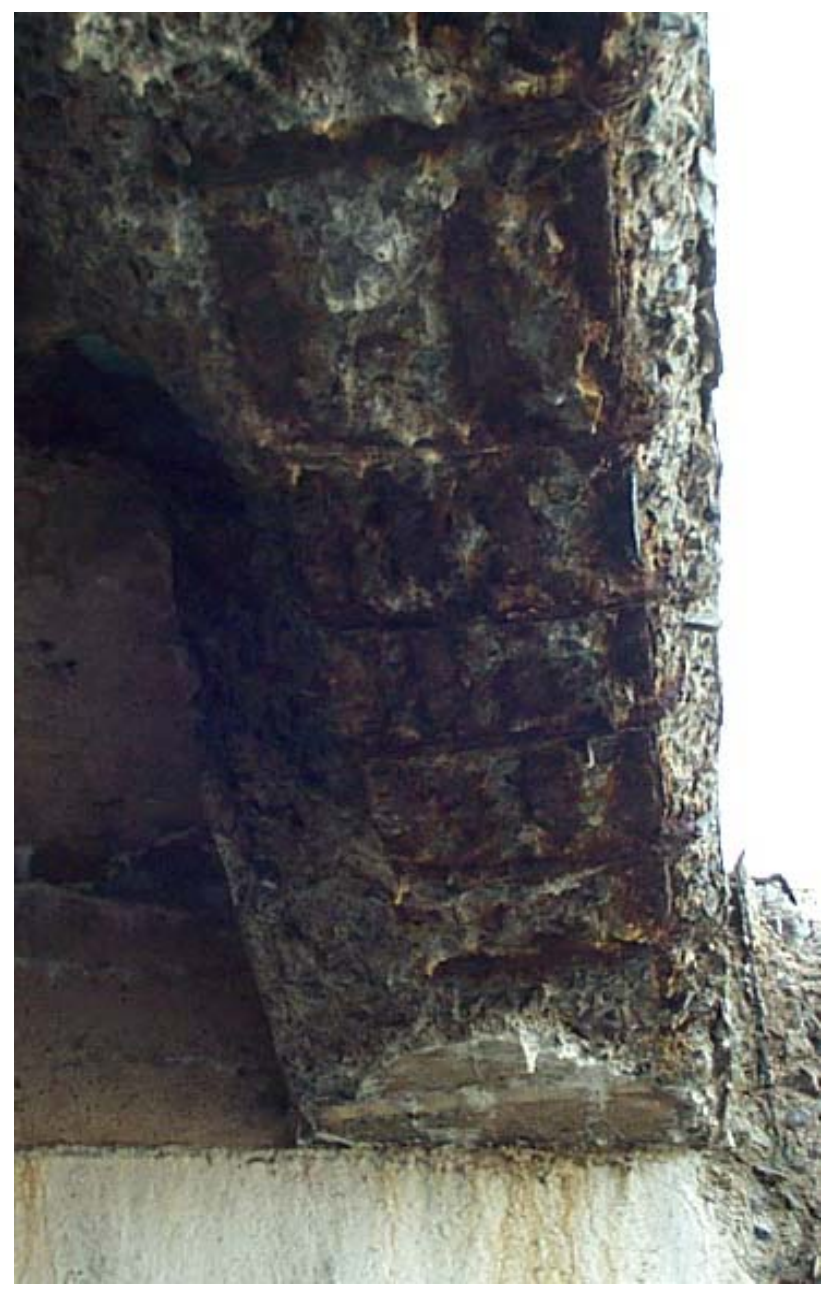

Details:
Span (ft): 30
Ranking: $4 / 10$
Year Built: 1938
Ranking: $5 / 10$
ADT: 10310
Ranking: $10 / 10$
ADTT: 648
Ranking: $9 / 10$
Visual Damage:
Ranking: $10 / 10$
Number of Spans: 1
Status: Open
Road: SR 45

Note: This is a likely candidate for repair. This bridge scored high because of its large traffic volume and its similarities in damage to the NCHRP Report 514. This bridge ranked high even though it scored relatively low in the span and age category.

Figure 3.6. Union County \#59-0045-0310-2011. Class \#1: Overall Score (84.8/100). 


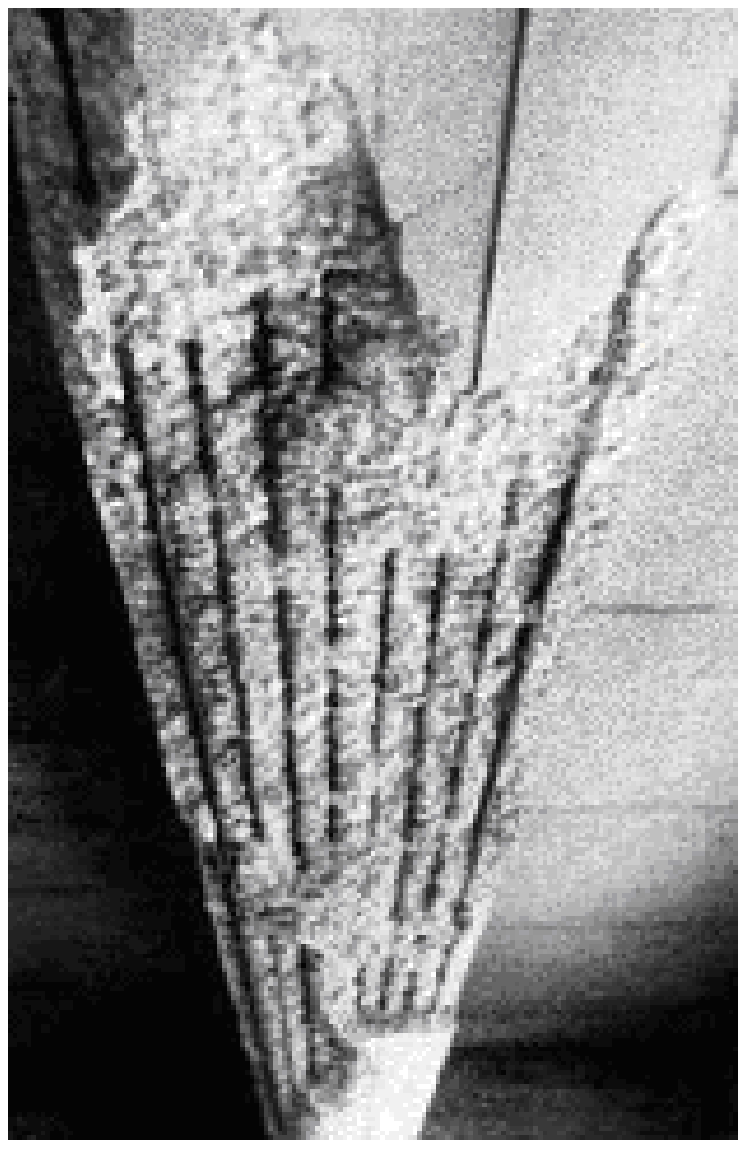

Photo on left: NCHRP Report 514, an example of a T-beam suitable for FRP repair techonology

Photo on right: Provided by PennDOT for bridge

\#08-4013-0250-1496

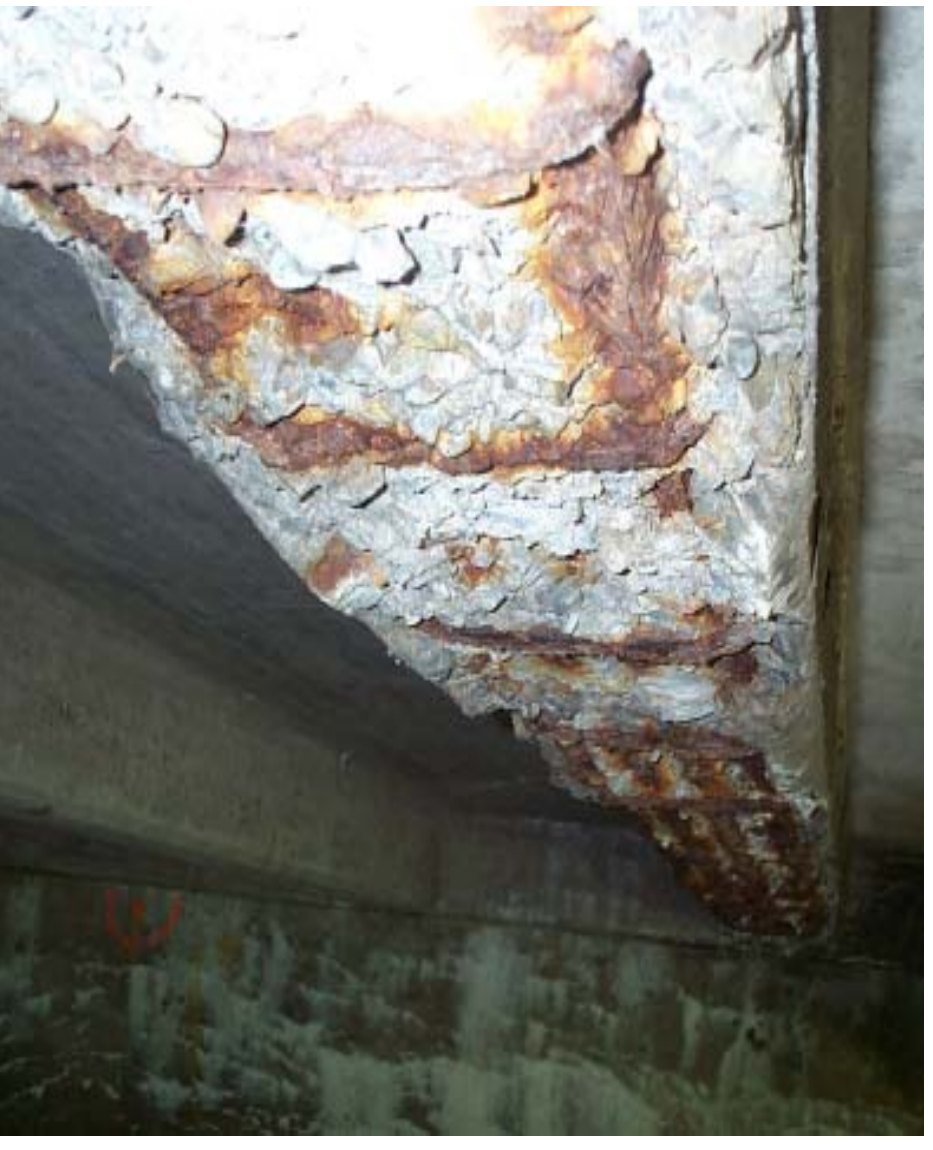

Note: Though this bridge scored low in the span and age category, this may be a good candidate bridge due to the traffic volume. Also, the bridge shows similar damage to that illustrated in the NCHRP Report 514. This bridge scores high in Class \#2 (score 50-70).

\section{Details:}

Span(ft): 25

Rank: 3/10

Year Built: 1927

Ranking: 3/10

ADT: 1606

Ranking: 6/10

ADTT: 161

Ranking: 5/10

Visual Damage:

Ranking: 10/10

Number of Spans: 1

Status: Open

Road: SR 4013

Figure 3.7. Bradford County \#08-4013-0250-1496. Class \#2: Overall Score (66.8/100). 


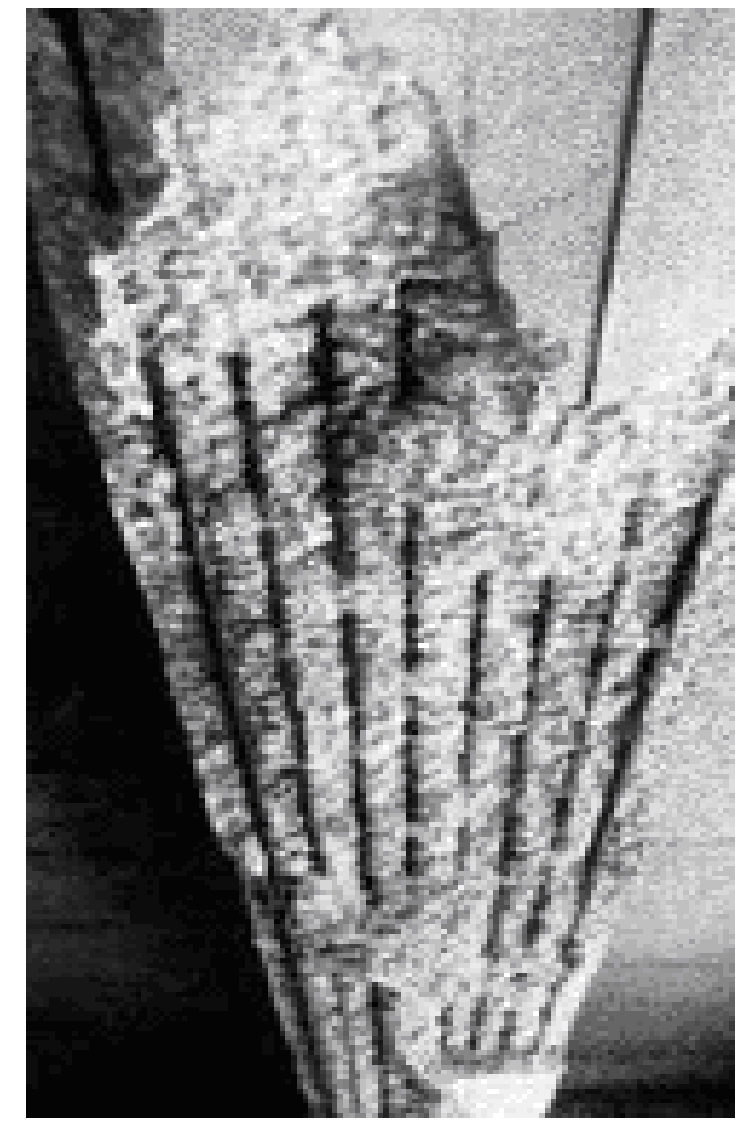

Photo on left: NCHRP Report 514, an example of a T-beam suitable for FRP repair techonology

Photo on right: Provided by PennDOT for bridge \#59-1001-0110-2058

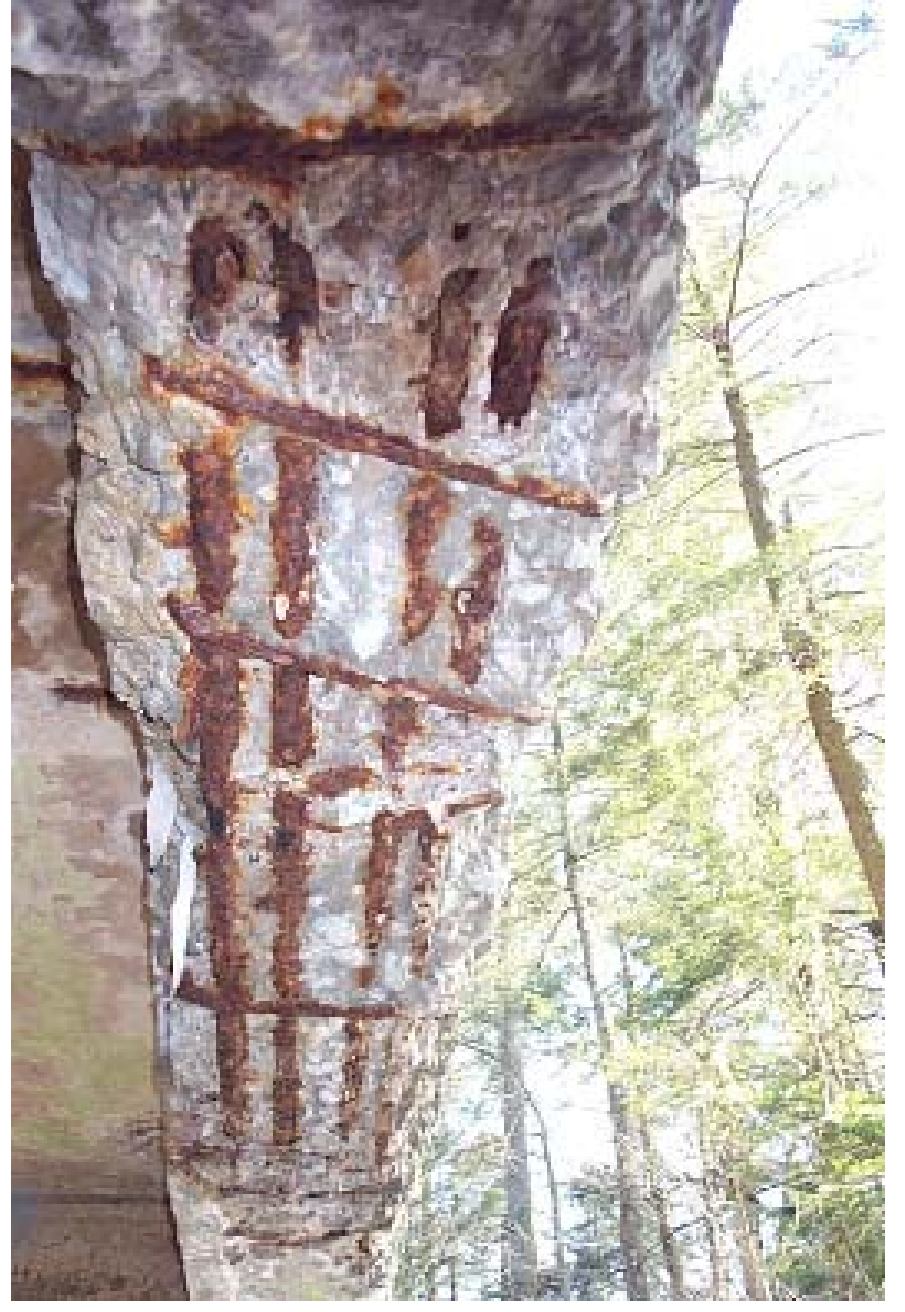

Details:

Span (ft): 32

Ranking: 4/10

Year Built: 1921

Ranking: 2/10

ADT: 1379

Ranking: 5/10

ADTT: 81

Ranking: 4/10

Visual Damage:

Ranking: 10/10

Number of Spans: 1

Status: Open

Road: SR 1001

Note: This bridge scores moderately in all of the catergories except the visual category. In the visual category, the bridge scores very high, because the damage shown is very similar to that described in the NCHRP Report 514. This bridge scores in the middle of the Class \#3 range

Figure 3.8. Union County \#59-1001-0110-2058. Class \#2: Overall Score (62.8/100). 


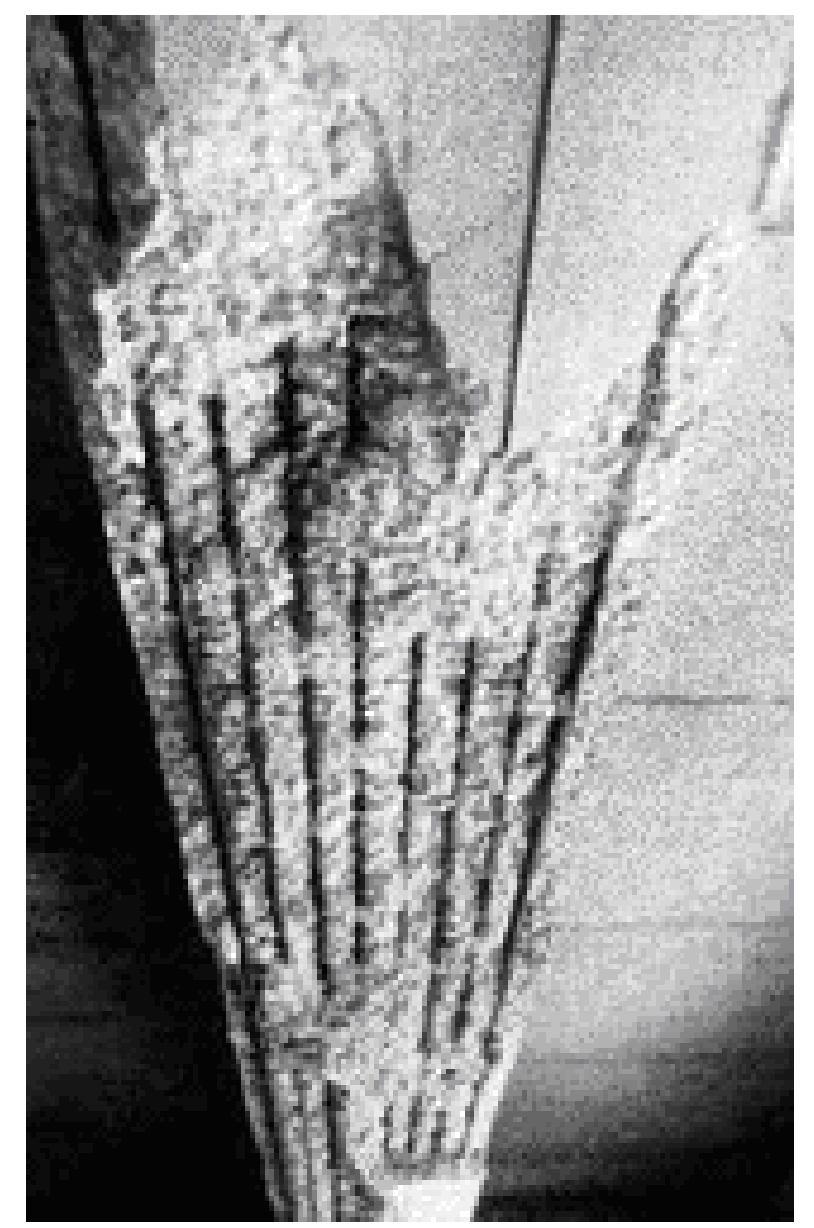

Photo on left: NCHRP Report 514, an example of a T-beam suitable for FRP repair techonology.

Photo on right: Provided by PennDOT for bridge \#54-0522-0090-1932

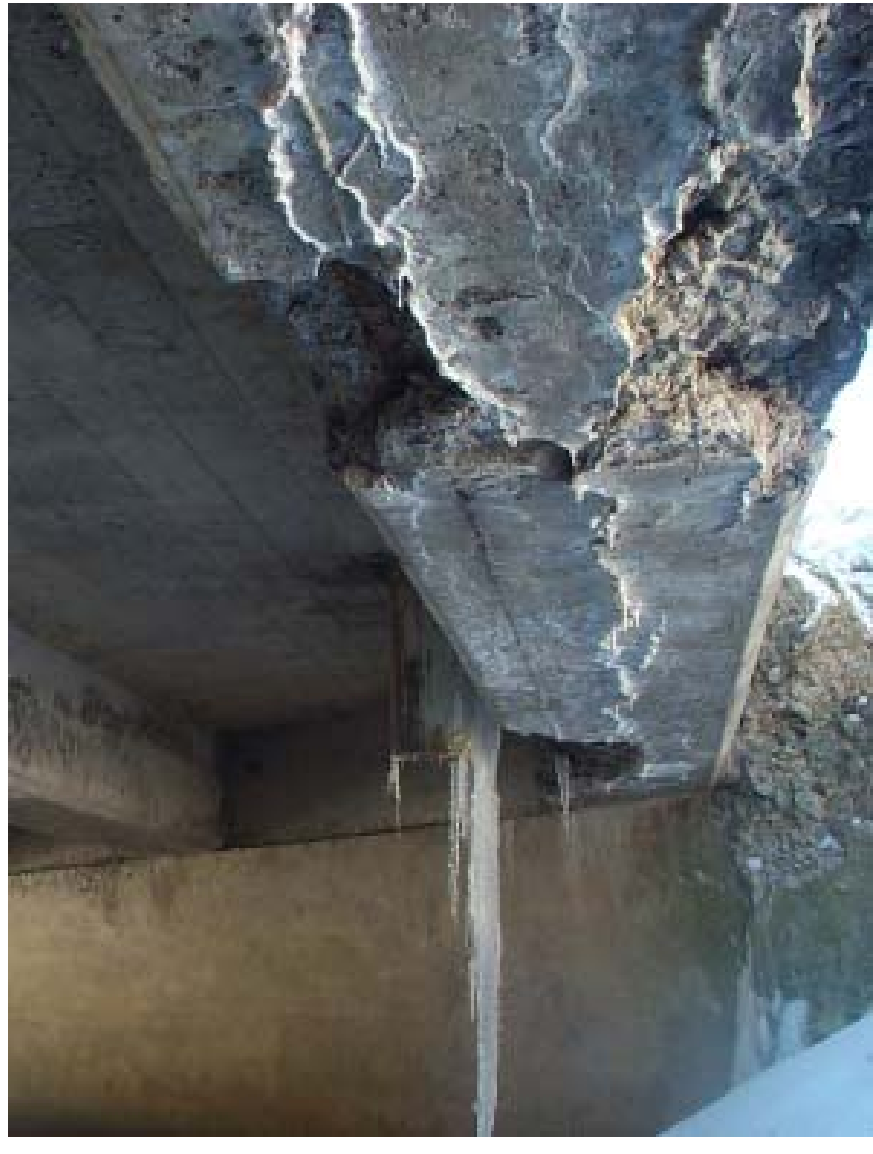

Note: Though this bridge carries a lot of traffic, and ranks high in the span category, it is ranked into Class \#2 because of the extent of the visual damage. This bridge would be suitable for repair by FRP technololgy.

\section{Details:}

Span (ft): 55

Ranking: 8/10

Year Built: 1929

Ranking: 3/10

ADT: 4195

Ranking: 8/10

ADTT: 299

Ranking: 7/10

Visual Damage:

Ranking: 6.67/10

Number of Spans: 2

Status: Open

Road: SR 522

Figure 3.9. Snyder County \#54-0522-0090-1932. Class \#2: Overall Score (65.4/100) 


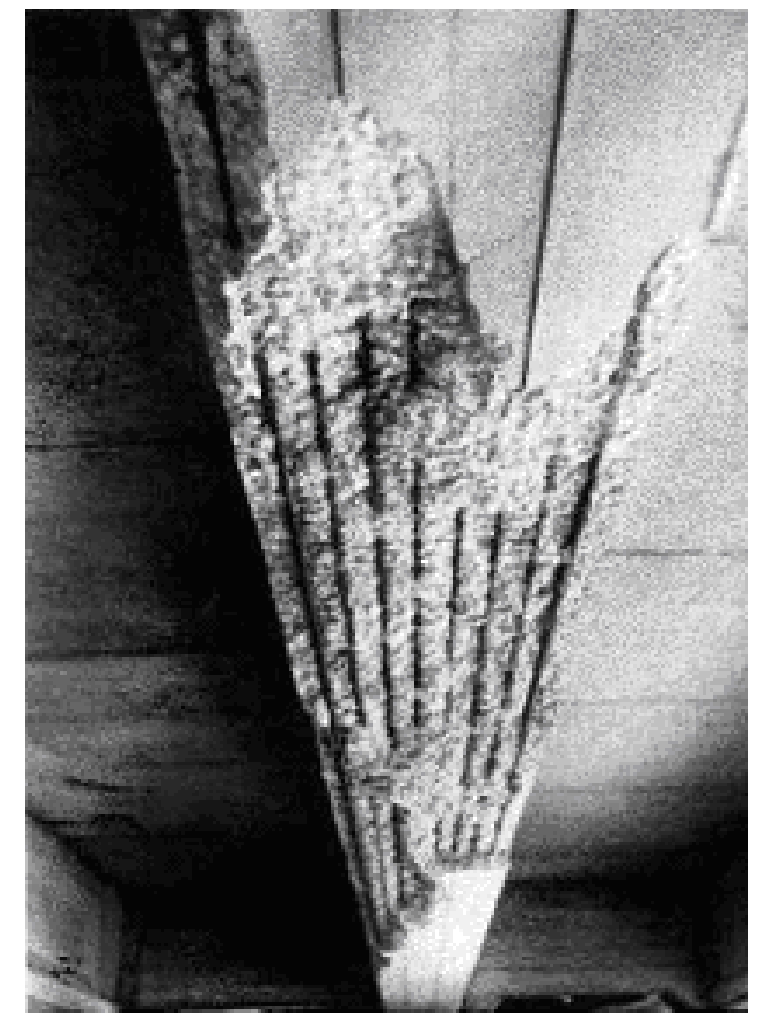

Photo on left: NCHRP Report 514, an example of a T-beam suitable for FRP repair techonology.

Photo on right: Provided by PennDOT for bridge \#19-3008-0100-0039.

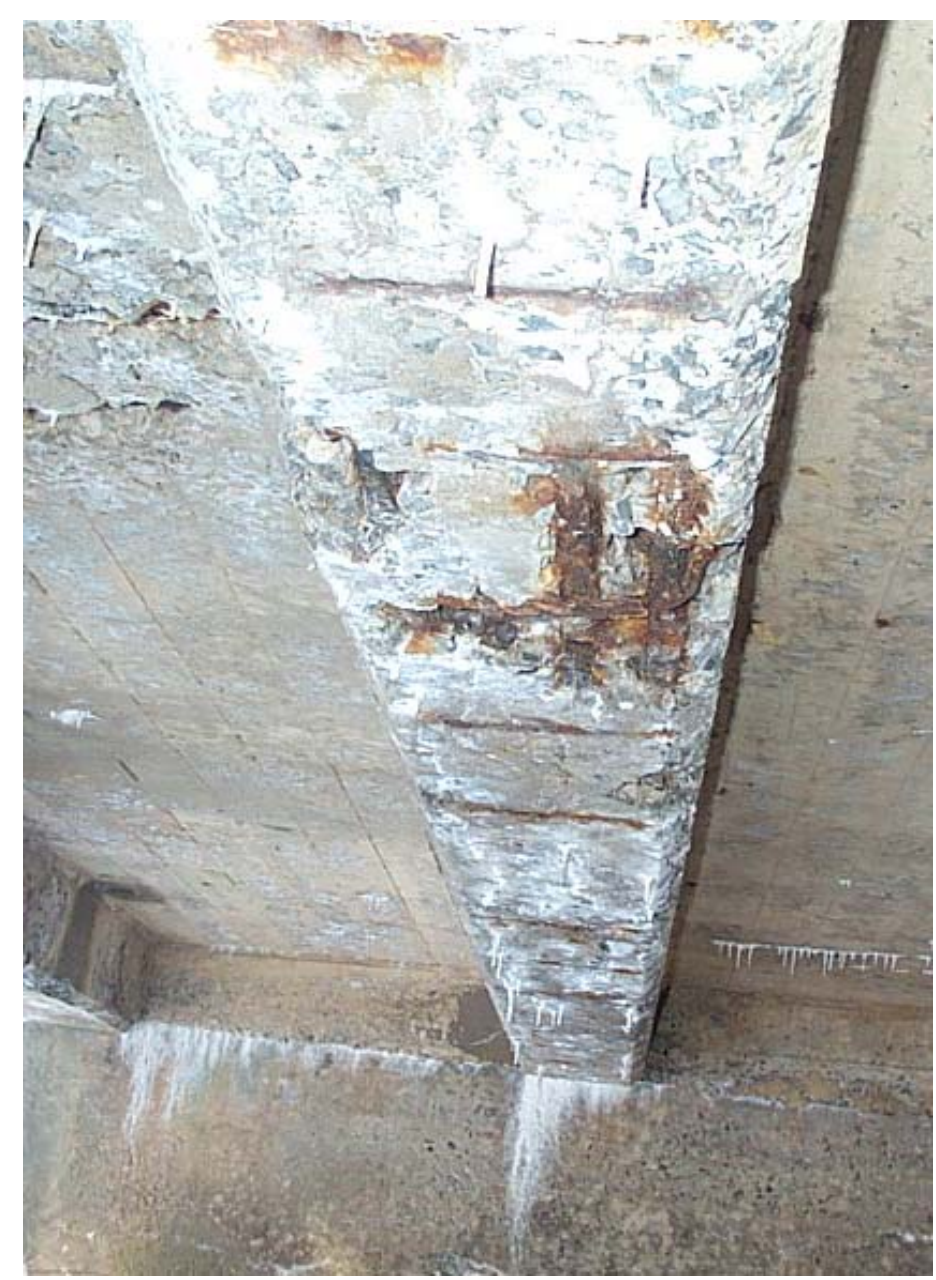

\section{Details:}

Span(ft): 23

Ranking: 2/10

Year Built: 1933

Ranking: 4/10

ADT: 265

Ranking: 2/10

ADTT: 20

Ranking: 1/10

Visual Damage:

Ranking: 3.33/10

Number of Spans: 1

Status: Open

Road: SR 3008

Note: This bridge ranked low overall because of low traffic volume, short span, and age. Also, the visual damage was not as severe as many of the other bridges. This is an example of a bridge which may not be a good candidate for the FRP technology.

Figure 3.10. Columbia County \#19-3008-0100-0039. Class \#3: Overall Score (39.9/100) 


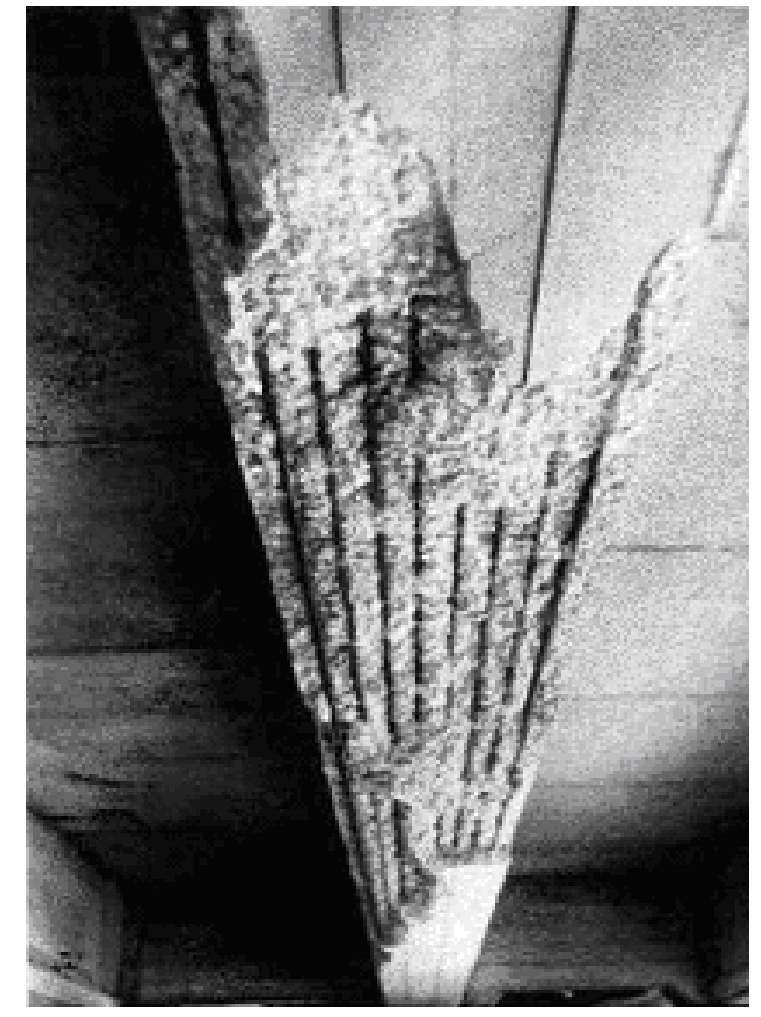

Photo on left: NCHRP Report 514, an example of a T-beam suitable for FRP repair techonology.

Photo on right: Provided by PennDOT for bridge

\#58-1002-0050-0000

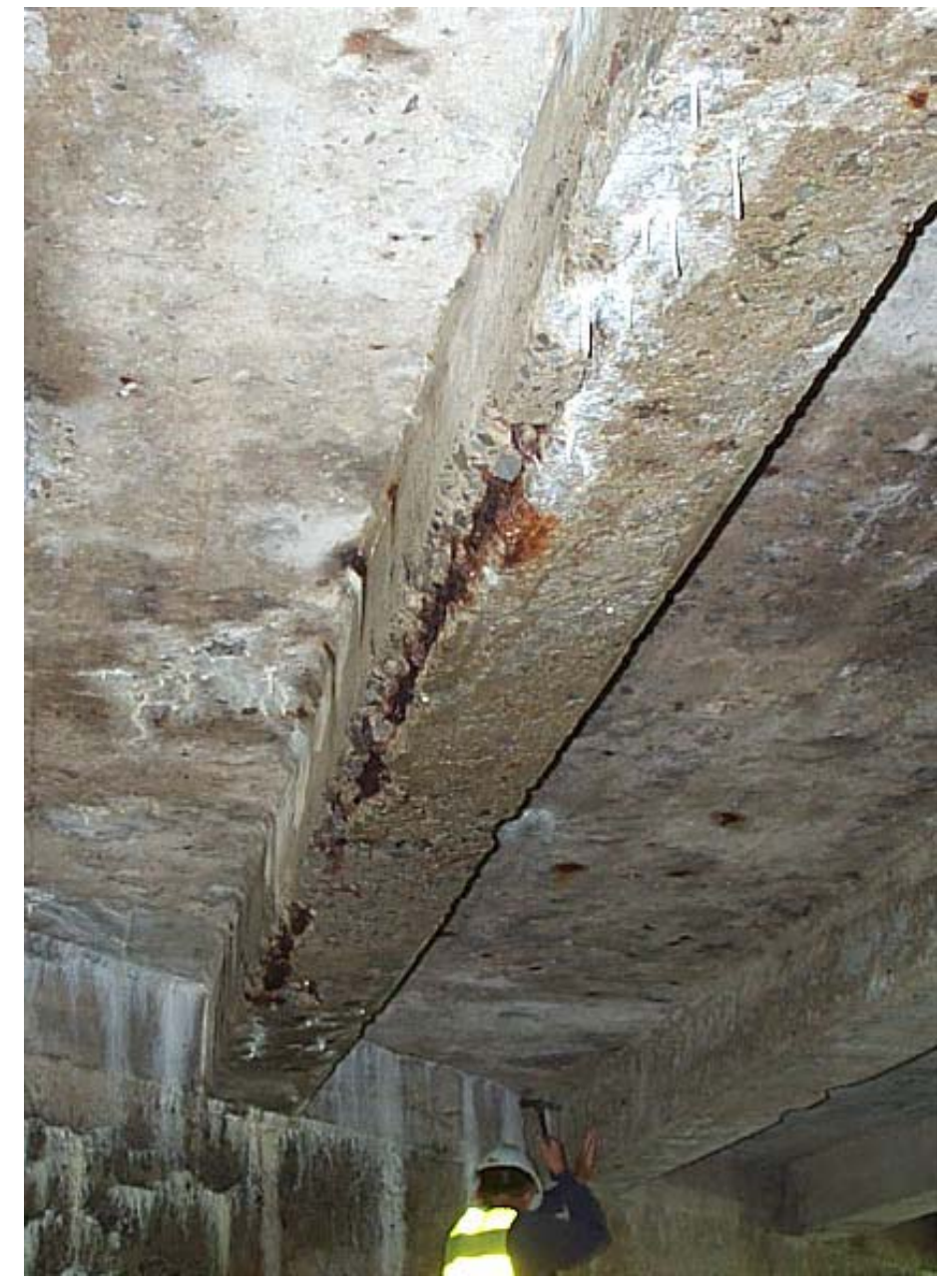

\section{Details:}

Span (ft): 27

Ranking: 3/10

Year Built: 1917

Ranking: 1/10

ADT: 568

Ranking: 4/10

ADTT: 57

Ranking: 3/10

\section{Visual Damage:}

Ranking: 3.33/10

Number of Spans: 1

Status: Open

Road: SR 1002

Note: This is a very old bridge which does not carrie much traffic. Also, the damage to this bridge seems to be extensive. However, this damange does not seem to closely resemble the damange described in NCHRP Report 514. Replacement of this bridge may be a better alternative to the FRP technology.

Figure 3.11. Tioga County \#58-1002-0050-0000. Class \#3: Overall Score (30.1/100). 

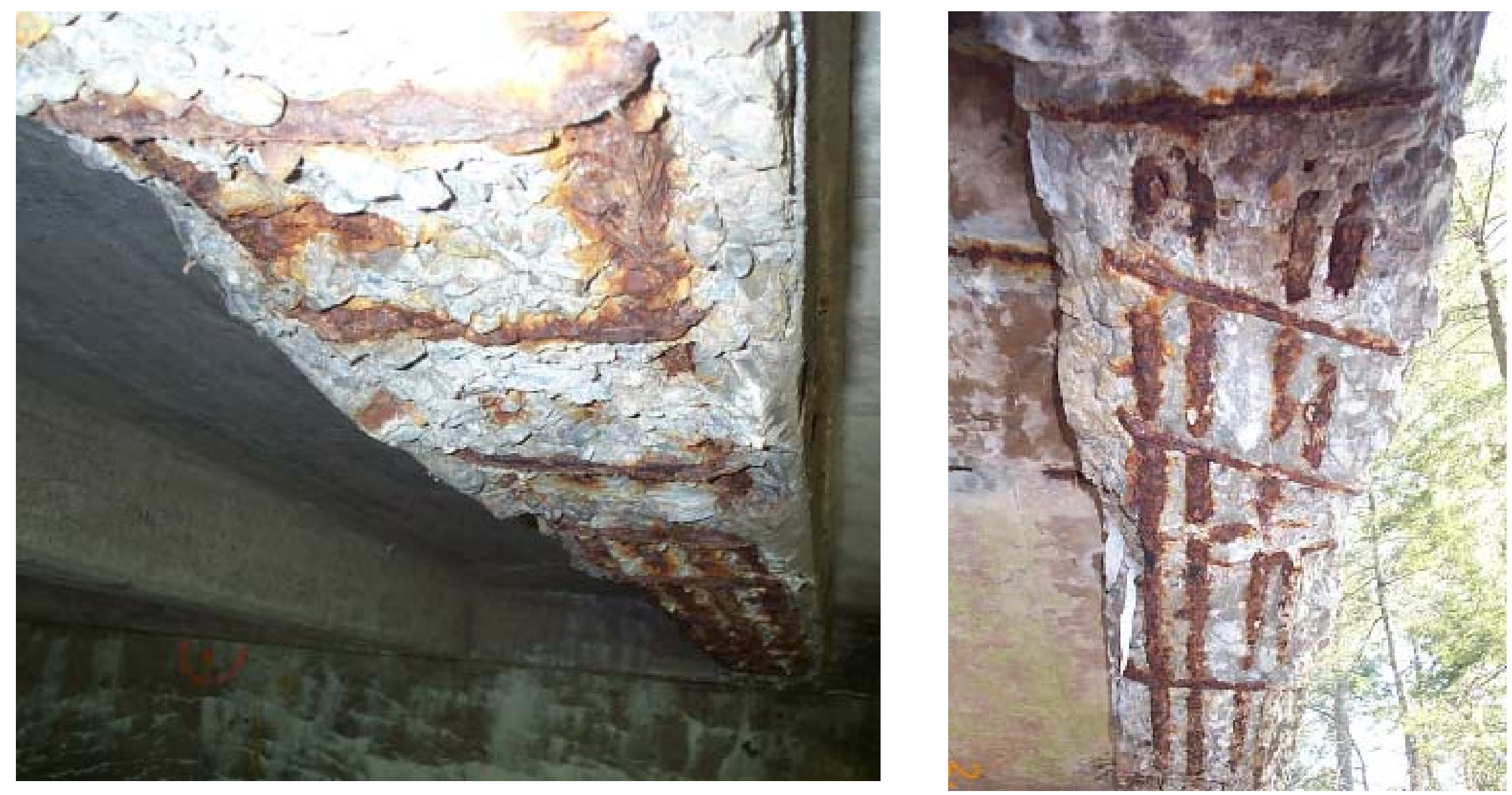

Photo on left: Provided by PennDOT for bridge \#08-4013-0250-1496

Photo on right: Provided by PennDOT for bridge \#59-1001-0110-2058

Figure 3.12. Visual Damage Score 10/10.
Note: The photos provided show extensive damage to the concrete T-beams. This type and extent of damage is suitable for FRP technology. Bridges with damage type and severity similar to this received a score of 10 out of 10 for visual damage. 


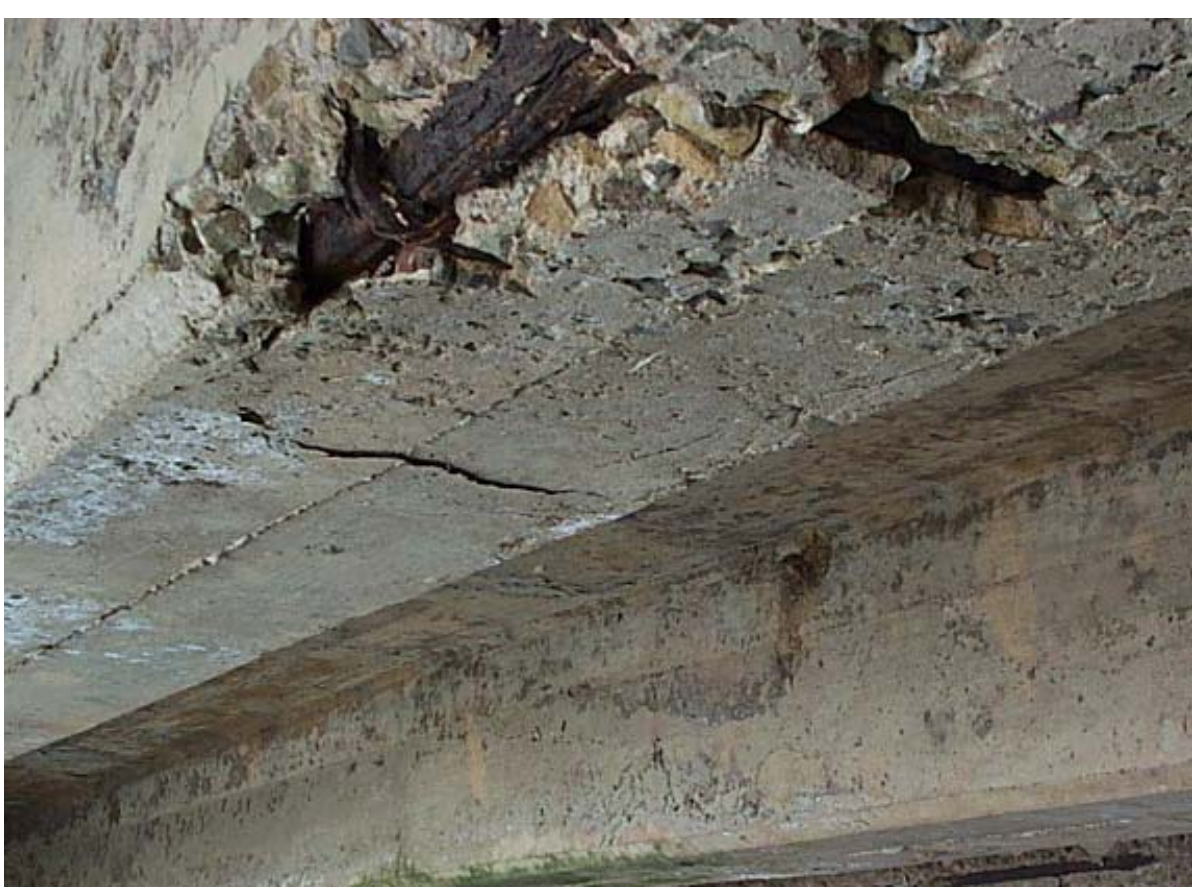

Photo on left: Provided by PennDOT for bridge \#19-0239-0060-0511

Photo on right: Provided by PennDOT for bridge \#19-3008-0100-0039

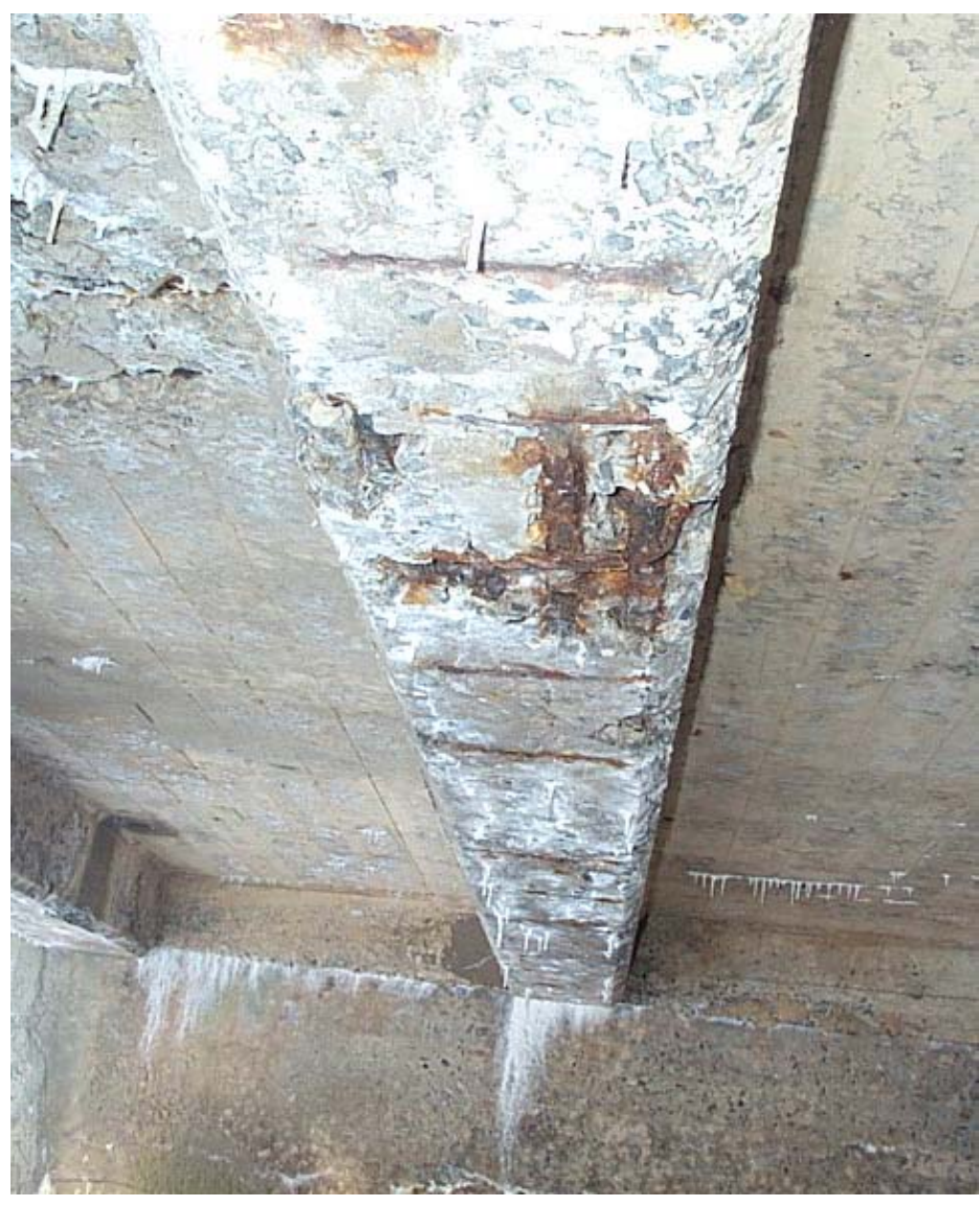

Note: The damage level shown in these photos indicated that these bridges are moderate candidates for repair using the FRP technology. Bridges with damage severity similar to these examples were scored 6.67 out of 10 .

Figure 3.13. Visual Damage Score 6.67/10. 


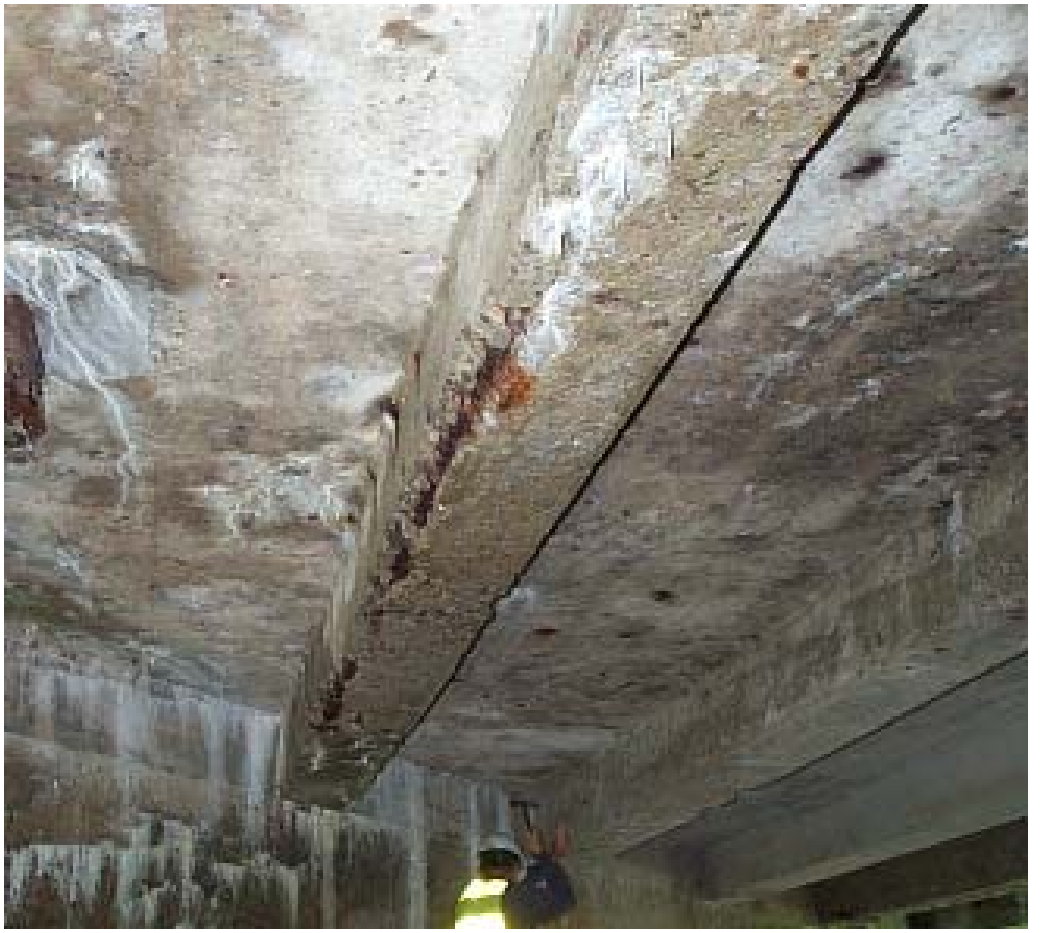

Photo on left: Provided by PennDOT for bridge \#58-1002-0050-0000

Photo on right: Provided by PennDOT for bridge \#56-0220-0530-0988

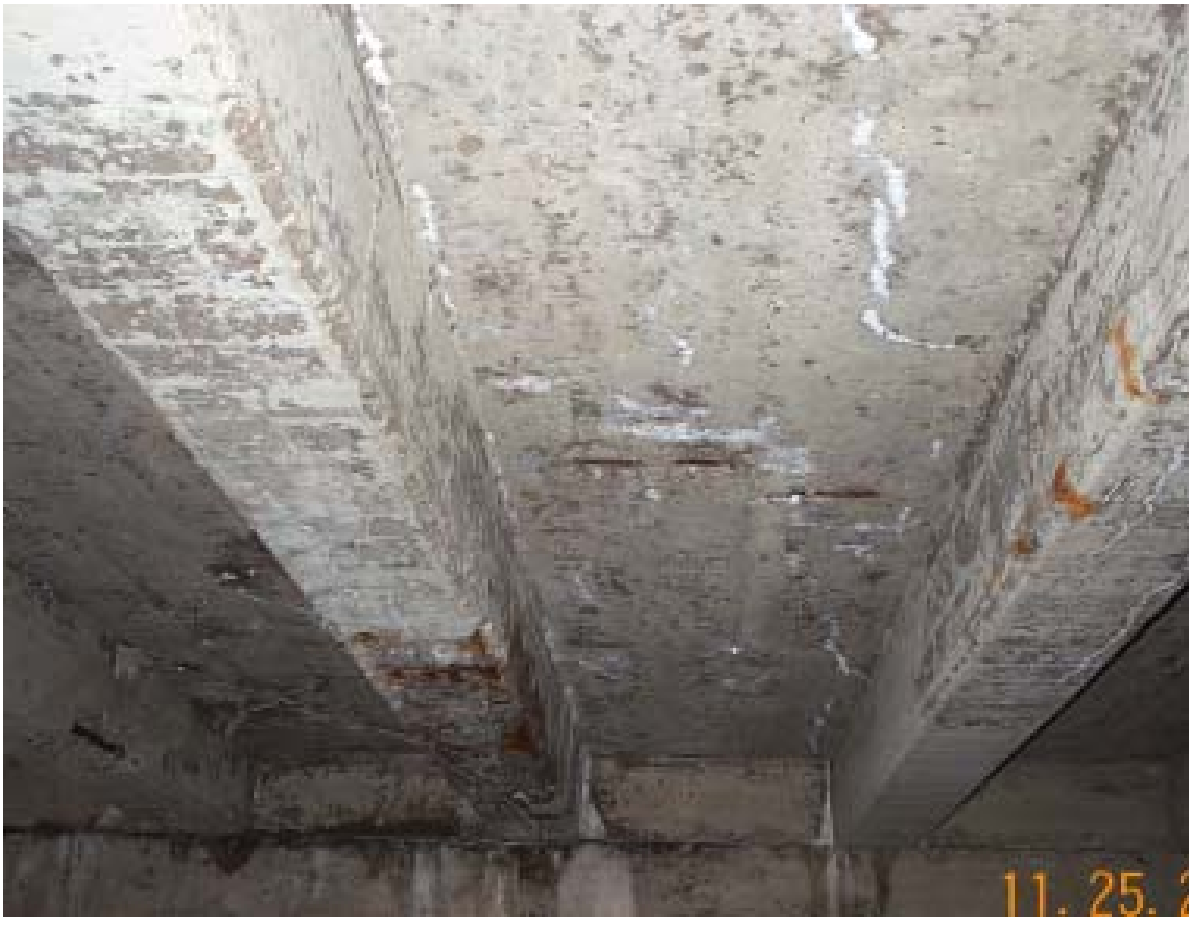

Note: Some of the photograps as shown above indicated low level of damage. Damage of this type may be suited for repair by either FRP technology or coventional methods, but these bridges are not likely candidates for the FRP technology.

Figure 3.14. Visual Damage Score 3.33/10. 


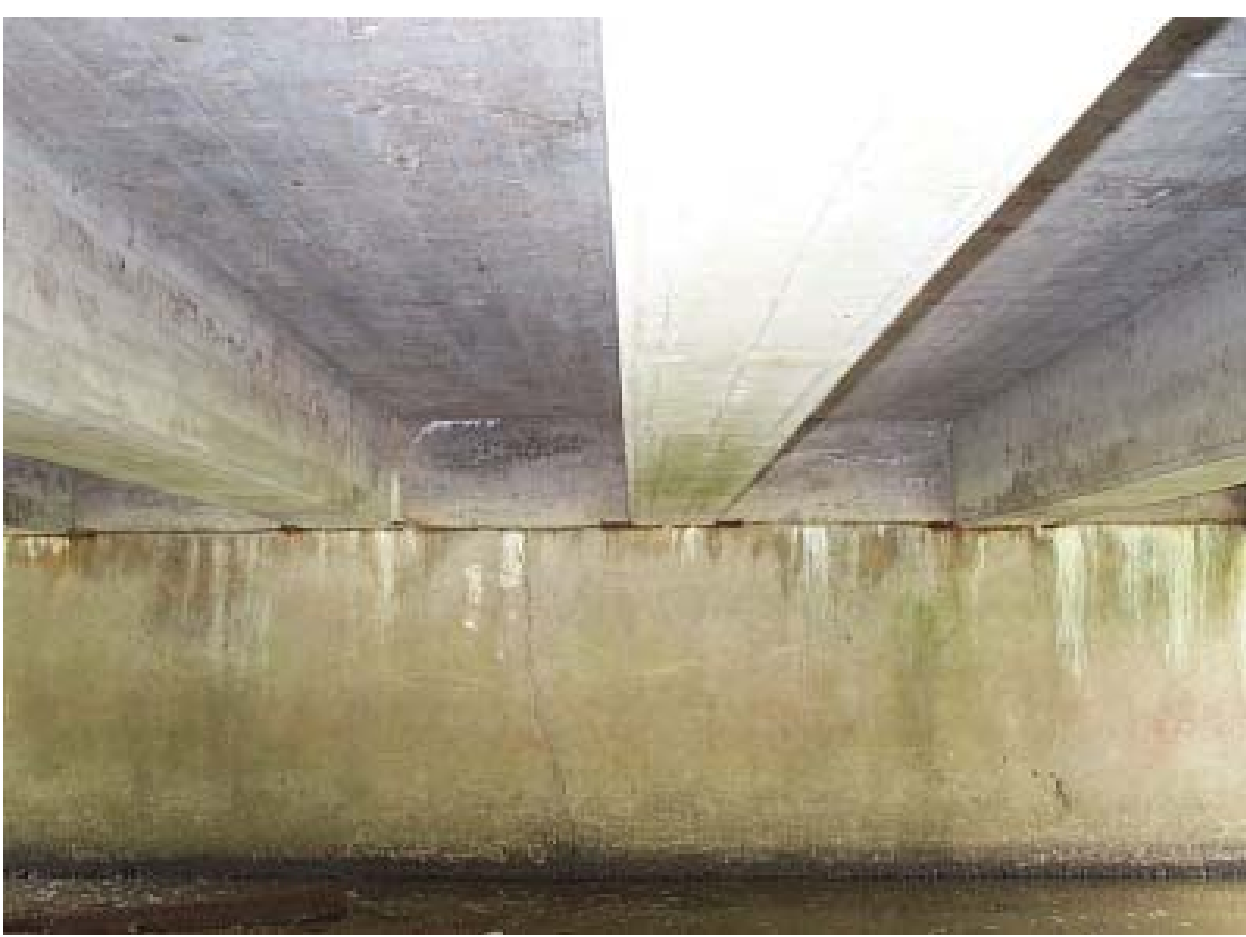

Photo on left: Provided by PennDOT for bridge \#59-1003-0140-0921

Photo on right: Provided by PennDOT for bridge \#59-0045-0440-1302

Figure 3.15. Visual Damage Score 0/10.

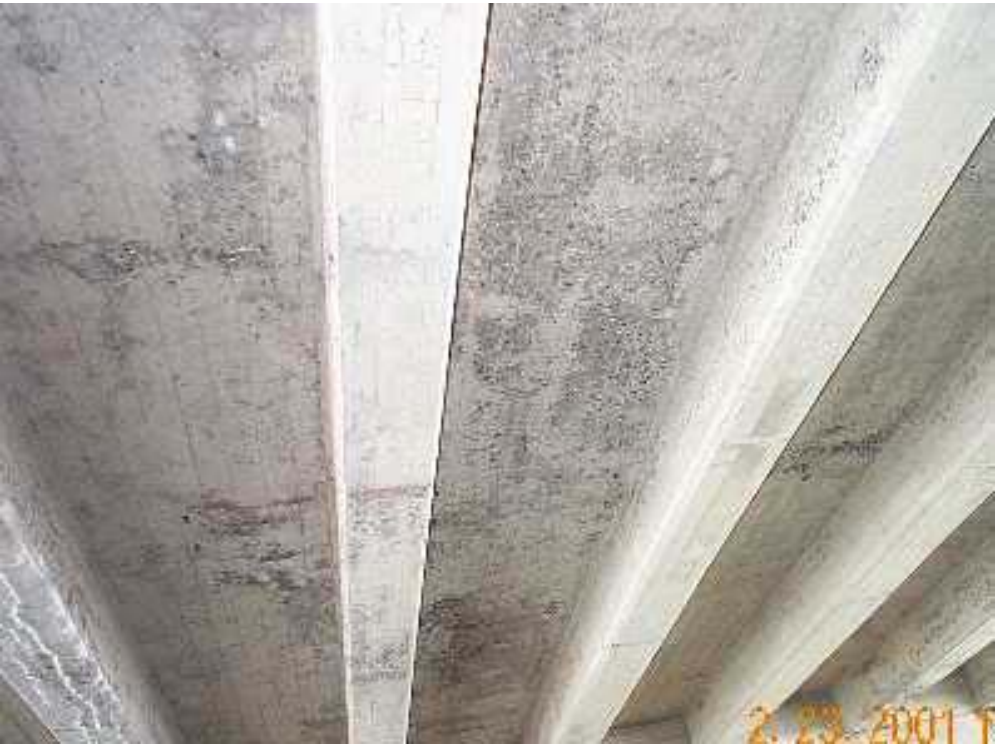

Note: Some of the photographs showed very little or no damage. Bridges of this type were scored 0/10 in the visual damage category, because these bridges in general probably do not require repair. 


\section{Chapter 4}

\section{Recommendations for Selecting Ideal Candidate Bridges}

This chapter answers the posed question: "Which bridges are ideal candidates for repair?” The PennDOT D-3 project is presented as an example to recommend a process for the selection of candidate bridges that have the greatest potential for demonstrating the benefits of surface applied FRP.

The selection of candidate bridges for FRP-repair can be based on the following two aspects: (1) considerations for selection (4.1), and (2) selection for different levels of repair efforts (4.2). Therefore, Section (4.3) suggests an educational program to allow PennDOT D-3 to adopt and continue the use of FRP repairs, both with outside contractors autonomously.

\subsection{Considerations for Selection of Candidate Bridges}

The considerations for selecting candidate bridges should include: (1) a rational procedure for identifying suitable candidate bridges, (2) a preliminary analysis method for performance and cost effectiveness, and (3) a detailed structural analysis and implementation plan.

\subsubsection{Suitable Candidates}

The rating methodology presented and applied in Chapter 3 identifies the list of potential candidate bridges from the general PennDOT D-3 inventory. In general, a significant portion of the structures targeted for repair include the following approximate range of characteristics:

- Age: Built between the 1920’s and 1960’s

- Span: Single span structures between 20 and 50 feet

- ADT: Any currently level

- ADTT: Any level with a large number of bridges carrying 1000 trucks per day

- Local Damage-Level 3 or Level 2 
Based on the classification shown in Table 3.2, approximately half of the PennDOT D-3 T-Beam concrete bridge inventory scored $50 \%$ or greater, indicating that they can be considered suitable candidates for FRP-repair technology. In the classification, 13 Prime Candidate Class- 1 bridges had a rating of $68 \%$ to $100 \%$, and 44 Moderate Candidate Class-2 bridges had a score ranging between $50 \%$ and $68 \%$. The remaining 71 Low Candidate Class-3 bridges scored between $0 \%$ and 50\%. This indicates that about half of the bridges are classified as being prime or likely candidates for FRP repair, and they can be further inspected for visual condition assessments to select appropriate structures for implementation of FRP repair.

Out of a total of 128, initially 61 bridges were identified as suitable candidates for FRP repair, and out of these 16 were further selected for visual inspection. During the visual inspection, a few of the structures in PennDOT D-3 inventory were immediately considered to be better suited for replacement than for repair. The anticipated scope of repair for all 128 bridges ranges from simple maintenance to possible replacement, and includes the following scenarios:

1. General cleaning and maintenance

2. Simple patching

3. Patching and use of surface bonded FRP

4. Moderate rehabilitation including concrete chipping, forming and casting, plus the use of surface bonded FRP

5. Extensive rehabilitation including chipping, forming and casting, with use of surface bonded FRP

6. Complete replacement

In summary, the candidate bridges for FRP repair should be selected from those listed in Appendix A either as Class 1 (Prime) or Class 2 (Moderate).

\subsubsection{Preliminary Analysis}

After a review of the bridges that were ranked either as Prime or Moderate candidates for FRP-repair, a preliminary analysis of selected candidate bridges should be conducted. 
The first and most fundamental consideration is the design loads. Current and future anticipated loads need to be considered to verify design assumptions. The two primary assumptions are:

- Loads are within the elastic range of the structure

- Existing section properties are known (area of steel, yield point of steel, concrete strength and dimensions of the beam)

For a likely candidate bridge, a preliminary design can be performed to estimate the quantities of required FRP. The preliminary design will also yield sufficient knowledge of the scope of repair using conventional materials. As-built drawings, original design sheets or further field surveys can be used to ascertain the initial data for analysis. Ultimately, field surveys to determine the actual area of steel, in-situ concrete strength, and knowledge of the damaged condition of the structure will be required for a detailed analysis.

The overall cost of repair can be determined and a cost comparison with conventional materials can be made. It is recommended that all factors be included in the cost comparison. Factors including labor, equipment, cost of lane closures, economic impact caused by detours, and future cost of replacement should be considered in addition to the acquisition cost of FRP materials.

In summary, for a given bridge selected from the recommended list of Prime or Moderate candidate bridges (Appendix A), a preliminary analysis should be performed. Also, this preliminary assessment should include a cost-benefit analysis as presented in Chapter 5 .

\subsubsection{Detailed Analysis}

After a candidate structure is identified for repair using surface bonded FRP, and following a preliminary analysis, a detailed analysis of the structure should be conducted. Currently there is no analysis or design standard in any AASHTO documents to determine the type and amount of FRP required. In lieu of an AASHTO standard or guide, it is recommended that the methodology presented by the American Concrete 
Institute in 440.2R - Guide for the Design and Construction of Externally Bonded FRP Systems for Strengthening Concrete Structures - be used as a basis for design.

This ACI document can guide the designer through the process of analyzing and detailing surface bonded FRP. Some of the highlights include analysis of existing structural conditions, analysis of section properties, computation and checks for applied loads, computation and checks for allowable strain, and consideration of deflection for serviceability.

One of the limitations of this approach is the lack of certainty of the actual existing conditions of the structure. It is important to determine the failure mode that will control the behavior of the repaired structural component. Three possible flexural failure modes are as follows:

1. Crushing of concrete prior to yielding of the reinforcing steel

2. Yielding of tension reinforcing steel followed by rupture of FRP

3. Yielding of steel prior to crushing of concrete

The knowledge of the failure mode is important to ensure that the structure is within the elastic range, that the behavior is ductile, and that full structural benefit of the FRP is realized.

In summary, a detailed analysis is required for the effective implementation of FRPrepair in a selected bridge project.

\subsection{Selection of Candidate Bridges for Different Levels of Repair}

Analysis, design and specification of the repair can be performed either by an outside consultant/contractor, or in-house personnel. Depending on the overall scope of work, the FRP-repair for candidate bridges may be defined at three levels: Repair Level-1 Major, with all work contracted out; Repair Level-2 Moderate, with combined outside consultant and in-house personnel; and Repair Level-3 Minor, with all work accomplished in-house. 
This Section describes the three proposed levels of FRP-repair, and identifies correspondingly suitable bridge examples from the recommended lists of Class 1 and Class 2 bridges, given in Appendix A.

\subsubsection{Major Candidate Bridges (Repair - Level 1)}

The first level should address a candidate bridge requiring extensive repair. At this level the engineering is performed by a consultant and the actual repair is contracted out through competitive bid. An example of a bridge that can be addressed by this level of repair is Bridge \#41-0118-0230-0644, as show in Figure 4.1.

At this level all of the preparatory concrete work and application of the surface bonded FRP would be performed per project specifications and construction drawings. It is expected that the overall scope of work may include other pay items such as abutment repair, bearing repair, and possibly expansion joint repair. While the application of the FRP may represent a smaller portion of the overall project cost, the scale of the project can offer sufficient opportunities for developing expertise with FRP technology.

Because of the extensive damage in such structures, as shown in this bridge, the use of FRP for additional strengthening is possible, such as in areas deficient in shear or areas that require confinement of reinforcing steel due to low cover or inadequate splice length. A typical project at this scale, used as a prototype demonstration structure for gaining experience with FRP technology, can include the following primary tasks: (1) field assessment of the structure, (2) structural analysis and load testing, (3) evaluation of insitu material properties from field samples, (4) design of FRP repair and other work, (5) repair implementation and evaluations, (6) testing of repaired structure, and (7) supporting lab-scale studies, and (8) development of draft specifications and standard drawings.

\subsubsection{Moderate Candidate Bridges (Repair - Level-2)}

The next level of repair should address a candidate bridge showing moderate level of damage. A combination of work performed by in-house forces and some contracting 
through specialty trades or engineering by a consultant is suggested. An example of a structure that could be addressed by this level of repair is Bridge \#59-0045-0310-2011, as show in Figuree 4.2.

At this level most field activities can be accomplished by in-house forces. However, because there may be a need for injecting cracks with either epoxy or urethane, or the overall cost may exceed allocated state project limits, it may be necessary to advertise portions of the project for competitive bids. Several possibilities could be explored, such as: (1) retaining a consultant for the engineering portion and using in-house forces for labor (possibly in phases); (2) performing the engineering in-house and contracting out the specialty items (crack injection or application of the FRP), with in-house forces acting as a general contractor; finally (3), performing the engineering in-house and contracting out all of the field work.

At this level of repair, the client would realize the benefits of competitive bidding while retaining overall design control and providing training opportunities.

\subsubsection{Minor Candidate Bridges (Repair - Level 3)}

The third level should be addressed for a candidate bridge with minor to moderate level of damage. This level can be described as a trial or test program to evaluate the implementation of repair techniques by in-house forces on a relatively small scale. A structure that could be addressed by this level of repair is Bridge \#41-0118-0020-1109, as shown in Figure 4.3. In general a structure with moderate and localized damage is a likely candidate for a trial program.

From a field assessment, the expected scope of work could include removing loose concrete, cleaning existing reinforcing steel, measuring the current area of steel, estimating the compressive strength of the concrete, forming and casting new concrete or mortar to re-establish the beam section, then application of surface bonded FRP after appropriate surface preparation. To expedite the project, final design to determine the quantities of the FRP can be performed while preparatory work is being completed. At 
this level the anticipated scope of work, although detailed, is small and it is realistic to assume that the client's forces could accomplish this using in-house engineering and forces. Funding for this type of maintenance construction is realistically within the limits of a state project account.

\subsection{Suggested Implementation Strategy}

The selection of candidate bridges should conform to the descending scale of FRP-repair work complexity, from Major to Moderate to Minor. This approach offers great potential for providing an efficient learning and training environment for in-house personnel, so that eventually, a Minor FRP-repair work of a candidate bridge can be accomplished entirely by in-house forces. Moreover, this approach provides an opportunity to develop more specific design and construction guidelines, leading to training seminars for State personnel.

\subsection{Conclusions}

This chapter answered the question: “Which bridges are ideal candidates for repair?” by presenting recommendations for the selection of ideal candidate bridges from the PennDOT D-3 inventory. Suitable characteristics for candidates have been presented and discussed. Also, the scope of repairs for this inventory has been presented. It was found that about 50 percent of bridges from the PennDOT D-3 inventory were suitable candidates for repair. From this set of bridges, a preliminary and detailed analysis was suggested to determine specific suitability.

From the characteristics classifications and repair-levels presented in Chapter 3, three candidate bridges have been selected. It has been suggested that, to train state employees, first the Repair - Level 1 (Major) project be performed. After this repair, a more detailed cost-benefit analysis can be performed and PennDOT D-3 can continue with more "hands-on” involvement on the Repair - Level 2 and 3 projects. 

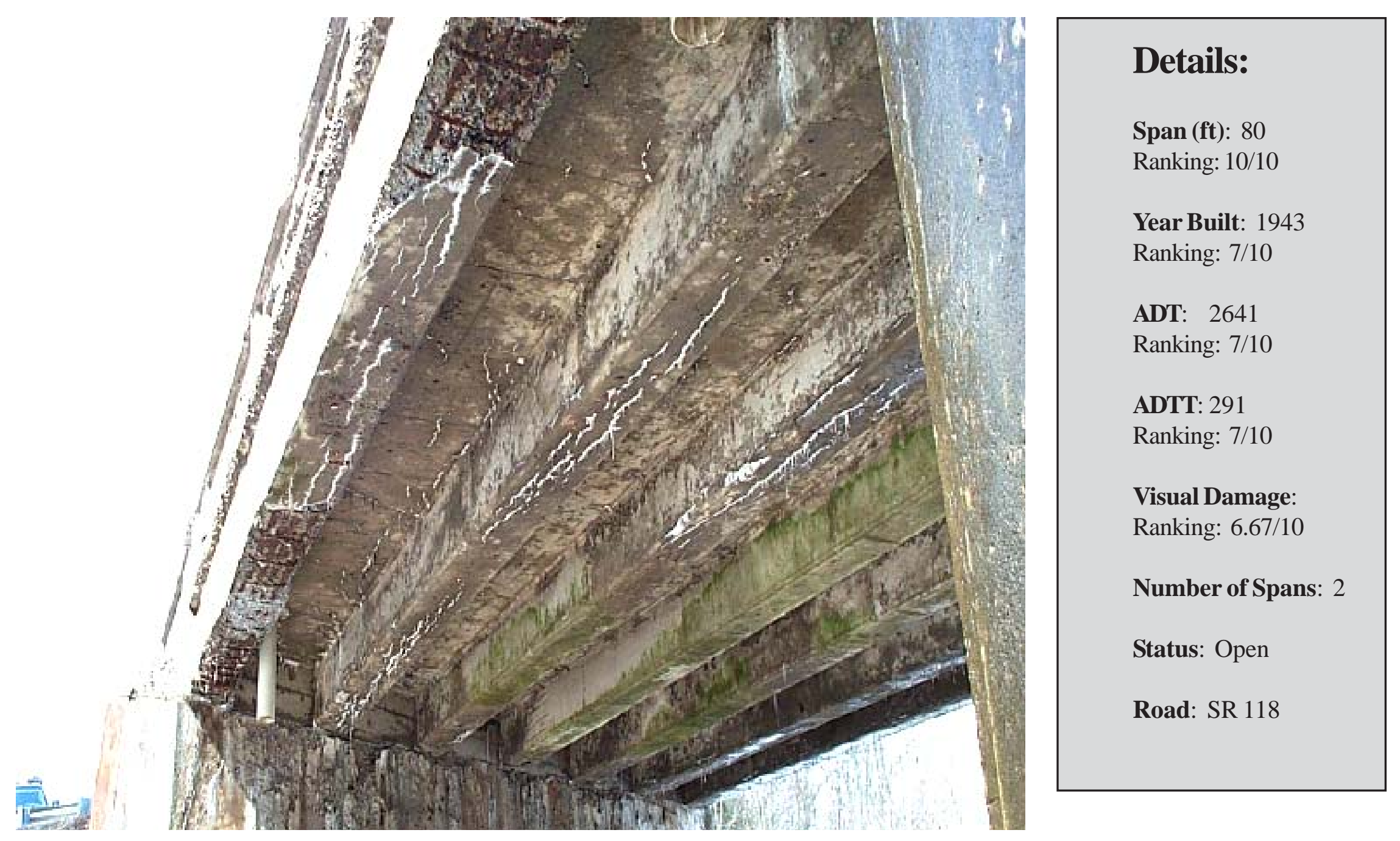

Figure 4.1. Major Candidate Bridge (Repair Level-1). Lycoming County \#41-0118-0230-0644. Class \#1: Overall Score (71.7/100). 


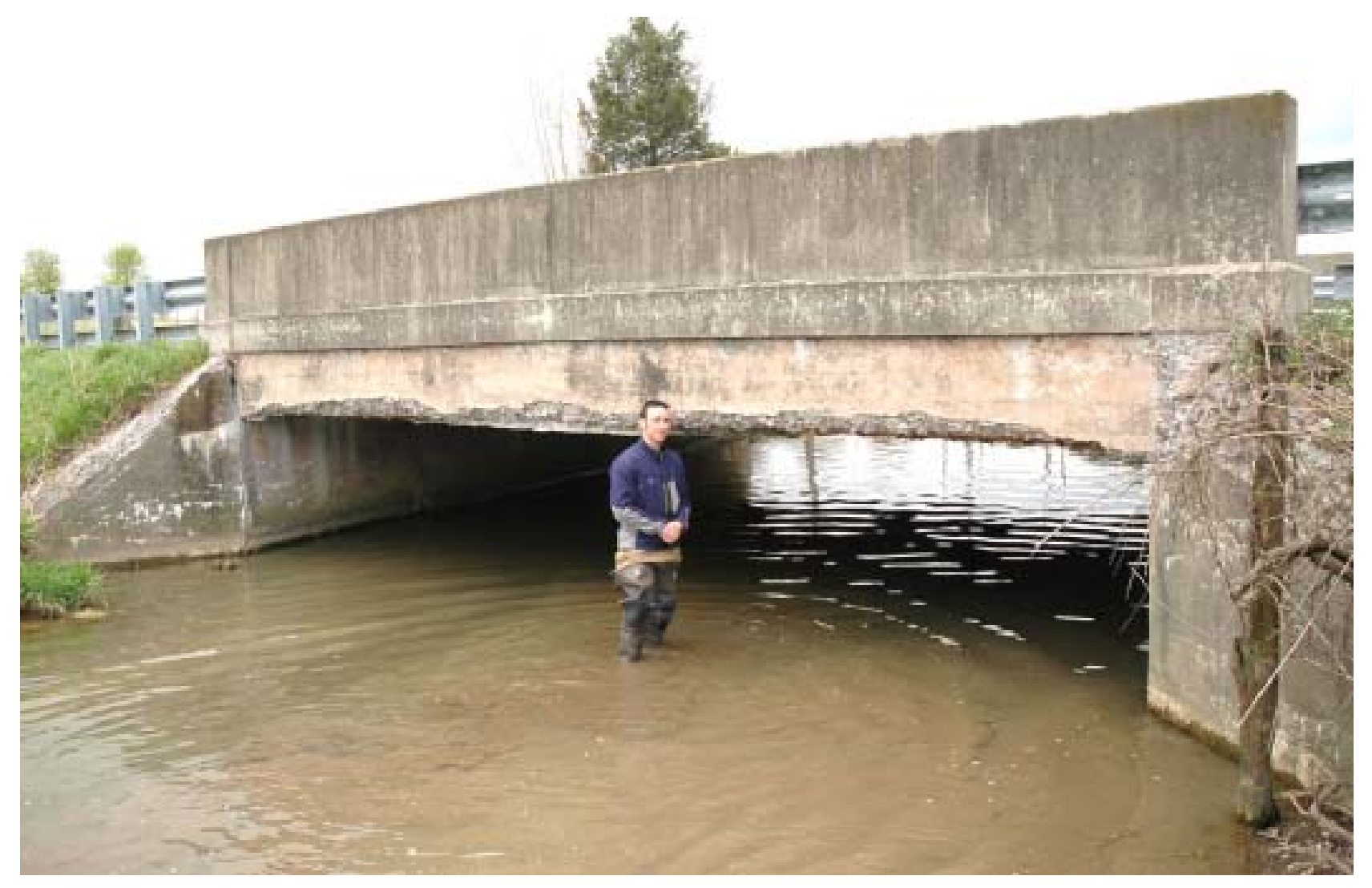

\section{Details:}

Span (ft): 30

Ranking: 4/10

Year Built: 1938

Ranking: 5/10

ADT: 10310

Ranking: 10/10

ADTT: 648

Ranking: 9/10

Visual Damage:

Ranking: 10/10

Number of Spans: 1

Status: Open

Road: SR 45

Figure 4.2. Moderate Candidate Bridge (Repair Level- 2). Union County \#59-0045-0310-2011. Class \#1: Overall Score (84.8/100). 


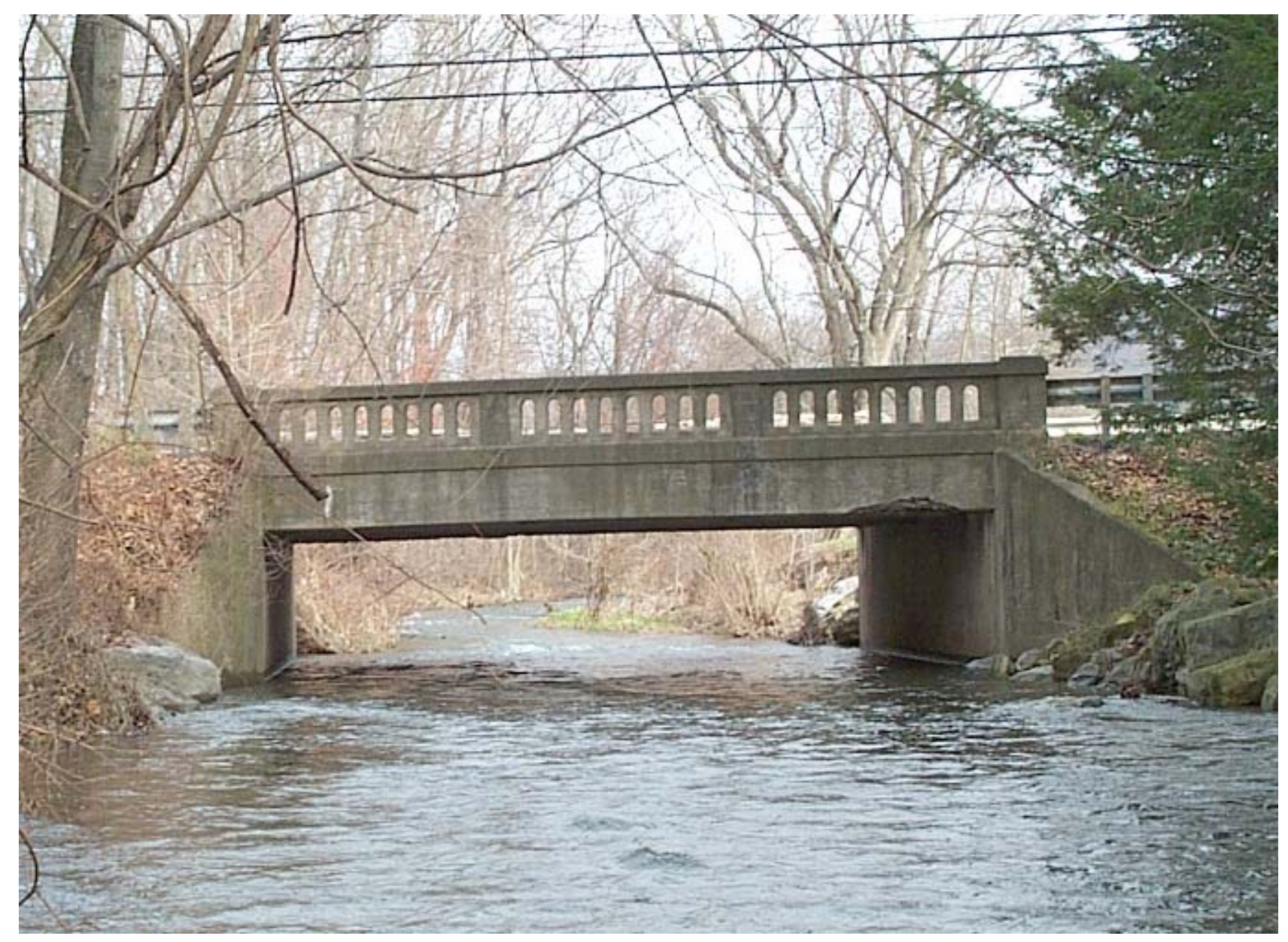

\section{Details:}

Span (ft): 31

Ranking: 4/10

Year Built: 1930

Ranking: 4/10

ADT: 5570

Ranking: 9/10

ADTT: 408

Ranking: 8/10

Visual Score:

Ranking: 10/10

Number of Spans: 1

Status: Open

Road: SR 118

Figure 4.3. Minor Candidate Bridge (Repair Level-3). Lycoming County \#41-0118-0020-1109. Class \#2: Overall Score (66.4/100) 


\section{Chapter 5}

\section{Comparison of Methods Based on Costs \& Construction for PennDOT D-3 Bridges}

This chapter answers the question: "Is the FRP technology economically feasible and competitive with the conventional repair method?” by investigating sample repair scenarios for three bridges in the PennDOT-D3 inventory. These bridges correspond to the examples suggested in Chapter 4 and include sample repairs from each of the three repair levels.

First design assumptions are presented (5.1). Next examples of FRP repair for RepairLevel 1, 2, and 3 (Repair-Examples 1, 2 and 3 respectively) are presented and compared to traditional methods (5.2, 5.3 and 5.4 respectively). Section (5.5) provides an insight on the "Learning Curve" Approach. Section (5.6) compares the two methods based on construction and section (5.7) discusses traffic control issues for each method. Finally, conclusions are presented in section (5.8).

\subsection{Design Assumptions}

\section{Surface-Bonded FRP Technology:}

From insight provided by PennDOT-D3, an approximate geometry for a standard concrete T-Beam was used to estimate the amount of FRP to be used per linear foot of TBeam to be repair (along the beam). From this approximate geometry, a standard TBeam section was designed. Figure 5.1 is the standard T-Beam section for the design assumptions.

\section{Conventional Technique:}

For repair using the conventional technique, an approximate geometry for a standard concrete T-Beam (insight provided by PennDOT-D3) was used to estimate the amount of concrete to be used per linear foot of T-Beam to be repaired (along the beam). From this approximate geometry, a standard T-Beam section was designed. Figure 5.2 is the standard T-Beam section for the design assumptions. 


\subsection{Repair-Example 1: Cost Comparison for Level 1 (Major) repair.}

Bridge \#41-0118-0230-0644 (Figure 5.3) was selected as a Repair-Level 1 because this bridge shows extensive overall damage. This bridge has the following characteristics: Total Span $=80 \mathrm{ft}$ (two span); Year Built = 1943; Number of beams = 7; ADT/ADTT = 2600/300; Overall Classification $=71.7$ - Class 1; Visual Rating $=2$ (moderately favorable for repair). Though this bridge was originally rated " 2 " in the visual category, additional photographical evidence justifies high favorability for repair of this structure.

Because of the type and extent of damage, repair using the conventional method may not be possible; hence the repair will be compared to replacement cost. The total span length of this bridge is 80 feet and there are 7 beams. For complete repair, about 560 feet of beam will be repaired using the FRP technology. Though not considered in the analysis, the damaged center pier may also be a candidate for repair using FRP technology (Figure 5.4). For this example repair, only one design scenario will be considered and the "firstcost” value will be used. This design and repair will require a significant endeavor and will likely be contracted out completely. Next, design and cost assumptions for FRP (5.2.1) and replacement (5.2.2), as well as a cost comparison (5.2.3) are presented for Repair-Example 1.

\subsubsection{Design and Cost Assumptions for Repair-Example 1}

\section{Design Assumptions for FRP Repair:}

From designs and drawings provided by PennDOT-D3, an approximate geometry for a standard concrete T-Beam was used to estimate the amount of FRP to be used per linear foot of T-Beam to be repair (along the beam). From this approximate geometry, a standard T-Beam section was designed (for details, See 5.1).

Assuming two layers of FRP, and the standard design assumptions $2 \times(16$ in $+2 \times 4$ in), a total of 48-in or $4 \mathrm{ft}$ of FRP per unit length of beam ( $\mathrm{ft}$ ) is required. For this example, 
560 feet of beam is to be repaired using FRP technology. Multiplying 560 feet of beam by $4 \mathrm{ft}$ per unit thickness yields a required cross-sectional area of FRP to be $2240 \mathrm{ft}^{2}$.

\section{Cost Assumptions for FRP repair:}

Using information provided by Mr. Steve Tysl, a consultant from Proto Composites, the cost estimate for a single repair of this bridge using the FRP technology is about $\$ 40,000$ "first cost". Details of this estimate are as follows.

Using the design assumptions, 2240 square feet of FRP will be required for repairs. FRP is about $\$$ 6.50-8.00 per square foot. For this estimate the cost of FRP is assumed to be $\$ 7$ per square foot. Multiplying the amount of material by the material cost yields $\$ 15,700$. To account for the cost of patching mortar and labor (for most projects this includes mobilization, small tools, and incidentals) as well as designing and contracting fees, an increase of 2.5 times will be assumed. By multiplying 2.5 by $\$ 15,700$, we estimate about $\$ 40,000$ for the repair cost. This cost estimate does not include cost of lane closure.

A parallel study from the University of Missouri-Rolla (URM) is in the process of developing a similar cost analysis. Due to the confidentiality of pricing details shared by manufacturers, no direct information can officially be provided. However, information from the ongoing study at UMR supports the overall cost estimate given in this chapter.

It should be noted that none of the costs described can be generalized or estimated with a great level of precision. Because the application of the FRP technologies to bridges is in its introductory phase of the product life cycle, practices and related costs vary significantly. Also, bidding prices may vary.

\subsubsection{Cost Assumptions for Replacement}

Replacement of this bridge would cost an estimated \$1.1 million "first cost”. Details of this cost are as follows. 
An Engineer from PennDOT-D3 quoted the cost of a new bridge to be about \$250-300 per square foot of bridge. In order to account for removal of the existing structure, an assumed cost of $\$ 275$ per square foot will be used. This new bridge will have a span length of 80 feet and will be 50 feet wide. Multiplying 80 feet by 50 feet, the total bridge area is 4000 square feet. Multiplying this by $\$ 275$ per square foot yields an estimate of about $\$ 1.1$ million.

\subsubsection{Comparison of Costs for Repair-Example 1}

Savings of FRP repair over replacement based on first cost is significant. Though the life-span of FRP repair is generally less than the life-span of a new structure, this repair would be a good example to illustrate the implementation of the FRP technology.

\subsection{Repair-Example 2: Cost comparison for Level 2 (Moderate) repair.}

Bridge \#59-0045-0310-2011 (Figure 5.5) has the following overall characteristics: Span $=30 \mathrm{ft}$, width $=43.0 \mathrm{ft}$; Year built $=1938$; Number of beams $=9$ (exterior beams $=20$-in x 15.5-in, interior beams = 15-in x 15.25-in); Slab thickness = 8.5-in; ADT/ADTT = 10,300/650; Overall Classification = 84.8-Class 1; Visual Rating = 3 (most favorable for repair). See Figure 5.6 for a cross-sectional diagram of this bridge. This example bridge has 3 damaged beams. The extent of damage on one beam is the entire length (30 feet). Another beam is damaged in two places for about 4 feet and about 5 feet in lengths. The third beam is damaged for about 15 feet. Thus, the total length of beam to be repaired is about 54 feet. The damage lengths are estimates based on photos and actual inspection of the bridge. The application of the composites will likely require more length of beam. Due to assumed lengths and unknown underlying conditions, the repair length will be increased by 25 percent, or a total repair length of about 60 feet.

Next, a cost-benefit “future-worth" comparison (5.3.1) is presented for Repair Example 2. This includes two design scenarios (5.3.2), a design and cost estimate (5.3.3), a present worth calculation for one of the scenarios (5.3.4), and a cost comparison for both scenarios (5.3.5). 


\subsubsection{Cost-Benefit Comparison for Repair-Example 2}

According to Nystrom et al. (2003): "First cost is the simplest and most frequently used analysis, and includes only the initial capital costs. It does not attempt to place a dollar value on future expenditures. This format of analysis is suitable for comparing alternatives with equivalent life expectancy, performance and maintenance. If significant differences are expected in one of these factors, first cost analysis will not give a true comparison of cost effectiveness of the various alternatives. Life cycle cost analysis is similar to first cost analysis except that future costs are also considered. Typically, future costs include maintenance, future rehabilitation expenditures, and probable replacement costs. In life cycle cost analysis, future costs must be discounted to present worth before they are combined with present (immediate) costs.”

When evaluating first-cost in relation to traditional methods, bonded FRP technology can be more expensive, but the key advantages of FRP repair are often overlooked in relation to their high material and manufacturing costs. FRP repairs can be cost-effective in the long run if their use leads to fewer re-repairs (Davalos, Barth, Ray, et al. 2005). A direct comparison of the unit price basis may not be appropriate, but rather an overall project

and life-cycle cost. A present-worth projection analysis will be conducted on the example bridge with estimates for material cost, installation, traffic detour cost and future maintenance. This analysis will be based on two scenarios of bridge maintenance, as discussed in the next section.

\subsubsection{Repair Scenarios Repair-Example 2}

These scenarios will analyze the future-worth of both the conventional method and the surface-bonded FRP technology. The scenarios are as follows: 


\begin{tabular}{|l|l|}
\hline \multicolumn{2}{|c|}{ Scenario 1 (Design Life $=30$ years) } \\
\hline FRP Repair & Conventional Repair \\
\hline 30 year design life & 15 year design life, repair twice \\
\hline Replace or re-repair after 30 years & Replace or re-repair after 30 years \\
\hline \multicolumn{2}{|c|}{ Scenario 2 (Design Life $=30$ years) } \\
\hline FRP Repair & Conventional Repair \\
\hline 30 year design life & 20 year design life \\
\hline Replace or re-repair after 30 years & Allow bridge to degrade, post bridge \\
\hline & Replace or re-repair after 30 years \\
\hline
\end{tabular}

It should be noted that the 30 year design life for FRP technology is a conservative estimate. Sources have quoted a design life of FRP repairs up to 50 years.

\subsubsection{Design and Cost Estimate for Repair-Example 2}

For Bridge \# 59-0045-0310-2011, 60 feet of repair will be assumed. The cost of FRP repair and the conventional repair are both about $\$ 3400$ "first cost". Details of this calculation are as presented next.

\section{Design Assumptions for FRP repair:}

From designs and drawings provided by PennDOT-D3, an approximate geometry for a standard concrete T-Beam (5.1) was used to estimate the amount of FRP to be used per linear foot of T-Beam to be repair (along the beam). From this approximate geometry, a standard T-Beam section was designed.

Assuming two layers of FRP, and the standard design assumptions $2 \times(16$ in $+2 \times 4$ in), a total of 48-in or $4 \mathrm{ft}$ of FRP per unit length of beam ( $\mathrm{ft}$ ) is required. For this example, 60 feet of beam is to be repaired using FRP technology. Multiplying 60 feet of beam by $4 \mathrm{ft}$ per unit length yields a required cross-sectional area of FRP to be $240 \mathrm{ft}^{2}$.

\section{Cost Assumptions for FRP repair:}

Using information provided by Mr. Steve Tysl, a consultant from Proto Composites, the cost estimate for a single repair of this example using the FRP technology is about $\$ 3400$ "first cost." Details of this estimate are given next. 
Using the design assumptions (5.1), 240 square feet of FRP will be required for repairs. FRP is about \$6.50-8.00 per square foot. For this estimate the cost of FRP is assumed to be $\$ 7$ per square foot. Multiplying the amount of material by the unit cost yields a total of $\$ 1680$. To account for the cost of patching mortar and labor (for most projects this includes mobilization, small tools, and incidentals), an increase of 2 times will be assumed. Multiplying 1680 by two, we obtain $\$ 3360$ or about $\$ 3400$ for the repair. This cost estimate does not include cost of lane closure, but does include labor and other costs associated with a contracted project.

A parallel study from the University of Missouri-Rolla (URM) is in the process of developing a similar cost analysis. Due to the confidentiality of pricing details shared by manufacturers, no direct information can officially be provided. However, information from the ongoing study at UMR supports the overall cost estimate given in this chapter.

It should be noted that none of the costs described can be generalized or estimated with a great level of precision. Because the application of the FRP technologies to bridges is in its introductory phase of the product life cycle, practices and related costs vary significantly.

\section{Design Assumptions for Conventional repair:}

With the assumed dimension from (5.1), a total cross-sectional area of $160 \mathrm{in}^{2}$ or $1.11 \mathrm{ft}^{2}$ per unit length of beam ( $\mathrm{ft}$ ) is required. A length of $60 \mathrm{ft}$ of T-beam is to be repaired for this example. Multiplying $60 \mathrm{ft}$ by $1.11 \mathrm{ft}^{2}$ yields a total volume of concrete of about 70 $\mathrm{ft}^{3}$ for the repair.

\section{Cost Assumptions for Conventional Repair:}

Using information provide by PennDOT-D3, the cost estimate for a single repair of the example bridge is about $\$ 3400$ “first cost." Details of this estimate are as follows. 
Using the designs assumptions, about $70 \mathrm{ft}^{3}$ of concrete will be required for repairs. A State Engineer from PennDOT-D3 has estimated the conventional repairs to cost \$22-30 per $\mathrm{ft}^{3}$ of concrete in place for materials and construction, and an additional $\$ 25 \mathrm{per}^{3} \mathrm{ft}^{3}$ for labor. Assuming a price of $\$ 50$ per $\mathrm{ft}^{3}$ of concrete and multiplying the amount of material by the material cost yields an estimate of about $\$ 3400$. This does not include cost of detours or traffic control.

\subsubsection{Present Worth of Scenario 1 for Repair-Example 2}

In order to compare initial and life-cycle costs for the conventional and FRP techniques, a present worth analysis will be conducted for Scenario 1, which includes a re-repair at $\mathrm{n}=$ 15 years. An interest rate of 5\% is used, with a future cost of $\$ 3400$ for the re-repairs. The present worth formula from (Au T. and Au T.P., 1993) is as follows:

$$
\mathrm{P}=\mathrm{F}(1+\mathrm{i})^{-\mathrm{n}}
$$

Where:

$\mathrm{P}=$ Present Worth (dollars)

$\mathrm{i}=$ interest rate (decimal)

$\mathrm{n}=$ number of periods (years)

Using the above equation (1), the present worth of a future repair (\$3400) is \$1635 or about \$1600. Adding this cost to the initial cost, the present worth cost of Scenario 1 is $\$ 5000$ (\$1600 + \$3400) for the conventional method. A present worth analysis does not apply to Scenario 2 because it does not include a future re-repair.

\subsubsection{Cost Comparison for Scenarios 1 and 2 for Repair-Example 2}

From present worth calculations, design assumptions, and cost assumptions, a comparison of costs for Scenarios 1 and 2 is as follows: For both Scenarios, the cost of the FRP repair is $\$ 3400$ for an assumed 30 year design life. For Scenario 1, the present worth cost of the conventional repair is $\$ 5000$. For Scenario 2, the cost of the repair using the conventional technique is $\$ 3400$. Figure 5.7 shows a cost comparison between methods for both Scenarios 1 and 2. The estimates for the FRP technology includes 
contracting costs (profit, overhead, etc), however once the FRP technology can be implemented by district forces, costs may decrease significantly.

\subsection{Repair-Example 3: Cost Comparison for a Level 3 (Minor) repair.}

From the inventory, Bridge \# 41-0118-0020-1109, which shows extensive but localized damage (one beam only), was selected as a Repair-Level 3 project (Fig. 5.8). This bridge has the following characteristics: Total Span $=31 \mathrm{ft}$; Year Built $=1930$; Number of beams = 7; ADT/ADTT = 5600/410; Overall Classification = 79.8 - Class 1; Visual Rating $=3$ (high desire for repair).

This bridge is relatively small and has experienced localized damage typical of the PennDOT-D3 inventory (extensive localized damage on exterior beam(s) only.) This bridge is a good candidate for repair using a trained, in-house state crew. Once trained (such as by participating in the implementation of repair of Examples 1 or 2), state "inhouse” forces can repair this and many other typical bridges in the inventory using FRP technology. A generalized "first-cost” estimate is provided in this chapter using design and cost assumptions from (5.1). Next, a design and cost estimate (5.4.1) is presented for this example.

\subsubsection{Design and Cost Estimate for Repair-Example 3}

For Bridge \# 41-0118-0020-1109, 30 feet of repair will be assumed. The cost of FRP repair is about $\$ 1700$, and the cost of conventional repair is about $\$ 1800$. Details of this calculation are presented next.

\section{Design Assumptions for Surface-Bonded FRP Technology:}

Assuming two layers of FRP, and the standard design assumptions (5.1), 2 x (16 in $+2 x 4$ in), a total of 48-in or $4 \mathrm{ft}$ of FRP per unit length of beam ( $\mathrm{ft}$ ) is required. For this example, 30 feet of beam is to be repaired using FRP technology. Multiplying 30 feet of beam by $4 \mathrm{ft}$ per unit length yields a required cross-sectional area of FRP to be $120 \mathrm{ft}^{2}$. 


\section{Cost Assumptions for FRP repair:}

Using information provided by Mr. Steve Tysl, a consultant from Proto Composites, the cost estimate for a single repair of the example bridge using the FRP technology is about $\$ 1700$ “first cost.” Details of this estimate are given next.

Using the design assumptions (5.1), 120 square feet of FRP will be required for repairs. FRP is about $\$ 6.50-8.00$ per square foot. For this estimate the cost of FRP is assumed to be $\$ 7$ per square foot. Multiplying the amount of material by the unit cost yields a total of $\$ 840$. To account for the cost of patching mortar and labor (for most projects this includes mobilization, small tools, and incidentals), an increase of 2 times will be assumed. Multiplying $\$ 840$ by two yields $\$ 1680$ or about $\$ 1700$ for the repair. This cost estimate does not include cost of lane closure, but does include labor and other costs associated with a contracted project.

A parallel study from the University of Missouri-Rolla (URM) is in the process of developing a similar cost analysis. Due to the confidentiality of pricing details shared by manufacturers, no direct information can officially be provided. However, information from the ongoing study at UMR supports the overall cost estimate given in this chapter.

It should be noted that none of the costs described can be generalized or estimated with a great level of precision. Because the application of the FRP technologies to bridges is in its introductory phase of the product life cycle, practices and related costs vary significantly.

\section{Design Assumptions for Conventional Technique:}

Using assumed dimensions (5.1), a total cross-sectional area of $160 \mathrm{in}^{2}$ or $1.11 \mathrm{ft}^{2}$ per unit length of beam ( $\mathrm{ft}$ ) is required. For the sample bridge, $30 \mathrm{ft}$ of T-beam is to be repaired. Multiplying $30 \mathrm{ft}$ by $1.11 \mathrm{ft}^{2}$ yields a total volume of concrete of about $35 \mathrm{ft}^{3}$ for the repaired. 


\section{Cost Assumptions for Conventional Repair:}

Using information provide by PennDOT-D3, the cost estimate for a single repair of this example is about $\$ 1800$ “first cost.” Details of this estimate are as follows.

Using the design assumptions, about $35 \mathrm{ft}^{3}$ of concrete will be required for repairs. A State Engineer from PennDOT-D3 has estimated the conventional repairs to cost \$22-30

per $\mathrm{ft}^{3}$ of concrete in place for materials and construction, and an additional \$25 per $\mathrm{ft}^{3}$ for labor. Assuming a cost of $\$ 50$ per $\mathrm{ft}^{3}$ of concrete and multiplying the amount of material by the material cost yields a cost of about $\$ 1800$. This does not include cost of detours or traffic control.

\subsection{Learning Curve Approach}

There are arguments that initial costs of new technologies decrease with time, as their use become more extensive and accepted. According to Xanthakos (1995), "Bridges that use FRP are expected to have higher initial costs than traditional reinforced concrete bridges, due to high cost of fiber and resins. However, this initial cost will decrease as more bridges are repaired according to the Learning Curve theory. The Learning Curve theory predicts that, as experience builds up, the cost will decrease in an exponential manner. Typical costs start high, but drop steeply when methods and materials become more cost effective as the product matures (Figure 5.9). Over time, the large inefficiencies are removed from the process and the costs stabilize.”

\subsection{Comparison of Construction Methods}

For both repairing methods, the initial surface preparation is similar. However, due to the importance of bonding with FRP, quality control for surface preparation is stricter. The two repair methods are quite different after the initial surface preparation. Figures 5.10 and 5.11 show sample Gantt charts for repair of a typical 3 beam system (RepairExample 2, Section 5.3) using both conventional and the FRP technologies respectively.

Microsoft Project, which is a project-management software, allows the user to input tasks, task durations, and task dependencies. This software was used to produce general 
Gantt charts, comparing construction processes for both the conventional method and the FRP technology.

These charts show an overview of the construction tasks, task dependencies, as well as the critical path (shown in red). These charts are provided to illustrate the general construction process of the conventional and FRP methods. Also, Figures 5.10, and 5.11 illustrate one key advantage of the FRP technology: traffic maintenance (bridge closure) is dependant on cure time for the conventional repair and is a critical path. However, traffic maintenance (lane closure) is not a critical path for the surface-bonded FRP technology. During the application of the FRP technology one lane of the bridge can remain open resulting in less traffic delay. Also, using FRP, this bridge is opened 8 days sooner. The economic effect of this is shown in the next section.

\subsection{Detour-Driving Mileage Costs for Repair-Example 2}

A key advantage of the FRP technology is that, for a typical Repair Level-2, this method allows opening the bridge about 8 days sooner than conventional repair (see Figures 5.10 and 5.11). Also, during construction using the FRP technology, one lane may remain open to traffic. Because of high traffic volumes on this bridge, a detour-driving cost analysis was performed. Using information provided by PennDOT-D3, the software package Microsoft Streets and Trips, and maps provided by PennDOT-D3, a detour scenario was created. Figures 5.12 and 5.13 show the original route and the shortest detour.

Microsoft Streets and Trips is a general driving and distance mapping program, which was used to estimate driving distances for the detour scenario presented in this chapter.

The un-detoured length of highway is 600 yards or 0.35 miles. The proposed detour is 1.5 miles, with a difference of 1.15 miles per vehicle. From information provided by PennDOT-D3, the ADT plus ADTT for this bridge is 10,950 (10,300 ADT, and 650 ADTT), resulting in a total of about 12,600 vehicle miles per day. Using the typical IRS rate of $\$ 0.485$ per mile, this cost is about $\$ 6000$ per day. 


\subsection{Analysis and Conclusions for Both Cost and Construction}

This chapter has addressed the posed question: "Is the FRP technology economically and feasibly competitive with the conventional repair method?” by presenting a comparative overview of repair approaches. Three Repair-Examples from the PennDOT-D3 inventory were chosen to illustrate the differences in processes and costs.

It was shown that, for Repair-Level 1, the cost of FRP technology is quite inexpensive in comparison to the cost of bridge replacement. Repair-Level 1, as presented in RepairExample 1 (Section 5.2), would provide familiarity and training experience for state employees to implement FRP repair using "in-house" forces. Based on experiences from this repair, state employees could begin using the FRP technology for a wide scale repair of deteriorating T-Beam structures, such as the suggested Repair-Example 3, a RepairLevel 3 effort (Section 5.4).

For Repair-Level 2 (Example 2, Section 5.3), two repair scenarios comparing the conventional method and FRP technique were provided to illustrate the "present-worth" and "life-cycle" methodology. For both scenarios, it was shown that the cost of FRP technology is competitive with the cost of the traditional method, and when "life-cycle" repairs were included, the FRP technology is less expensive. Also, it is likely that once the FRP technology becomes more widely accepted and used, both material cost and experience in installation will improve as suggested in Section 5.5 (Learning Curve theory).

Setting aside cost differentials, the FRP technology has many other advantages over the conventional repair method. The most pronounced advantage is speed of application. The FRP technology may allow for the bridge to remain open during repairs. Also, the installation and curing time for the FRP technology is quite short in comparison to the more complex forming and longer curing of concrete encasing (as discussed in Section 5.7). Thus the rapid application of FRP repair can lead to reductions in detour costs and inconveniences. Also, FRP material installation is quite simple; the material is light and 
can be installed using hand tools. There is a high likelihood that, once trained, the technology can be applied by state employees. Though gains in structural strength may not be a concern for rehabilitation, bridges repaired using the FRP technology will experience increases in strength and therefore have higher capacities. Since the costs of the FRP technology included contracting fees (profit, overhead, etc.), the application of the FRP technology may become significantly less expensive once this repair is performed exclusively by state “in-house” forces.

It has been shown that the FRP technology is being applied and working satisfactorily in several state DOTs, such as Missouri. Repairs using this technique are easier and faster to implement. Also, these repairs tend to be more durable than those using conventional techniques, allowing for less frequent re-repairs. 


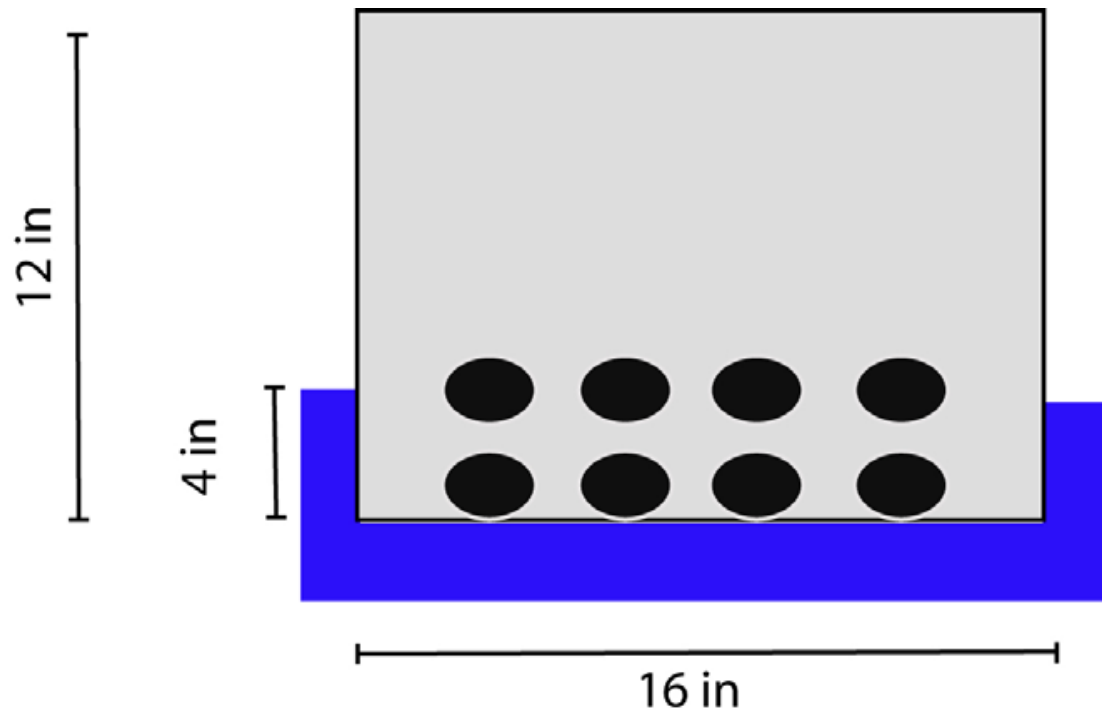

Figure 5.1. Standard T-Beam Section for Design Assumptions for the FRP Repair.

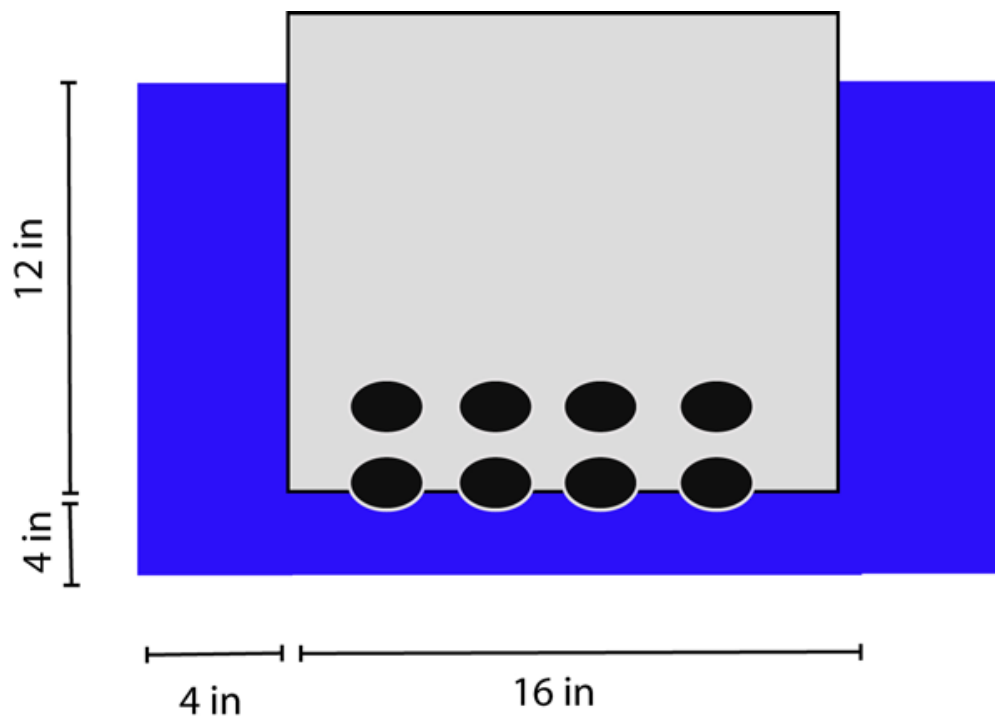

Figure 5.2. Standard T-Beam Section for Design Assumptions for the Conventional Repair. 


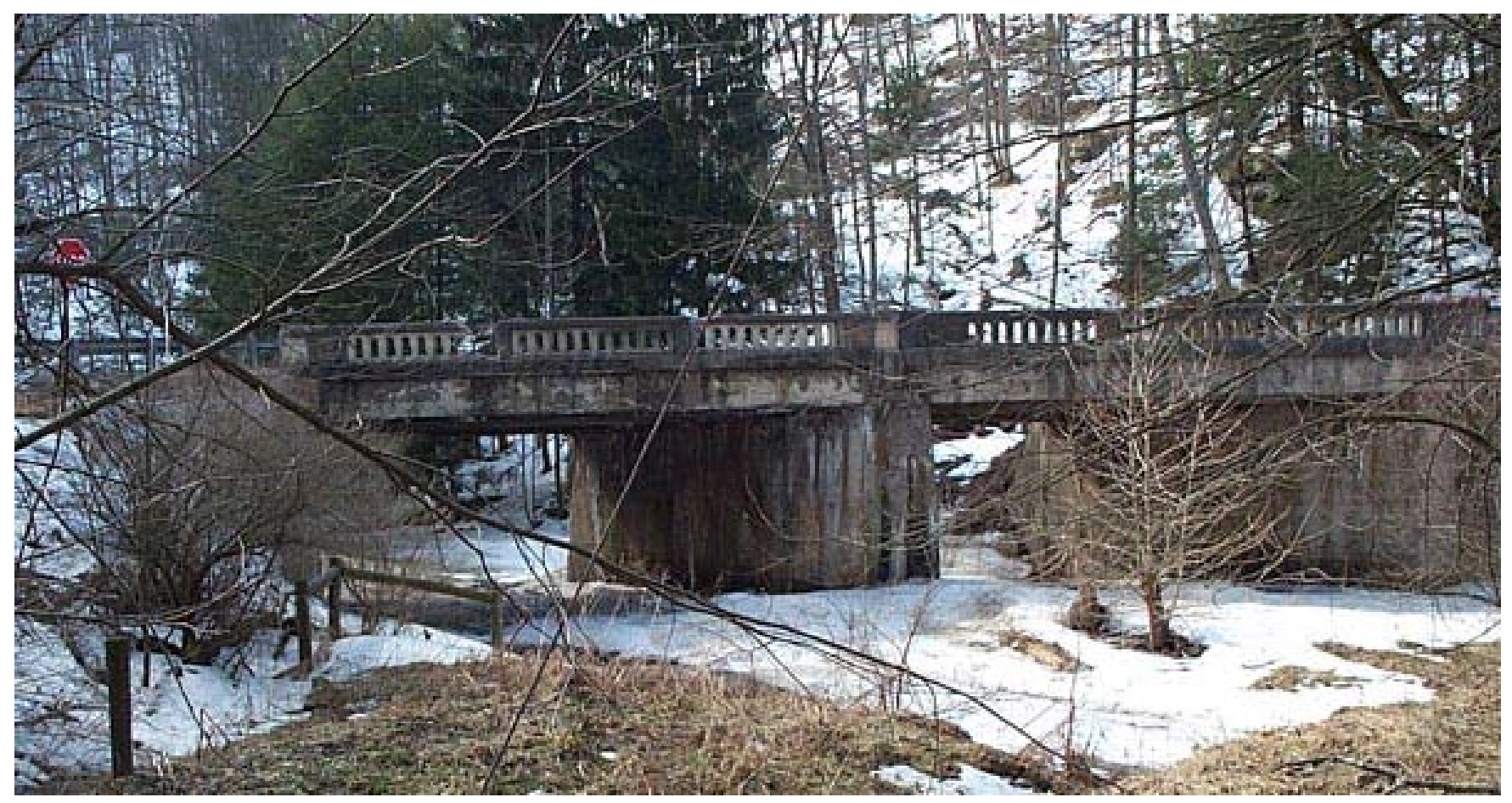

Figure 5.3. Bridge \#41-0118-0230-0644, PennDOT-D3 Inventory.

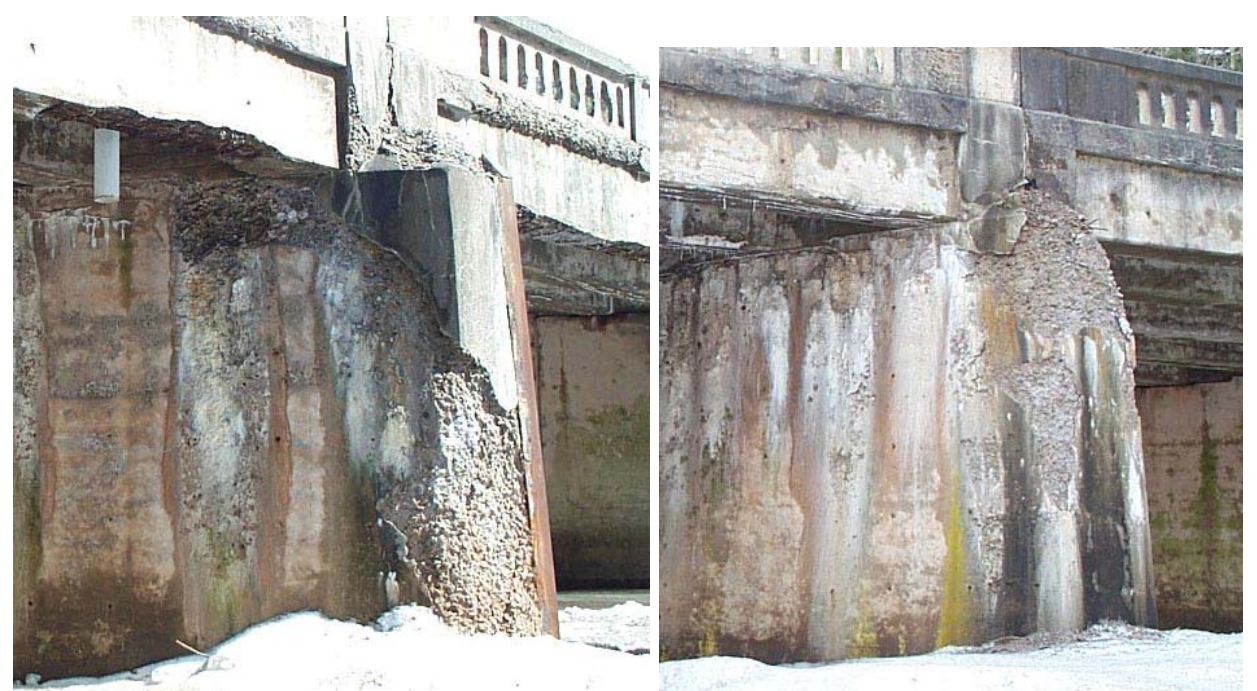

Figure 5.4. Photographical Indication of Damage to the Pier of Repair-Example 1. 

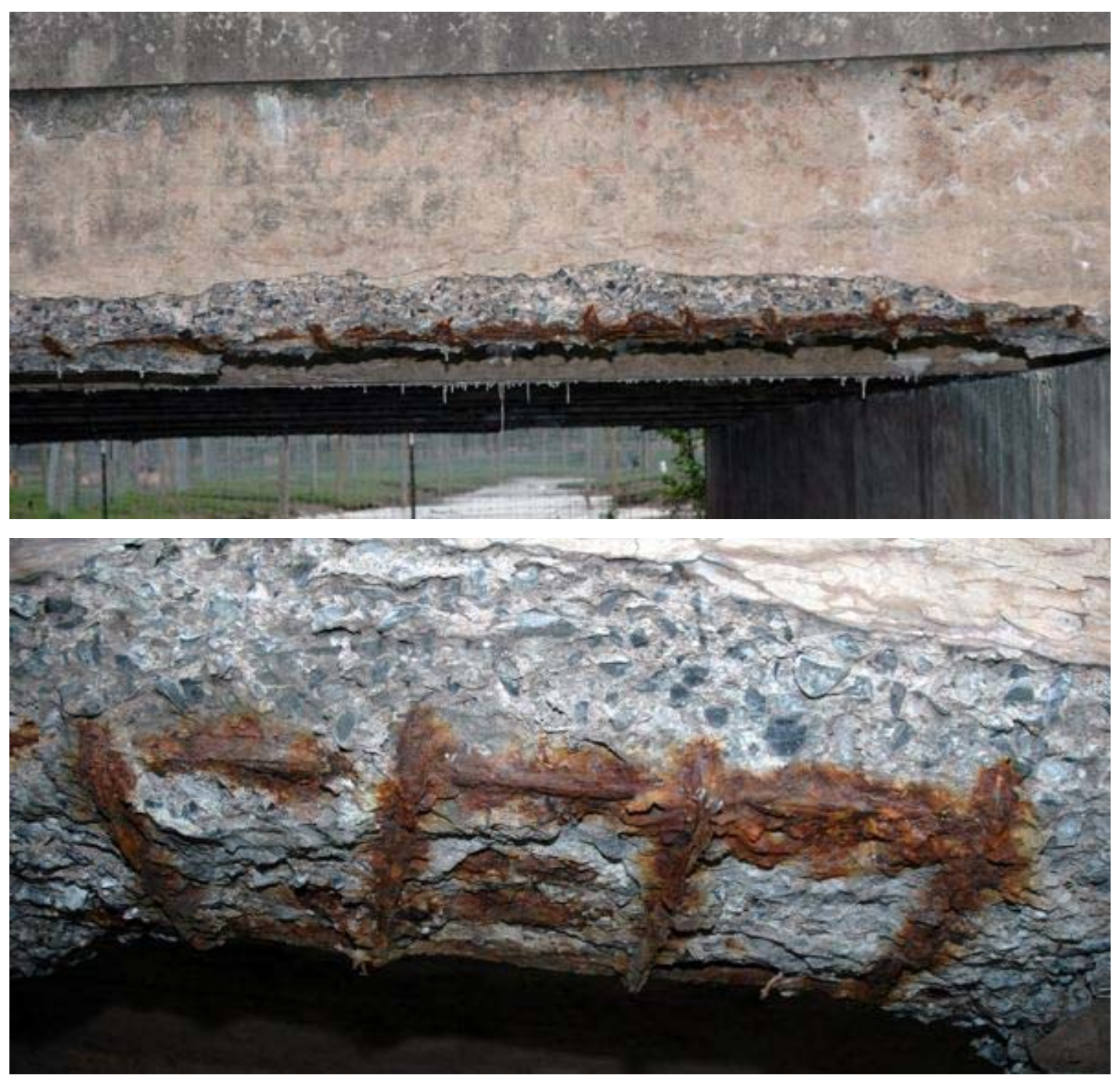

Figure 5.5. Bridge \#59-0045-0310-2011.

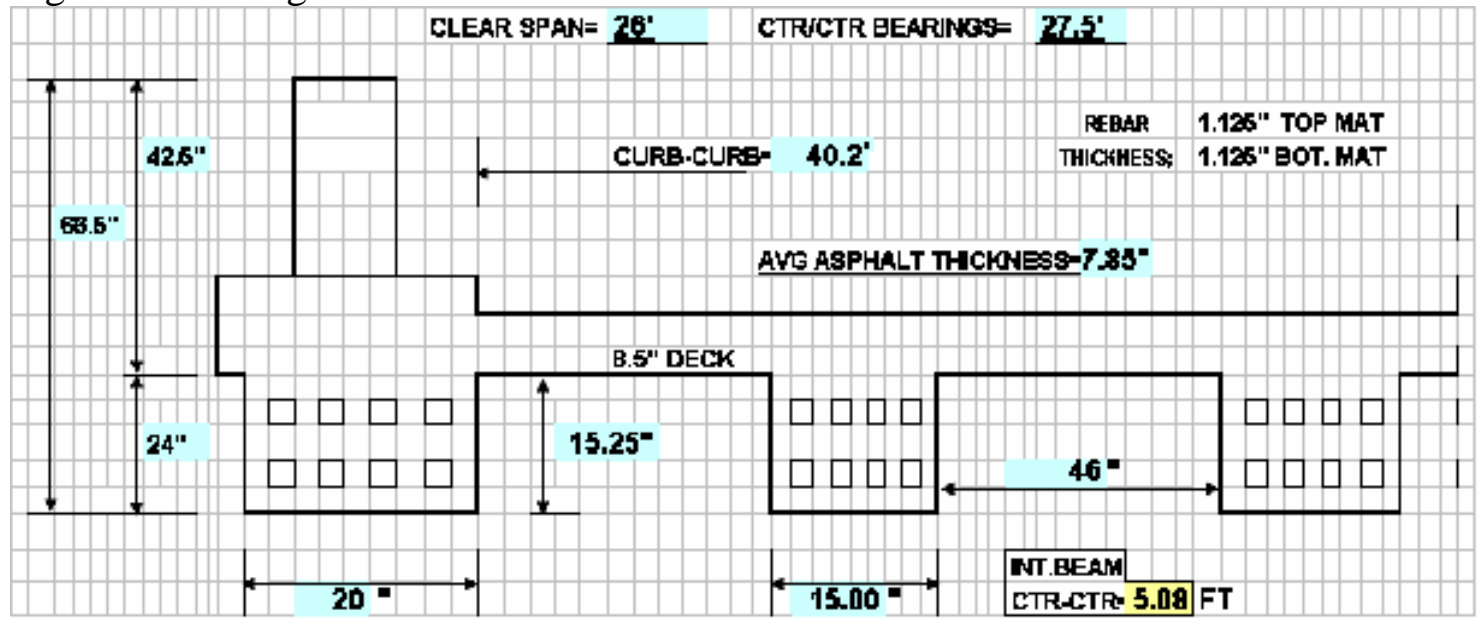

Figure 5.6. A Cross-Sectional Diagram of the Bridge \#59-0045-0310-2011, Provided by PennDOT-D3. 


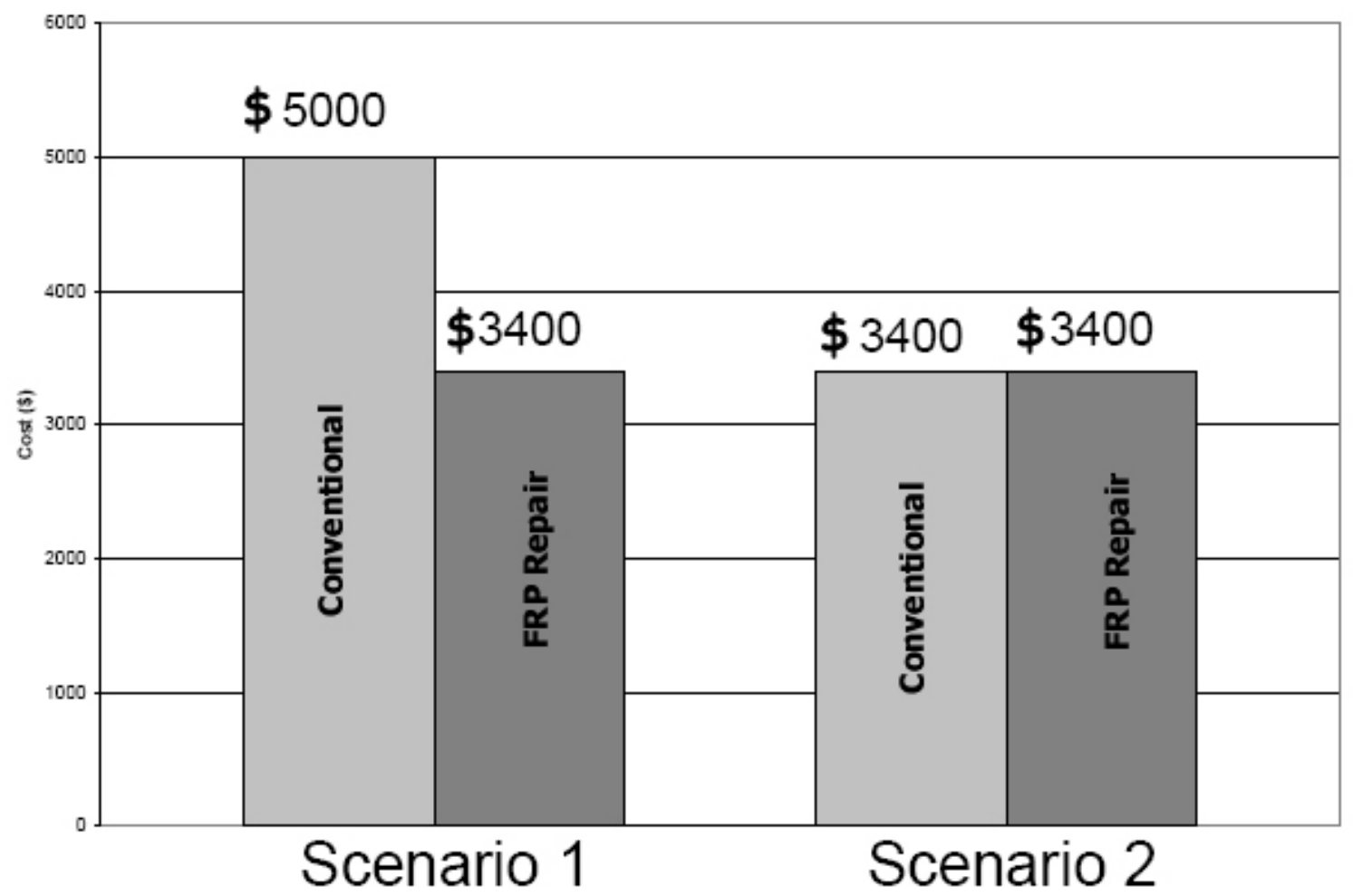

Figure 5.7. Cost Comparisons Between Conventional and FRP Methods for Example 2, Scenarios 1 and 2. 

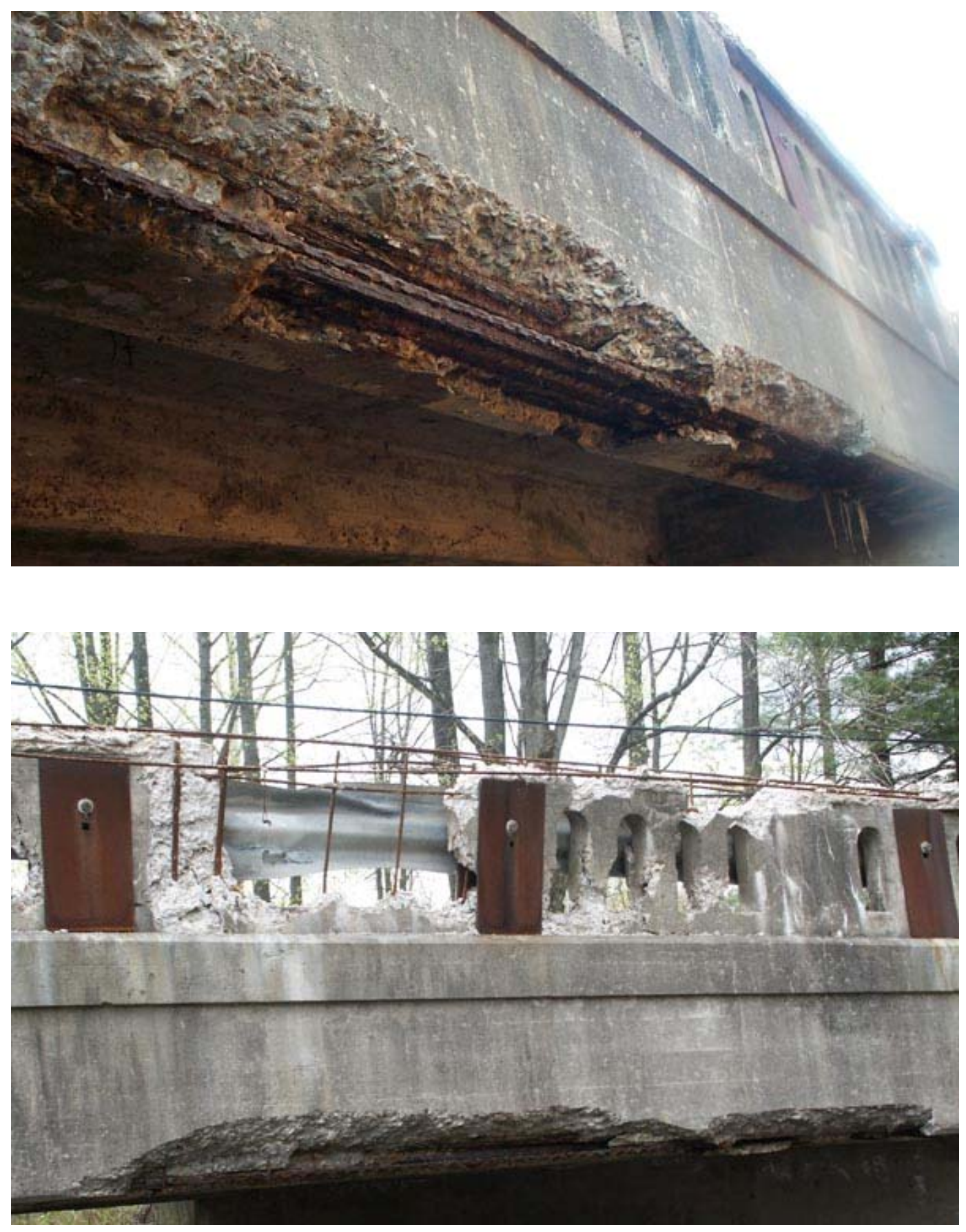

Figure 5.8. Bridge \#41-0118-0020-1109. 


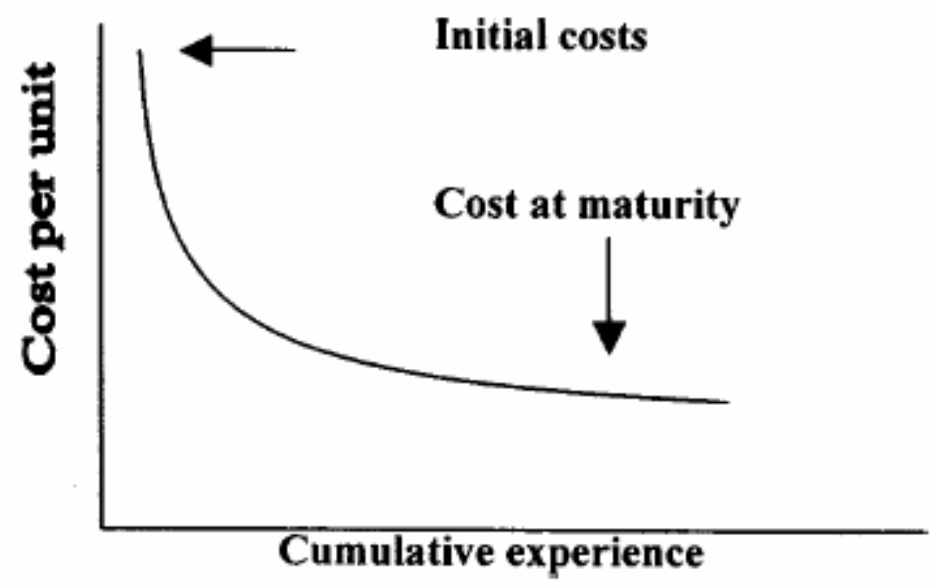

Figure 5.9. Typical Learning Curve (Xanthakos, 1995)

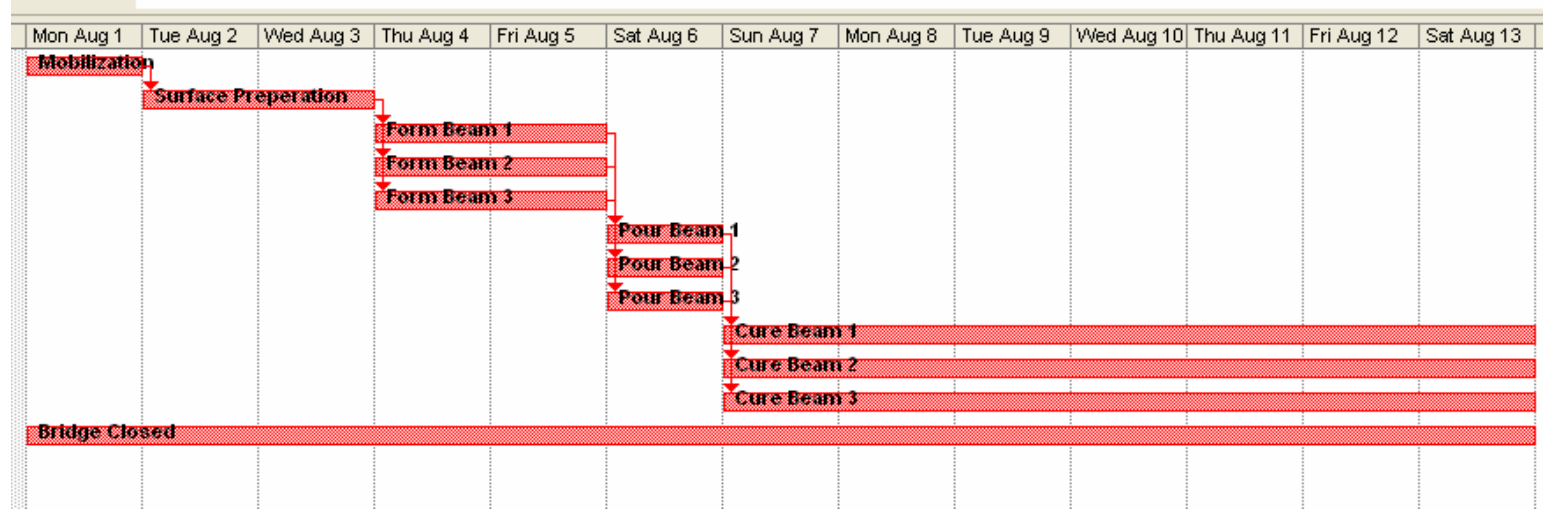

Figure 5.10. Gantt Chart for Conventional Repair (obtained with Microsoft Project).

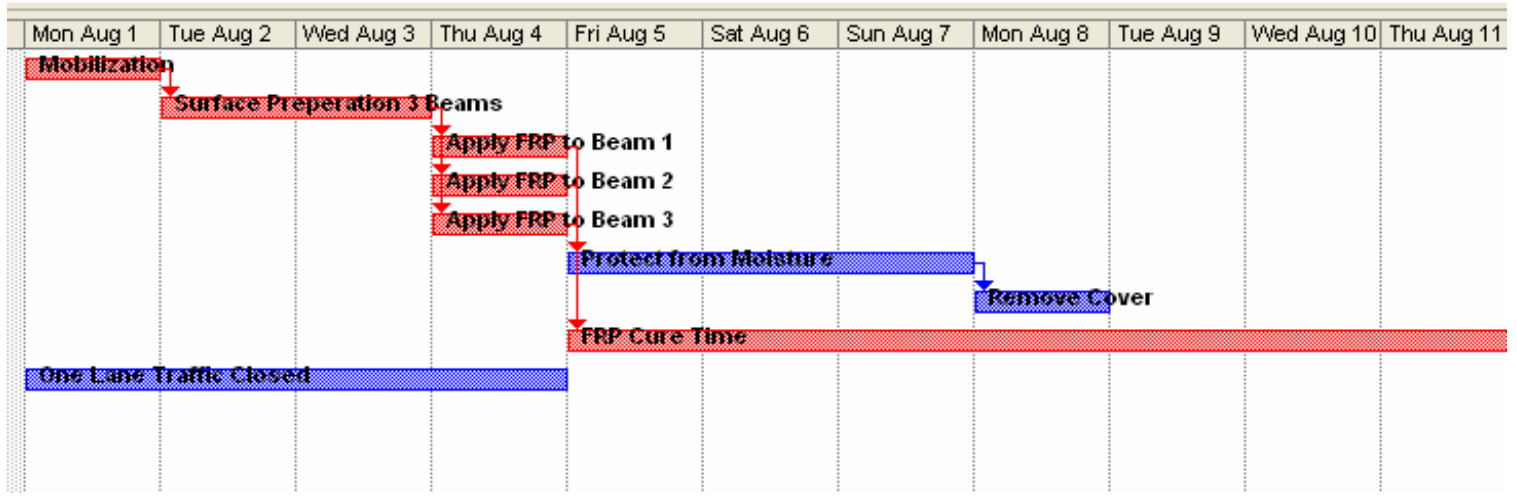

Figure 5.11. Gantt Chart for Surface-Bonded FRP Technology (obtained with Microsoft Project). 


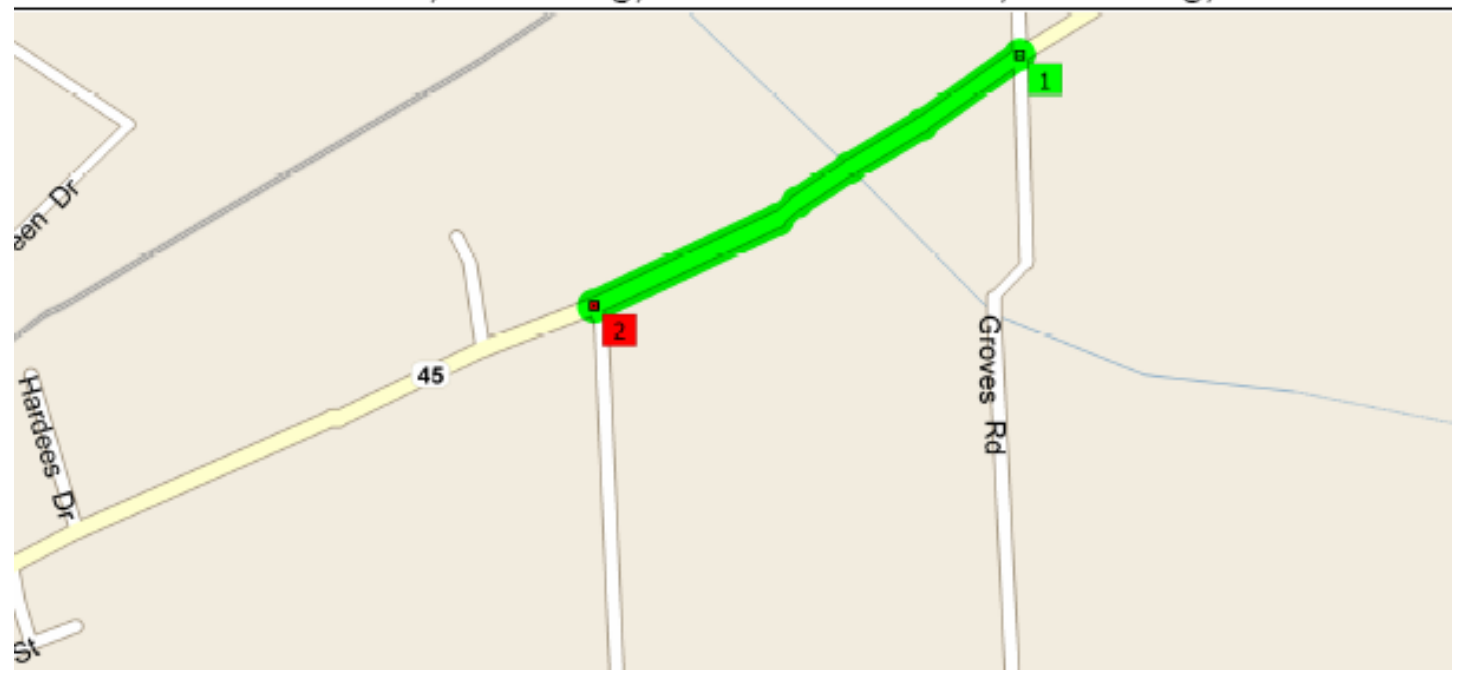

Figure 5.12. Open Traffic Plans for Example Bridge 2 (distance $=600$ yards).

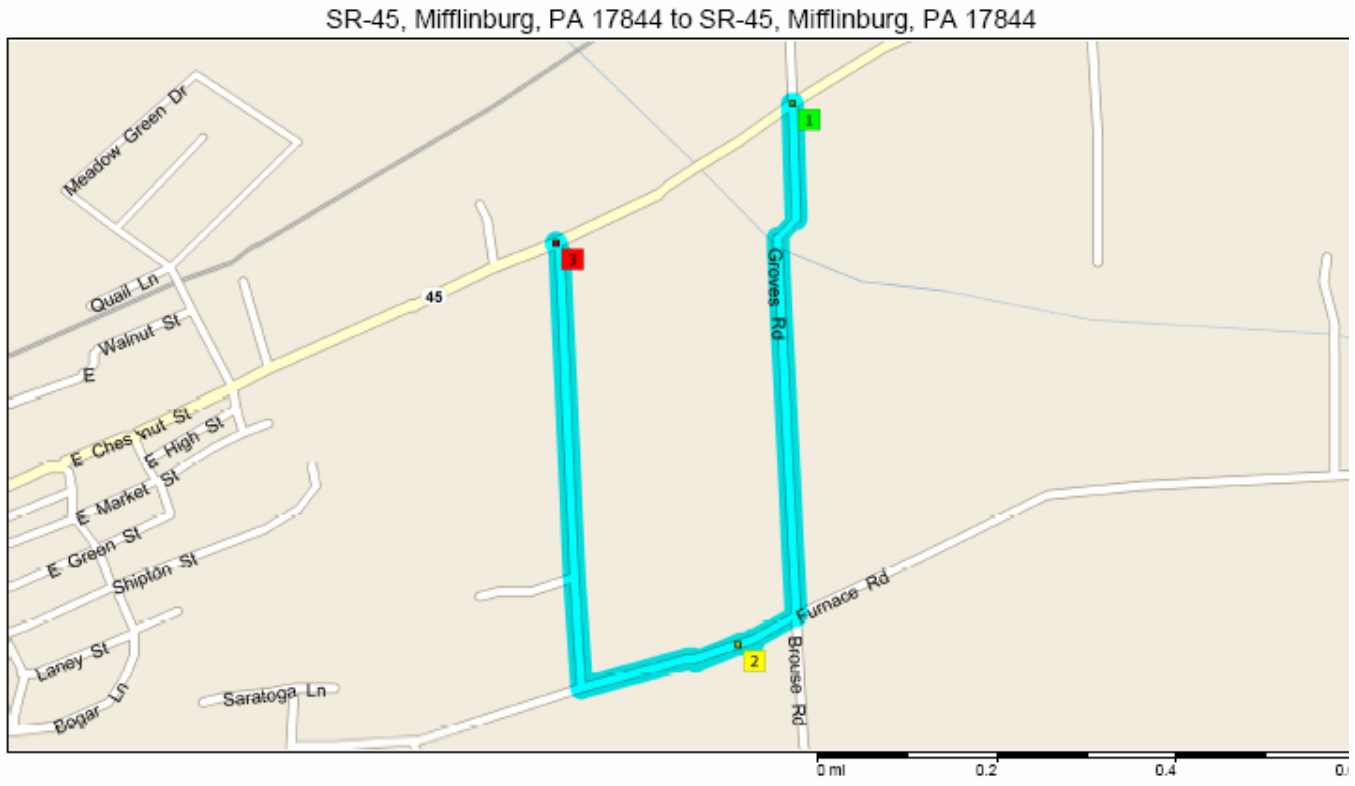

Figure 5.13. Proposed Detour Plan for Example Bridge 2 (distance $=1.5$ miles). 


\section{Chapter 6}

\section{Recommendations for Implementation}

This Chapter addresses the question: "What are the implementation steps for FRP repair of the selected bridge(s)?” by discussing alternative approaches for adoption (Section 6.1); presenting Phase 2 of the PennDOT-D3 Project as an example (Section 6.2); and showing three other repair examples (Section 6.3). Conclusions are presented in Section (6.4).

\subsection{Various Approaches to Implementation}

Once FRP repair has been chosen, several implementation methods can be practiced. Because this technology is still in its infancy, outside consulting is strongly recommended. A good approach is to engage a local University. This will promote education and further development of the technology. A second approach is to contact a materials supplier. FRP suppliers generally are specialized in this technology and can provide assistance from the classification stage to design, all the way through construction. An example of this is Fyfe Co: “The Fyfe Company staff of in-house engineers, material specialists and installation technicians has the combined expertise that comes with over a decade of experience and thousands of completed projects in every region of the world. Our engineers are ready to assist you, at no cost, with advanced composite system information” (Fyfe Co. LLC.) The best approach may to be to engage a collaboration between both a University and a supplier. This will not only promote education, but allow for an intimate involvement of a contractor from the start of the project to completion.

\subsection{PennDOT-D3 Implementation}

This Section describes the proposed steps of implementation to be performed by PennDOT D-3 with West Virginia University as a consultant. Bridges in PennDOT D3's inventory have been classification and sample bridges have been presented. Phase 2 
will begin tentatively in Summer/Fall 2006. The implementation may include, but not be limited to:

- Sampling and testing to determine quality of substrate

- Developing a plan for repair (Example: see section 6.3.1)

- Designing of the FRP

- Checking of failure modes (Example: see section 6.3.1)

- Application of the FRP (Example: see section 4)

- Load testing before and after application (Example: see section 6.3.2)

- Long-term monitoring (Example: see section 6.3.2)

- Cost-benefit analysis after implementation (Example: see section 6.3.3)

- Evaluation of technology as a replacement for conventional methods

\subsection{Other Example of FRP Repair}

This Section provides examples of the implementation procedures presented in 6.2.

\subsubsection{Castlewood Canyon Arch Bridge.}

Fafach, et al. (2004) investigates the repair of the Castlewood Canyon Arch Bridge Retrofit (Figure 6.1). This was performed in summer 2003 by the Colorado Department of Transportation (CDOT) in conjunction with Peter Milligan of Fyfe Co., and the University of Colorado-Boulder. This project represents a wide-scale FRP rehabilitation project. Typical damage to this bridge is shown in Figure 6.2. "The arches were repaired and strengthened with Fiberwrap, an FRP product manufactured by Fyfe Co. The plan for repair was as follows:

1) Loose materials and debris were removed from the surfaces and from around the reinforcing.

2) Exposed reinforcing bars were sandblasted clean from rust.

3) Penetrating corrosion inhibitor was applied to the surface of concrete arches and struts to address hidden damage. 
4) Leadline CFRP rods manufactured by Mitsubishi were anchored into the footings with epoxy around the bases of the arches to strengthen the archfoundation connection.

5) The surfaces of the arches were finished to the original surfaces using hand and machine applied mortar. Cracks were sealed using epoxy injection.

6) New pedestals were constructed for new spandrel columns.

7) Fiberwrap, an externally bonded CFRP, was applied to arch ribs to confine concrete and to reinforce and strengthen the arch.

8) The arches were then painted to appear like concrete. (Fafach, et al. 2004)

Fafach, et al. (2004) continues with the evaluation and strength testing of scale models. It was found (using scale test specimens) that during failure, the FRP sheets first de-bonded from the concrete substrate. Next, due to stress concentrations, the FRP sheets rupture. This is the intended failure mode for reinforced concrete members (tension zone yielding instead of concrete crushing). Further details of this load test can be found in Fafach et al. (2004).

A similar analysis and sample testing is suggested for any failure critical member retrofitted with FRP.

\subsubsection{Application and In-Service Evaluation of FRP Repair}

The following two sources: (Hag-Elsafi, Alampalli, and Kunin, 2001) and (Hag-Elsafi, Alampalli, and Kunin, 2003) investigate an FRP repair in New York. These sources discuss the repair and load testing of a Reinforced Concrete T-Beam bridge in Rensselaer County, New York. The geometry of these bridges is similar to that of the PennDOT D-3 inventory: short-span, older bridges which have an average length to width ratio approximately equal to 1 . Damage to this bridge is similar to a local-damage Level-2 PennDOT bridge. The New York State Department of Transportation (NYSDOT) elected to rehabilitate the structure using the FRP method. The entire project was implemented between August-November 1999. Figure 6.3 shows photos of the FRP application. The work cited in these sources was to load test the bridge before and after application of FRP and to monitor the quality of the FRP-substrate bond. 
In (Hag-Elsafi, Alampalli, Kunin, and 2001), using various loadings, and strain gauges, it was determined that "after installation of laminates, main rebar stresses were moderately reduced, concrete stresses (flexural and shear) moderately increased, and transverse liveload distribution to the beams slightly improved under service loads. Various similar studies have concluded significant increase in ultimate capacities of concrete members strengthened using FRP laminates.”

In (Hag-Elsafi, Alampalli, and Kunin, 2003), the same bridge repair described in (HagElsafi, Alampalli, and Kunin, 2001) was evaluated two years later. This evaluation included NDE/NDT techniques and load tests to monitor and assess the effectiveness of the FRP-substrate bond. "The 2001 load test indicated that recorded strains were generally lower than those measured during the 1999 test. The results also indicated that the quality of the bond between the FRP laminates and concrete and effectiveness of the retrofit system have not changed after two years in service. Thermographic imaging using an infrared camera provided images which supported this conclusion.”

\subsubsection{Strengthening of a Bridge Cap-Beam using FRP}

Hag-Elsafi, Lund, and Alampalli, (2002) investigated the strengthening of the cap-beam of Pier 3 of East Church Street Bridge in Elmira, New York using FRP (see Figure 6.4). This source analyzed this repair and discussed cost-benefit compared to conventional repair. Using FRP as shear reinforcement, it was found that the FRP sheets were effective in reducing live load stresses in the cap-beam. "Compared to conventional methods, the FRP retrofit system used in this project proved to be a cost-effective solution ( $\$ 18,000$ compared to about $\$ 150,000)$. The FRP system was relatively easy to install and caused minimal interruption to traffic. These are important features, which make FRP an attractive alternative. 


\subsection{Conclusions}

Several recommendations for implementation were presented in this chapter. However, a collaboration between a University and a materials supplier is suggested to both promote education and include industry and research views throughout the project. A proposed implementation procedure for the PennDOT D-3 project was presented, and examples of the suggested steps were illustrated using repairs from various sources. 


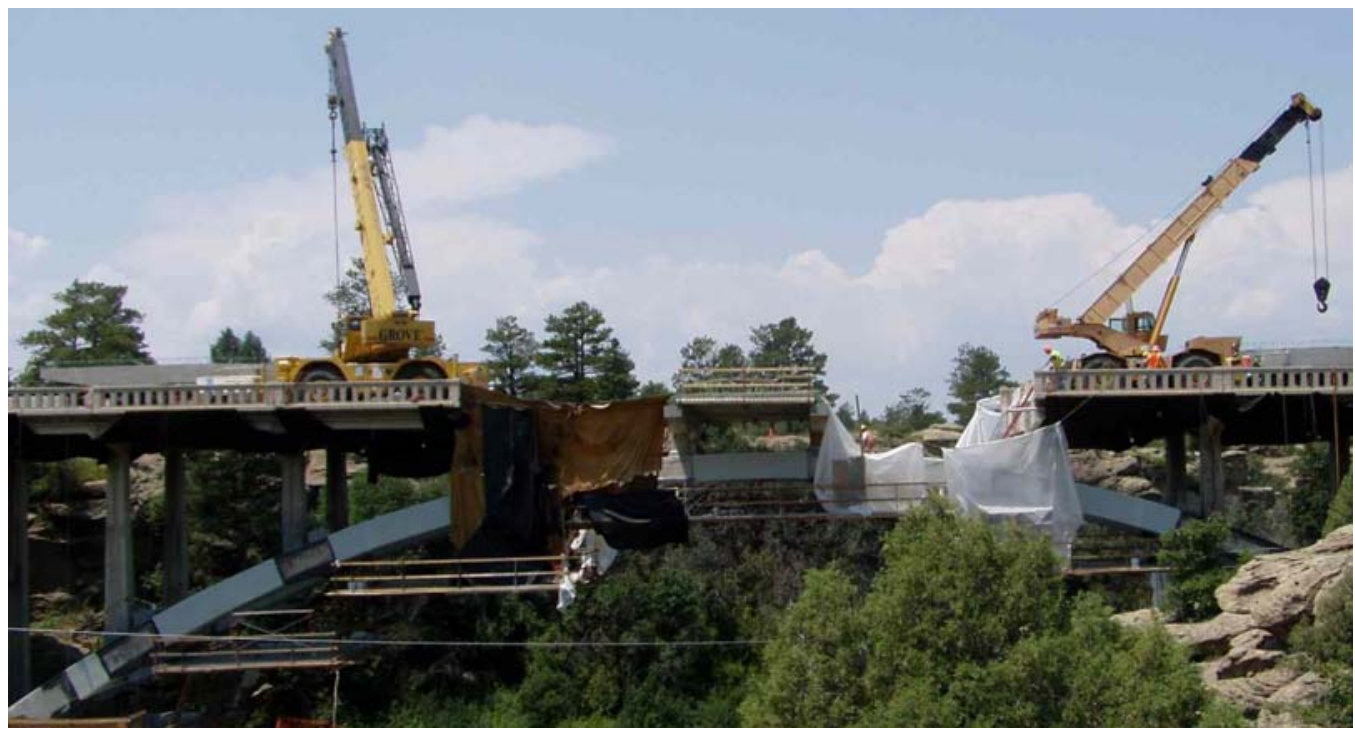

Figure 6.1. Castlewood Canyon Arch Bridge FRP Repair. (ASCE Website) 

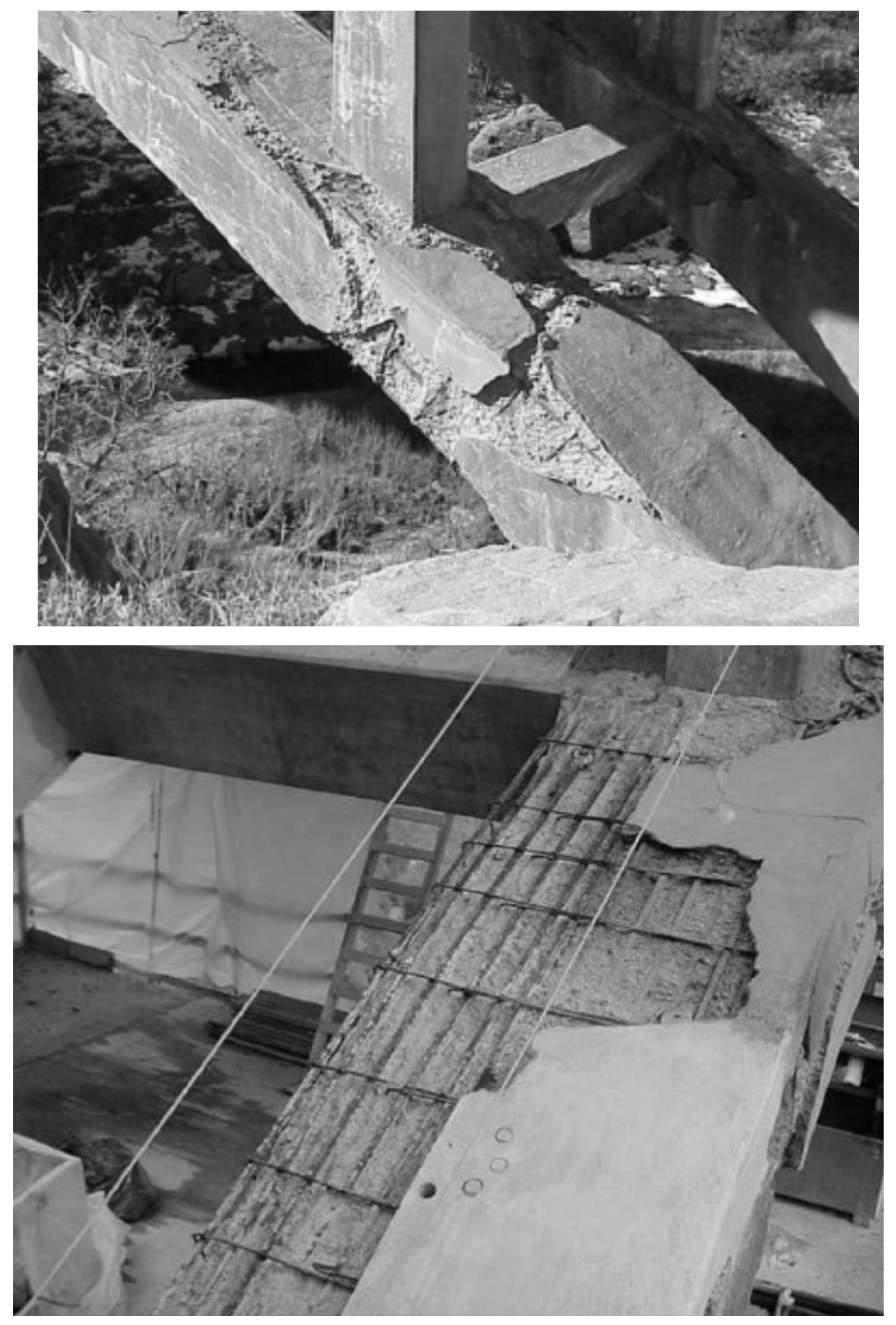

Figure 6.2. Typical Damage to the Castlewood Canyon Arch Bridge. (Fafach, et al., 2004) 

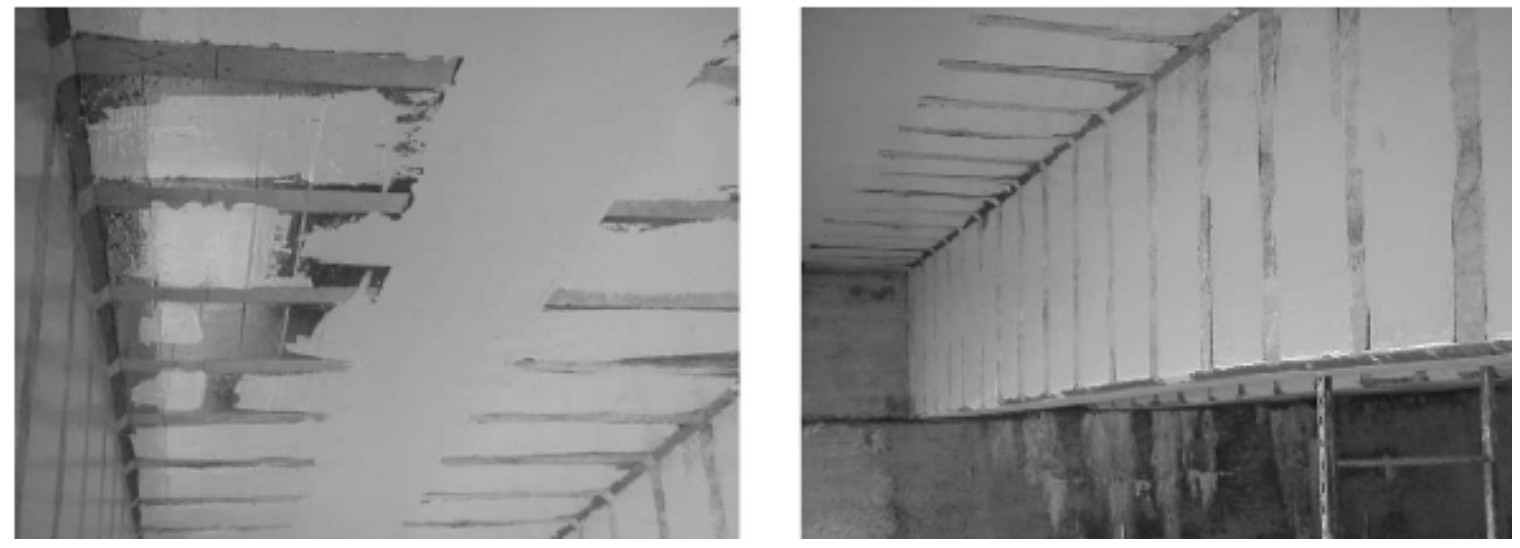

Figure 6.3. FRP repair described by (Hag-Elsafi, Alampalli, Kunin, 2001) and (HagElsafi, Alampallil, Kunin, 2003).

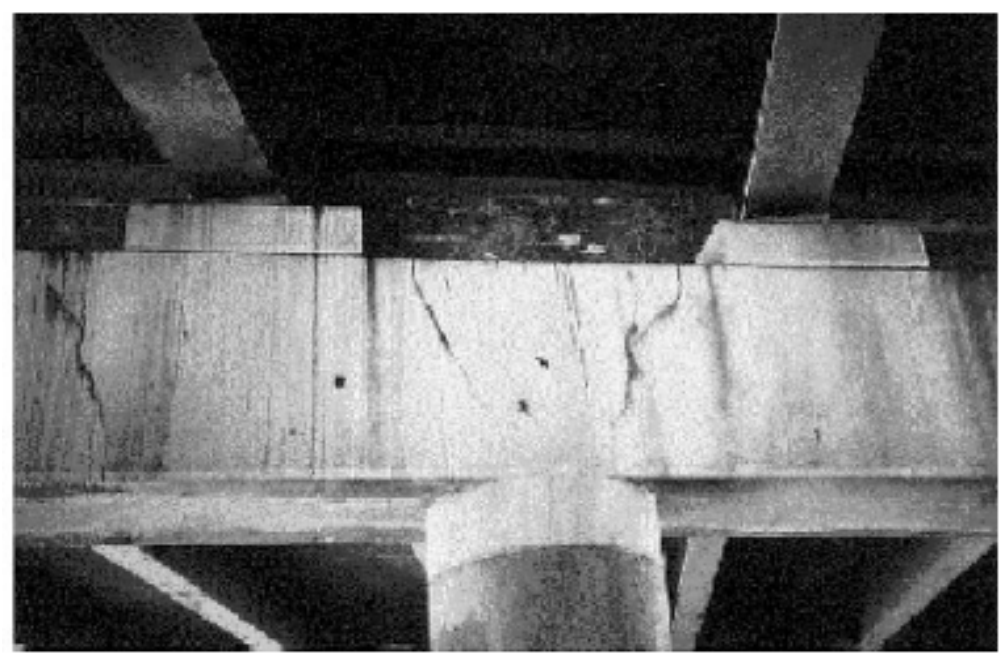

Figure 6.4. Damaged Beam-Cap repaired described by (Hag-Elsafi, Lund, Alampalli, 2002) 


\section{Chapter 7}

\section{Conclusions and Recommendations}

This thesis has presented a component of an overall project performed for PennDOT D-3 by a research team at West Virginia University. The interest of PennDOT D-3 was to investigate the practical and economic feasibility of FRP repair, in relation to conventional methods.

The scope of this thesis included: (1) An overview of the conventional repair method employed by PennDOT D-3 and FRP repair methods (Chapter 2); (2) Classification of PennDOT D-3 bridges based on both characteristics and levels of damage, as well as a prescription for general classifications for any inventory (Chapter 3); (3) Suggested steps for the selection of ideal candidate bridges (Chapter 4); (4) A cost-benefit and construction comparison between both the conventional and FRP repair methods (Chapter 5); and (5) Suggested steps for implementation (Chapter 6).

Detailed conclusions have been given in each Chapter. In this Chapter, brief answers to the questions posed in Chapter 1 are presented (7.1), and recommendations for future work are given (7.2).

\subsection{Concluding Remarks}

This Section answers the six questions posed in Chapter 1.

1. “Is FRP a valid repair method for bridges in the PennDOT D-3 inventory?” It is apparent from Chapter 2 that the FRP method is indeed applicable to the PennDOT D-3 inventory. An example specification from a materials provider and a sample repair from MODOT both illustrate repair with FRP for bridges which are similar to those in the PennDOT D-3 inventory. 
2. "Which bridges are suitable and favorable for repair using FRP?"

Chapter 3 proposes a set of classifications to determine which bridges in the PennDOT D-3 are suitable and favorable for FRP repair. It was found that about 50 percent of the 128 bridges in the PennDOT D-3 are applicable and favorable for FRP repair.

3. "Which bridges are ideal candidates for a trial repair program?"

Chapter 3 classifies bridges from the PennDOT D-3 inventory into three classes for favorability of repair: Class 1 (Prime), Class 2 (Moderate) and Class 3 (Low). In Chapter 4, using bridges from the Class 1 (Prime) category, 3 candidates are chosen from each Repair-Level (also defined in Chapter 3). A repair scheme is suggested, proposing, first, a Repair-Level 1 (major) project that will provide a training experience for the PennDOT D-3 inventory. Once trained, state employees can continue with more "hands-on" involvement in Repair-Level 2 (moderate) and 3 (minor) projects.

4. "Is the FRP technology economically feasible and competitive with the conventional repair method?”

Chapter 5 presented three examples to show that FRP is a cost-effective alternative to conventional repair methods and replacement. Also, FRP is still a new material. Once FRP has been adopted for wide-scale applications, costs may be reduced significantly.

5. "What are the implementation steps for FRP repair of the selected bridge(s)?" Though it is still a "new" and "innovative" material, FRP has been implemented in many projects. Chapter 7 discussed various steps of implementation for FRP repair and suggested an implementation plan for the PennDOT D-3 Project. Several examples have also been presented to demonstrate these steps. 


\subsection{Recommendations for Future Work}

Now that the PennDOT D-3 inventory has been classified and candidate bridges have been suggested. The next step is to implement the repair procedure. This will range from materials testing, to design of FRP, repair implementation, and finally monitoring. In order to determine failure modes for the PennDOT inventory, testing of scale models is suggested. Also, load rating before and after the repair is suggested to determine the overall effect of the FRP retrofit. A cost-benefit analysis is suggested after the repair to determine the feasibility of a wide-scale repair compared to conventional methods. Finally, long-term monitoring is suggested to evaluate the FRP-substrate bond. 


\section{Reference}

American Society of Civil Engineers (ACSE)

http://sections.asce.org/colorado/images/castlewood.jpg

Au T., and Au T. P. “Engineering Economics for Capital Investment Analysis.” Allyn and Bacon, Inc: 1993.

Davalos J.F., Lin C., Ray I., and Brayack D. “Applications of Externally Bonded Composites for Concrete Repair and Rehabilitation.” American Society for Composites, $20^{\text {th }}$ Annual Technical Conference. September 7-9, 2005. Drexel University, Philadelphia, Pa.

Davalos, J.F., Barth, K.E., Ray, I., Lin, C, Brayack, D.A., Matzzie, D., and Tysl, S.

“District 3-0 Investigation of Fiber-Wrap Technology for Bridge Repair and

Rehabilitation (Phase-I).” August 25 ${ }^{\text {th }}, 2005$.

Fafach, D., Shing, B., Chang, S., and Xi, Y. "Evaluation of the FRP-Retrofitted Arches in the Castlewood Canyon Bridge.” Report No. CDOT-DTD-R-2005-01. Department of Transportation Research, December 2004.

Fyfe CO LLC. "http://www.fyfeco.com/”

Fyfe Co. LLC, “Carbon Composite Laminate Strengthening.” Specifications,

Hag-Elsafi, Lund, R.,O., and Alampalli, A. "Strengthening of a Bridge Pier Capbeam Using Bonded FRP Composite Plates”. Composite Structures. 2002.

Hag-Elsafi, O., Alampalli, S., and Kunin, J. “Application of FRP Laminates for Strengthening of a Reinforced Concrete T-Beam Bridge Structure”. Composite Structures. 2001. 
Hag-Elsafi, O., Alampalli, S., and Kunin, J. "In-Service Evaluation of a Reinforced Concrete T-Beam Bridge FRP Strengthening System”. Composite Structures. 2003.

Microsoft Corporation. "Microsoft Office Project 2003.”

Microsoft Corporation. "Microsoft Streets and Maps.”

Neville, A.M. (1996). Properties of Concrete, 4th ed., John Wiley \& Sons, Inc., London, England.

Nystrom Halvard E., Watkins Steve E., Nanni Antonio, and Murray Susan. 2003.

"Financial Viability of Fiber-Reinforced Polymer (FRP) Bridges.” Journal of Management in Engineering, 19(1): 2-8.

Sen, R., and Mullins, G. "Issues Related to the FRP Wrap of Corroded Pilings." Composites 2004 Convention and Trade Show. Tampa, Florida, October 6-8 ${ }^{\text {th }}, 2004$.

The Times: Beaver Newspaper Inc. Pennsylvania. Thursday, 29 December 2005. UMR University. 2004. "Strengthening of Bridge T-0530, Crawford County, MO," Volume 2. (http://campus.umr.edu/utc/research/r098/reports/vol2/T-0530.pdf)

UMR University. 2004. "Strengthening of Bridge X-0596, Morgan County, MO," Volume 2. (http://campus.umr.edu/utc/research/r098/reports/vol2/X-0596.pdf) Xanthakos Petros P. “Bridge Strengthening and Rehabilitation.” Prentice Hall PTR; $1^{\text {st }}$ edition: 1995. 


\section{Appendix A}

\section{Details of Characteristics Classifications}

Class 1 Prime Candidate for Repair: (Total = 13)

\begin{tabular}{|c|c|c|c|c|c|c|c|c|c|c|c|c|}
\hline Listing & Bridge & Span & Span SC & $\mathrm{Yr}$ & Age SC & ADT & ADT SC & ADTT & ADTT SC & Visual & v sc & Rank \\
\hline 1 & 59-0045-0310-2011 & 30 & 4 & 38 & 5 & 10300 & 10 & 650 & 9 & 3 & 10.0 & 84.8 \\
\hline 2 & 59-0045-0430-1068 & 29 & 3 & 37 & 5 & 10300 & 10 & 650 & 9 & 3 & 10.0 & 83.8 \\
\hline 3 & $41-0220-0131-1268$ & 45 & 7 & 41 & 6 & 11000 & 10 & 1100 & 10 & 2 & 6.7 & 77.7 \\
\hline 4 & 41-2014-0380-0000 & 23 & 2 & 36 & 5 & 6900 & 9 & 340 & 7 & 3 & 10.0 & 77.5 \\
\hline 5 & 49-0405-0260-0942 & 27 & 3 & 30 & 4 & 5700 & 9 & 110 & 5 & 3 & 10.0 & 73.5 \\
\hline 6 & 19-1014-0052-0442 & 29 & 3 & 38 & 5 & 3300 & 8 & 100 & 5 & 3 & 10.0 & 73.3 \\
\hline 7 & $49-4012-0250-1032$ & 48 & 7 & 34 & 4 & 2200 & 6 & 100 & 5 & 3 & 10.0 & 72.3 \\
\hline 8 & 41-0118-0230-0644 & $80^{a}$ & 10 & 43 & 7 & 2600 & 7 & 300 & 7 & 2 & 6.7 & 71.7 \\
\hline 9 & $41-0042-0050-1036$ & 41 & 6 & 40 & 6 & 1700 & 6 & 62 & 3 & 3 & 10.0 & 70.8 \\
\hline 10 & 41-2005-0052-0000 & 39 & 5 & 25 & 3 & 2400 & 6 & 210 & 6 & 3 & 10.0 & 70.5 \\
\hline 11 & 41-2001-0130-0652 & 27 & 3 & 37 & 5 & 2600 & 7 & 80 & 4 & 3 & 10.0 & 69.8 \\
\hline 12 & $19-4003-0010-0082$ & $174^{\mathrm{b}}$ & 10 & 23 & 2 & 1200 & 5 & 80 & 4 & 3 & 10.0 & 68.8 \\
\hline 13 & 58-4024-0110-0000 & 46 & 7 & 34 & 4 & 650 & 4 & 110 & 5 & 3 & 10.0 & 68.8 \\
\hline
\end{tabular}

a. Two-span bridge, with overall span of 80 feet.

b. Three-span bridge, with overall span of 174 feet. 


\section{Appendix A (Continued)}

Class 2 Moderate Candidate for Repair: (Total = 44)

\begin{tabular}{|c|c|c|c|c|c|c|c|c|c|c|c|c|}
\hline Listing & Bridge & Span & Span SC & $\mathrm{Yr}$ & Age SC & ADT & ADT SC & ADTT & ADTT SC & Visual & V SC & Rank \\
\hline 1 & $41-0118-0290-0000$ & 41 & 6 & 43 & 7 & 2600 & 7 & 300 & 7 & 2 & 6.7 & 67.7 \\
\hline 2 & 41-0118-0030-1331 & 39 & 5 & 30 & 4 & 5600 & 9 & 410 & 8 & 2 & 6.7 & 67.4 \\
\hline 3 & 41-0118-0020-1109 & 31 & 4 & 30 & 4 & 5600 & 9 & 410 & 8 & 2 & 6.7 & 66.4 \\
\hline 4 & 49-0061-0016-1066 & $62^{a}$ & 9 & 34 & 4 & 5400 & 9 & 160 & 5 & 2 & 6.7 & 66.2 \\
\hline 5 & $41-0654-0210-1810$ & 48 & 7 & 34 & 4 & 6900 & 9 & 200 & 6 & 2 & 6.7 & 65.9 \\
\hline 6 & $54-0522-0210-0000$ & 39 & 5 & 29 & 3 & 6200 & 9 & 400 & 8 & 2 & 6.7 & 65.9 \\
\hline 7 & $41-0014-0220-0000$ & 27 & 3 & 30 & 4 & 3200 & 8 & 600 & 9 & 2 & 6.7 & 65.4 \\
\hline 8 & 54-0522-0090-1932 & $55^{b}$ & 8 & 29 & 3 & 4200 & 8 & 300 & 7 & 2 & 6.7 & 65.4 \\
\hline 9 & 41-0014-0260-0368 & 34 & 4 & 28 & 3 & 3200 & 8 & 600 & 9 & 2 & 6.7 & 64.9 \\
\hline 10 & $49-0225-0180-0000$ & 66 & 9 & 27 & 3 & 3000 & 8 & 200 & 6 & 2 & 6.7 & 64.7 \\
\hline 11 & $19-1025-0050-0000$ & 41 & 6 & 41 & 6 & 3700 & 8 & 110 & 5 & 2 & 6.7 & 64.4 \\
\hline 12 & $58-0414-0350-0000$ & 31 & 4 & 41 & 6 & 2500 & 7 & 300 & 7 & 2 & 6.7 & 64.2 \\
\hline 13 & $41-0442-0160-0000$ & $97^{\mathrm{C}}$ & 10 & 27 & 3 & 3800 & 8 & 130 & 5 & 2 & 6.7 & 63.9 \\
\hline 14 & 59-0304-0060-1859 & 45 & 7 & 41 & 6 & 3011 & 8 & 90 & 4 & 2 & 6.7 & 63.7 \\
\hline 15 & $54-0522-0230-1430$ & 24 & 2 & 27 & 3 & 6300 & 9 & 400 & 8 & 2 & 6.7 & 62.9 \\
\hline 16 & $19-0239-0060-0511$ & 33 & 4 & 26 & 3 & 1800 & 6 & 40 & 2 & 3 & 10.0 & 62.5 \\
\hline 17 & 49-1039-0020-0000 & 30 & 4 & 30 & 4 & 500 & 4 & 50 & 3 & 3 & 10.0 & 62.3 \\
\hline 18 & $56-0220-0550-0000$ & 30 & 4 & 25 & 3 & 3400 & 8 & 340 & 7 & 2 & 6.7 & 61.4 \\
\hline 19 & $58-4002-0020-0000$ & 33 & 4 & 35 & 5 & 3700 & 8 & 120 & 5 & 2 & 6.7 & 60.9 \\
\hline 20 & 59-0015-0091-1230 & 50 & 8 & 30 & 4 & 9900 & 9 & 1300 & 10 & 1 & 3.3 & 60.6 \\
\hline 21 & $19-0042-0690-1821$ & 29 & 3 & 55 & 10 & 5400 & 9 & 350 & 7 & 1 & 3.3 & 59.3 \\
\hline
\end{tabular}

a. Two-span bridge with overall span length of 62 feet.

b. Two-span bridge with overall span length of 55 feet.

c. Two-span bridge with overall span length of 97 feet. 


\section{Appendix A (Continued)}

\section{Class 2 (continued)}

\begin{tabular}{|c|c|c|c|c|c|c|c|c|c|c|c|c|}
\hline Listing & Bridge & Span & Span SC & Yr & Age SC & ADT & ADT SC & ADTT & ADTT SC & Visual & V SC & Rank \\
\hline 22 & 59-0045-0350-0000 & 27 & 3 & 40 & 6 & 10300 & 10 & 650 & 9 & 1 & 3.3 & 58.6 \\
\hline 23 & $58-0249-0322-0000$ & 51 & 8 & 36 & 5 & 1260 & 5 & 80 & 4 & 2 & 6.7 & 57.9 \\
\hline 24 & $19-4006-0082-0000$ & $48^{a}$ & 7 & 34 & 4 & 1000 & 5 & 150 & 5 & 2 & 6.7 & 57.2 \\
\hline 25 & $58-0249-0062-0000$ & 48 & 7 & 32 & 4 & 1500 & 6 & 90 & 4 & 2 & 6.7 & 57.2 \\
\hline 26 & 08-4034-0140-1580 & 50 & 8 & 52 & 9 & 350 & 3 & 35 & 2 & 2 & 6.7 & 56.9 \\
\hline 27 & 19-0442-0050-0264 & 37 & 5 & 31 & 4 & 2100 & 6 & 100 & 5 & 2 & 6.7 & 56.9 \\
\hline 28 & 08-0414-0200-0000 & 30 & 4 & 26 & 3 & 1500 & 6 & 200 & 6 & 2 & 6.7 & 56.2 \\
\hline 29 & 19-2009-0010-0594 & 41 & 6 & 30 & 4 & 2500 & 7 & 70 & 3 & 2 & 6.7 & 56.2 \\
\hline 30 & 58-2014-0152-0000 & 34 & 4 & 37 & 5 & 100 & 1 & 7 & 1 & 3 & 10.0 & 55.0 \\
\hline 31 & 49-0225-0380-0000 & 29 & 3 & 34 & 4 & 1500 & 6 & 130 & 5 & 2 & 6.7 & 54.9 \\
\hline 32 & 08-0014-0580-0000 & 27 & 3 & 57 & 10 & 2500 & 7 & 250 & 6 & 1 & 3.3 & 54.1 \\
\hline 33 & $41-0014-0100-0000$ & 43 & 6 & 28 & 3 & 4000 & 8 & 600 & 9 & 1 & 3.3 & 53.6 \\
\hline 34 & 08-4013-0250-1496 & 25 & 3 & 27 & 3 & 1600 & 6 & 160 & 5 & 2 & 6.7 & 53.4 \\
\hline 35 & $54-0522-0140-0000$ & $67^{b}$ & 9 & 29 & 3 & 4200 & 8 & 300 & 7 & 1 & 3.3 & 53.1 \\
\hline 36 & 19-0093-0110-1085 & 27 & 3 & 73 & 10 & 3900 & 8 & 75 & 4 & 1 & 3.3 & 52.3 \\
\hline 37 & 49-0054-0090-0835 & 25 & 3 & 59 & 10 & 3000 & 8 & 90 & 4 & 1 & 3.3 & 52.3 \\
\hline 38 & $49-3010-0110-0000$ & 48 & 7 & 31 & 4 & 636 & 4 & 60 & 3 & 2 & 6.7 & 51.9 \\
\hline 39 & 49-0642-0130-0000 & 29 & 3 & 30 & 4 & 2200 & 6 & 70 & 3 & 2 & 6.7 & 51.4 \\
\hline 40 & 49-2002-0010-1145 & 44 & 6 & 35 & 5 & 740 & 4 & 40 & 2 & 2 & 6.7 & 50.7 \\
\hline 41 & 58-0015-0820-2041 & 37 & 5 & 42 & 7 & 12300 & 10 & 2100 & 10 & 0 & 0.0 & 50.5 \\
\hline 42 & $19-4036-0012-0000$ & 48 & 7 & 26 & 3 & 500 & 4 & 60 & 3 & 2 & 6.7 & 50.4 \\
\hline 43 & 54-2013-0010-0000 & 23 & 2 & 22 & 2 & 200 & 2 & 20 & 1 & 3 & 10.0 & 50.3 \\
\hline 44 & 49-4018-0010-0649 & 27 & 3 & 22 & 2 & 3400 & 8 & 40 & 2 & 2 & 6.7 & 50.2 \\
\hline
\end{tabular}

a. Two-span bridge with overall span length of 48 feet.

b. Two-span bridge with overall span length of 67 feet. 


\section{Appendix A (Continued)}

\section{Class 3 Low Candidate for Repair: $($ Total = 71)}

\begin{tabular}{|c|c|c|c|c|c|c|c|c|c|c|c|c|}
\hline Listing & Bridge & Span & Span SC & $\mathrm{Yr}$ & Age SC & ADT & ADT SC & ADTT & ADTT SC & Visual & V Sc & Rank \\
\hline 1 & 59-1001-0110-2058 & 32 & 4 & 21 & 2 & 1400 & 5 & 80 & 4 & 2 & 6.7 & 49.4 \\
\hline 2 & $54-0522-0040-0000$ & 35 & 5 & 27 & 3 & 3000 & 8 & 360 & 7 & 1 & 3.3 & 49.1 \\
\hline 3 & $56-0220-0530-0988$ & 33 & 4 & 25 & 3 & 4300 & 8 & 340 & 7 & 1 & 3.3 & 48.1 \\
\hline 4 & $41-1005-0130-0000$ & 39 & 5 & 40 & 6 & 300 & 3 & 4 & 1 & 2 & 6.7 & 47.7 \\
\hline 5 & $58-0249-0112-2535$ & 23 & 2 & 52 & 9 & 1500 & 6 & 90 & 4 & 1 & 3.3 & 46.3 \\
\hline 6 & $41-0414-0080-0000$ & 25 & 3 & 37 & 5 & 300 & 3 & 30 & 2 & 2 & 6.7 & 45.9 \\
\hline 7 & 54-2004-0030-1543 & 33 & 4 & 41 & 6 & 160 & 2 & 13 & 1 & 2 & 6.7 & 44.9 \\
\hline 8 & $59-0045-0440-1302$ & 33 & 4 & 38 & 5 & 10300 & 10 & 650 & 9 & 0 & 0.0 & 44.8 \\
\hline 9 & 54-2016-0050-0000 & 29 & 3 & 42 & 7 & 1100 & 5 & 100 & 5 & 1 & 3.3 & 44.3 \\
\hline 10 & $19-0042-0090-0000$ & 33 & 4 & 40 & 6 & 2200 & 6 & 75 & 4 & 1 & 3.3 & 43.8 \\
\hline 11 & $19-1025-0050-1308$ & 33 & 4 & 41 & 6 & 2900 & 7 & 70 & 3 & 1 & 3.3 & 43.8 \\
\hline 12 & 59-2001-0020-0000 & 33 & 4 & 32 & 4 & 440 & 3 & 20 & 1 & 2 & 6.7 & 43.7 \\
\hline 13 & $58-1002-0050-0000$ & 27 & 3 & 17 & 1 & 600 & 4 & 60 & 3 & 2 & 6.7 & 43.4 \\
\hline 14 & $19-4045-0030-1814$ & 35 & 5 & 34 & 4 & 220 & 2 & 20 & 1 & 2 & 6.7 & 42.9 \\
\hline 15 & $59-3006-0050-0282$ & 23 & 2 & 45 & 7 & 120 & 1 & 12 & 1 & 2 & 6.7 & 42.7 \\
\hline 16 & $59-2009-0040-0000$ & 23 & 2 & 30 & 4 & 1500 & 6 & 200 & 6 & 1 & 3.3 & 42.3 \\
\hline 17 & 08-4031-0200-0000 & 23 & 2 & 29 & 3 & 360 & 3 & 35 & 2 & 2 & 6.7 & 41.9 \\
\hline 18 & $58-2005-0220-0320$ & 33 & 4 & 42 & 7 & 950 & 4 & 80 & 4 & 1 & 3.3 & 41.8 \\
\hline 19 & 49-3018-0120-1195 & 35 & 5 & 38 & 5 & 1000 & 5 & 90 & 4 & 1 & 3.3 & 41.6 \\
\hline 20 & $41-2019-0080-0000$ & 27 & 3 & 37 & 5 & 140 & 1 & 10 & 1 & 2 & 6.7 & 40.7 \\
\hline 21 & $54-0522-0150-1440$ & 40 & 6 & 28 & 3 & 5200 & 9 & 400 & 8 & 0 & 0 & 40.25 \\
\hline 22 & 19-3008-0100-0039 & 23 & 2 & 33 & 4 & 270 & 2 & 20 & 1 & 2 & 6.7 & 39.9 \\
\hline 23 & $56-0154-0050-0000$ & 50 & 8 & 35 & 5 & 360 & 3 & 70 & 3 & 1 & 3.3 & 39.3 \\
\hline 24 & 08-0414-0230-1008 & 26 & 3 & 19 & 1 & 1500 & 6 & 200 & 6 & 1 & 3.3 & 38.8 \\
\hline 25 & 54-0104-0120-2462 & 29 & 3 & 30 & 4 & 5200 & 9 & 450 & 8 & 0 & 0.0 & 38.8 \\
\hline 26 & $54-0104-0230-0000$ & 27 & 3 & 30 & 4 & 5600 & 9 & 450 & 8 & 0 & 0.0 & 38.8 \\
\hline
\end{tabular}


Class 3 (continued)

\begin{tabular}{|c|c|c|c|c|c|c|c|c|c|c|c|c|}
\hline Listing & Bridge & Span & Span SC & Yr & Age SC & ADT & ADT SC & ADTT & ADTT SC & Visual & v sc & Rank \\
\hline 27 & 54-0522-0110-0469 & $55^{a}$ & 8 & 29 & 3 & 4200 & 8 & 300 & 7 & 0 & 0.0 & 38.8 \\
\hline 28 & $58-0549-0020-0000$ & 32 & 4 & 53 & 9 & 2700 & 7 & 160 & 5 & 0 & 0.0 & 38.5 \\
\hline 29 & 54-4012-0130-0000 & 35 & 5 & 39 & 5 & 560 & 4 & 50 & 3 & 1 & 3.3 & 38.1 \\
\hline 30 & $58-0006-0610-0000$ & 19 & 1 & 42 & 7 & 6500 & 9 & 260 & 6 & 0 & 0.0 & 37.8 \\
\hline 31 & $58-2016-0260-0543$ & 38 & 5 & 42 & 7 & 900 & 4 & 20 & 1 & 1 & 3.3 & 37.6 \\
\hline 32 & $58-1022-0090-0000$ & 31 & 4 & 38 & 5 & 300 & 3 & 30 & 2 & 1 & 3.3 & 33.6 \\
\hline 33 & $54-0235-0150-0000$ & $94^{b}$ & 10 & 30 & 4 & 1100 & 5 & 100 & 5 & 0 & 0.0 & 33.5 \\
\hline 34 & 49-4001-0090-0066 & 25 & 3 & 41 & 6 & 2700 & 7 & 160 & 5 & 0 & 0.0 & 33.0 \\
\hline 35 & $54-4012-0020-0000$ & 25 & 3 & 38 & 5 & 460 & 3 & 40 & 2 & 1 & 3.3 & 32.6 \\
\hline 36 & $54-0235-0140-0239$ & $78^{\mathrm{C}}$ & 9 & 30 & 4 & 1100 & 5 & 100 & 5 & 0 & 0.0 & 32.5 \\
\hline 37 & 58-2014-0040-0946 & 38 & 5 & 59 & 10 & 1200 & 5 & 40 & 2 & 0 & 0.0 & 32.3 \\
\hline 38 & 58-2014-0050-0815 & 38 & 5 & 59 & 10 & 1200 & 5 & 40 & 2 & 0 & 0.0 & 32.3 \\
\hline 39 & $54-4003-0030-0254$ & 44 & 6 & 48 & 8 & 1100 & 5 & 50 & 3 & 0 & 0.0 & 32.0 \\
\hline 40 & $58-0414-0430-0190$ & 42 & 6 & 57 & 10 & 330 & 3 & 50 & 3 & 0 & 0.0 & 31.5 \\
\hline 41 & 49-3010-0160-0263 & $84^{d}$ & 10 & 40 & 6 & 750 & 4 & 70 & 3 & 0 & 0.0 & 31.3 \\
\hline 42 & $58-2014-0092-0000$ & 50 & 8 & 34 & 4 & 100 & 1 & 7 & 1 & 1 & 3.3 & 30.8 \\
\hline 43 & 54-0235-0120-0094 & 43 & 6 & 30 & 4 & 1100 & 5 & 100 & 5 & 0 & 0.0 & 29.5 \\
\hline 44 & $58-0006-0020-0000$ & $67^{e}$ & 9 & 24 & 2 & 3500 & 8 & 32 & 2 & 0 & 0.0 & 29.5 \\
\hline 45 & $58-0414-0110-0261$ & 36 & 5 & 57 & 10 & 310 & 3 & 40 & 2 & 0 & 0.0 & 28.8 \\
\hline 46 & $54-2010-0040-1803$ & 25 & 3 & 37 & 5 & 120 & 1 & 10 & 1 & 1 & 3.3 & 27.3 \\
\hline 47 & 59-3001-0010-1018 & 30 & 4 & 25 & 3 & 200 & 2 & 15 & 1 & 1 & 3.3 & 27.1 \\
\hline 48 & $58-1026-0040-0304$ & 35 & 5 & 59 & 10 & 300 & 3 & 15 & 1 & 0 & 0.0 & 27.0 \\
\hline 49 & $58-3014-0120-0000$ & 27 & 3 & 57 & 10 & 350 & 3 & 35 & 2 & 0 & 0 & 26.75 \\
\hline 50 & $41-2083-0040-1285$ & 26 & 3 & 34 & 4 & 140 & 1 & 10 & 1 & 1 & 3.3 & 25.8 \\
\hline 51 & 49-4006-0160-0589 & 27 & 3 & 60 & 10 & 480 & 3 & 5 & 1 & 0 & 0.0 & 25.0 \\
\hline
\end{tabular}

a. Two-span bridge with overall span length of 55 feet.

b. Two-span bridge with overall span length of 94 feet.

c. Two-span bridge with overall span length of 78 feet.

d. Two-span bridge with overall span length of 84 feet.

e. Two-span bridge with overall span length of 67 feet. 


\section{Appendix A (Continued)}

\section{Class 3 (continued)}

\begin{tabular}{|c|c|c|c|c|c|c|c|c|c|c|c|c|}
\hline Listing & Bridge & Span & Span SC & Yr & Age SC & ADT & ADT SC & ADTT & ADTT SC & Visual & V SC & Rank \\
\hline 52 & $58-0414-0540-1036$ & 19 & 1 & 54 & 9 & 330 & 3 & 50 & 3 & 0 & 0.0 & 25.0 \\
\hline 53 & $54-3012-0080-0000$ & 27 & 3 & 37 & 5 & 520 & 4 & 80 & 4 & 0 & 0.0 & 24.5 \\
\hline 54 & 49-4022-0010-1591 & 23 & 2 & 22 & 2 & 230 & 2 & 10 & 1 & 1 & 3.3 & 23.6 \\
\hline 55 & 49-2001-0020-0000 & 23 & 2 & 28 & 3 & 120 & 1 & 10 & 1 & 1 & 3.3 & 23.3 \\
\hline 56 & 58-3006-0060-3546 & 33 & 4 & 50 & 9 & 150 & 2 & 15 & 1 & 0 & 0.0 & 22.8 \\
\hline 57 & 54-2012-0090-0091 & 29 & 3 & 51 & 9 & 210 & 2 & 2 & 1 & 0 & 0.0 & 21.8 \\
\hline 58 & 49-3011-0010-0238 & 27 & 3 & 57 & 10 & 70 & 1 & 6 & 1 & 0 & 0.0 & 21.5 \\
\hline 59 & 56-0154-0150-1564 & 26 & 3 & 35 & 5 & 360 & 3 & 70 & 3 & 0 & 0.0 & 21.0 \\
\hline 60 & $56-4008-0080-0000$ & 30 & 4 & 50 & 9 & 120 & 1 & 10 & 1 & 0 & 0.0 & 21.0 \\
\hline 61 & 49-3003-0020-0645 & 24 & 2 & 22 & 2 & 1000 & 5 & 90 & 4 & 0 & 0.0 & 20.8 \\
\hline 62 & 59-1003-0140-0921 & 35 & 5 & 36 & 5 & 385 & 3 & 10 & 1 & 0 & 0.0 & 19.5 \\
\hline 63 & 54-2003-0020-0000 & 23 & 2 & 49 & 8 & 150 & 2 & 6 & 1 & 0 & 0.0 & 19.3 \\
\hline 64 & 56-4020-0010-0000 & 26 & 3 & 49 & 8 & 140 & 1 & 10 & 1 & 0 & 0.0 & 18.5 \\
\hline 65 & 56-1010-0030-0980 & 19 & 1 & 51 & 9 & 110 & 1 & 10 & 1 & 0 & 0.0 & 18.0 \\
\hline 66 & 56-1002-0110-0000 & 22 & 2 & 41 & 6 & 100 & 1 & 10 & 1 & 0 & 0.0 & 14.5 \\
\hline 67 & $56-1002-0140-0000$ & 15 & 1 & 40 & 6 & 100 & 1 & 10 & 1 & 0 & 0.0 & 13.5 \\
\hline 68 & $49-4020-0010-1014$ & 31 & 4 & 21 & 2 & 230 & 2 & 20 & 1 & 0 & 0.0 & 12.3 \\
\hline 69 & 49-2005-0040-1415 & 24 & 2 & 30 & 4 & 130 & 1 & 10 & 1 & 0 & 0.0 & 11.5 \\
\hline 70 & 58-1004-0120-1913 & 27 & 3 & 19 & 1 & 300 & 3 & 9 & 1 & 0 & 0 & 11.5 \\
\hline 71 & 54-2004-0020-0000 & 23 & 2 & 22 & 2 & 160 & 2 & 13 & 1 & 0 & 0 & 10.25 \\
\hline
\end{tabular}




\section{Appendix B}

\section{Classification Based on Local Damage}

Bridge Damage Ranking of 3: Severe Local Damage (Total = 15)

\begin{tabular}{|c|r|r|l|}
\hline Bridge & Visual & V SC & \multicolumn{1}{|c|}{ Description } \\
\hline $41-2014-0380-0000$ & 3 & 10.0 & Extensive and moderate damage \\
\hline $59-0045-0310-2011$ & 3 & 10.0 & Extensive damage \\
\hline $59-0045-0430-1068$ & 3 & 10.0 & Extensive damage \\
\hline $49-0405-0260-0942$ & 3 & 10.0 & Extensive damage \\
\hline $19-1014-0052-0442$ & 3 & 10.0 & Extensive damage \\
\hline $49-4012-0250-1032$ & 3 & 10.0 & Extensive to moderate damage. \\
\hline $41-2005-0052-0000$ & 3 & 10.0 & Extensive damage \\
\hline $41-2001-0130-0652$ & 3 & 10.0 & Extensive damage \\
\hline $19-4003-0010-0082$ & 3 & 10.0 & Extensive damage to rebars, replace? \\
\hline $58-4024-0110-0000$ & 3 & 10.0 & Extensive damage \\
\hline $19-0239-0060-0511$ & 3 & 10.0 & Extensive damage \\
\hline $49-1039-0020-0000$ & 3 & 10.0 & Extensive damage \\
\hline $58-2014-0152-0000$ & 3 & 10.0 & Extensive damage \\
\hline $54-2013-0010-0000$ & 3 & 10.0 & Extensive damage \\
\hline $41-0042-0050-1036$ & 3 & 10.0 & Extensive damage \\
\hline
\end{tabular}

Bridge Damage Ranking of 2: Moderate Local Damage $($ Total $=44)$

\begin{tabular}{|c|r|r|l|}
\hline Bridge & Visual & \multicolumn{1}{c|}{$\begin{array}{c}\text { V } \\
\text { Sc }\end{array}$} & \multicolumn{1}{|c|}{ Description } \\
\hline $41-0118-0230-0644$ & 2 & 6.7 & Severe overall damage, minor local damage, replace? \\
\hline $58-0414-0350-0000$ & 2 & 6.7 & Minor local damage \\
\hline $49-3010-0110-0000$ & 2 & 6.7 & Extensive local damage \\
\hline $41-0220-0131-1268$ & 2 & 6.7 & Extensive local damage \\
\hline $41-0118-0290-0000$ & 2 & 6.7 & Extensive local damage \\
\hline $41-0118-0030-1331$ & 2 & 6.7 & Extensive local damage \\
\hline $41-0118-0020-1109$ & 2 & 6.7 & Extensive local damage \\
\hline $49-0061-0016-1066$ & 2 & 6.7 & Extensive local damage \\
\hline $41-0654-0210-1810$ & 2 & 6.7 & Extensive local damage \\
\hline $54-0522-0210-0000$ & 2 & 6.7 & Extensive local damage \\
\hline $41-0014-0220-0000$ & 2 & 6.7 & Moderate overall damage \\
\hline $54-0522-0090-1932$ & 2 & 6.7 & Moderate local damage \\
\hline $41-0014-0260-0368$ & 2 & 6.7 & Moderate local damage \\
\hline $49-0225-0180-0000$ & 2 & 6.7 & Moderate local damage \\
\hline $19-1025-0050-0000$ & 2 & 6.7 & Extensive local damage \\
\hline $41-0442-0160-0000$ & 2 & 6.7 & Extensive local damage \\
\hline $59-0304-0060-1859$ & 2 & 6.7 & Moderate local damage \\
\hline $54-0522-0230-1430$ & 2 & 6.7 & Extensive local damage \\
\hline $56-0220-0550-0000$ & 2 & 6.7 & Moderate local damage \\
\hline $58-4002-0020-0000$ & 2 & 6.7 & Extensive local damage \\
\hline $58-0249-0322-0000$ & 2 & 6.7 & Moderate local damage \\
\hline $19-4006-0082-0000$ & 2 & 6.7 & Extensive local damage \\
\hline
\end{tabular}




\section{Appendix B (continued)}

\section{Bridge Damage Ranking of 2 (continued)}

\begin{tabular}{|l|r|r|l|}
\hline Bridge & Visual & \multicolumn{1}{|c|}{$\begin{array}{c}\text { S } \\
\text { SC }\end{array}$} & \multicolumn{1}{|c|}{ Description } \\
\hline $58-0249-0062-0000$ & 2 & 6.7 & Extensive local damage \\
\hline $08-4034-0140-1580$ & 2 & 6.7 & Extensive local damage \\
\hline $19-0442-0050-0264$ & 2 & 6.7 & Extensive local damage \\
\hline $08-0414-0200-0000$ & 2 & 6.7 & Extensive damage to ext beam, damage to deck \\
\hline $19-2009-0010-0594$ & 2 & 6.7 & Extensive local damage \\
\hline $49-0225-0380-0000$ & 2 & 6.7 & Moderate local damage \\
\hline $08-4013-0250-1496$ & 2 & 6.7 & Extensive local damage \\
\hline $49-0642-0130-0000$ & 2 & 6.7 & Moderate local damage \\
\hline $49-2002-0010-1145$ & 2 & 6.7 & Extensive local damage \\
\hline $19-4036-0012-0000$ & 2 & 6.7 & Extensive local damage \\
\hline $49-4018-0010-0649$ & 2 & 6.7 & Extensive local damage \\
\hline $59-1001-0110-2058$ & 2 & 6.7 & Extensive local damage \\
\hline $41-1005-0130-0000$ & 2 & 6.7 & Extensive local damage \\
\hline $41-0414-0080-0000$ & 2 & 6.7 & Extensive local damage \\
\hline $54-2004-0030-1543$ & 2 & 6.7 & Moderate local damage \\
\hline $59-2001-0020-0000$ & 2 & 6.7 & Moderate local damage \\
\hline $58-1002-0050-0000$ & 2 & 6.7 & Moderate overall damage \\
\hline $19-4045-0030-1814$ & 2 & 6.7 & Extensive local damage \\
\hline $59-3006-0050-0282$ & 2 & 6.7 & Moderate local damage \\
\hline $08-4031-0200-0000$ & 2 & 6.7 & Extensive local damage \\
\hline $41-2019-0080-0000$ & 2 & 6.7 & Moderate local damage \\
\hline $19-3008-0100-0039$ & 2 & 6.7 & Minor but global damage \\
\hline
\end{tabular}




\section{Appendix B (continued)}

\section{Bridge Damage Ranking of 1: Minimal Damage $($ Total = 29)}

\begin{tabular}{|l|r|r|l|}
\hline \multicolumn{1}{|c|}{ Bridge } & Visual & $\begin{array}{c}\text { V } \\
\text { Sc }\end{array}$ & \multicolumn{1}{|c|}{ Description } \\
\hline $59-0015-0091-1230$ & 1 & 3.3 & Minor overall damage \\
\hline $19-0042-0690-1821$ & 1 & 3.3 & Minor local damage \\
\hline $59-0045-0350-0000$ & 1 & 3.3 & Minor overall damage \\
\hline $08-0014-0580-0000$ & 1 & 3.3 & Minor damages \\
\hline $41-0014-0100-0000$ & 1 & 3.3 & Minor damages \\
\hline $54-0522-0140-0000$ & 1 & 3.3 & Minor damages to deck \\
\hline $19-0093-0110-1085$ & 1 & 3.3 & Extensive narrowly local damage \\
\hline $49-0054-0090-0835$ & 1 & 3.3 & Minor damages \\
\hline $54-0522-0040-0000$ & 1 & 3.3 & Minor local damage \\
\hline $56-0220-0530-0988$ & 1 & 3.3 & Minor local damage \\
\hline $58-0249-0112-2535$ & 1 & 3.3 & Minor local damage \\
\hline $19-0042-0090-0000$ & 1 & 3.3 & General overall damage, should investigate \\
\hline $19-1025-0050-1308$ & 1 & 3.3 & Minor local damage \\
\hline $59-2009-0040-0000$ & 1 & 3.3 & Minor local damage \\
\hline $58-2005-0220-0320$ & 1 & 3.3 & Minor local damage \\
\hline $49-3018-0120-1195$ & 1 & 3.3 & Minor local damage \\
\hline $56-0154-0050-0000$ & 1 & 3.3 & Minor local damage \\
\hline $08-0414-0230-1008$ & 1 & 3.3 & Minor damages \\
\hline $54-4012-0130-0000$ & 1 & 3.3 & Minor local damage \\
\hline $58-2016-0260-0543$ & 1 & 3.3 & Minor overall damage \\
\hline $58-1022-0090-0000$ & 1 & 3.3 & Moderate local damage \\
\hline $54-4012-0020-0000$ & 1 & 3.3 & Minor local damage \\
\hline $58-2014-0092-0000$ & 1 & 3.3 & Minor overall damage \\
\hline $54-2010-0040-1803$ & 1 & 3.3 & Minor local damage \\
\hline $59-3001-0010-1018$ & 1 & 3.3 & Minor local damage \\
\hline $41-2083-0040-1285$ & 1 & 3.3 & Minor damages \\
\hline $49-4022-0010-1591$ & 1 & 3.3 & Minor local damage \\
\hline $49-2001-0020-0000$ & 1 & 3.3 & Minor damages \\
\hline $54-2016-0050-0000$ & 1 & 3.3 & Extensive local damage \\
\hline
\end{tabular}




\section{Appendix B (continued)}

\section{Bridges with No Visual Damage $($ Total $=40)$}

\begin{tabular}{|l|r|r|l|}
\hline \multicolumn{1}{|c|}{ Bridge } & Visual & $\begin{array}{c}\text { V } \\
\text { SC }\end{array}$ & \\
\hline $58-0015-0820-2041$ & 0 & 0.0 & No visible damage \\
\hline $59-0045-0440-1302$ & 0 & 0.0 & No visible damage \\
\hline $54-0522-0150-1440$ & 0 & 0.0 & No visible damage \\
\hline $54-0104-0120-2462$ & 0 & 0.0 & No visible damage \\
\hline $54-0104-0230-0000$ & 0 & 0.0 & No visible damage \\
\hline $54-0522-0110-0469$ & 0 & 0.0 & Minor damages \\
\hline $58-0549-0020-0000$ & 0 & 0.0 & Abutment failure not applicable \\
\hline $58-0006-0610-0000$ & 0 & 0.0 & No visible damage \\
\hline $54-0235-0150-0000$ & 0 & 0.0 & No visible damage \\
\hline $49-4001-0090-0066$ & 0 & 0.0 & No visible damage \\
\hline $54-0235-0140-0239$ & 0 & 0.0 & No visible damage \\
\hline $58-2014-0040-0946$ & 0 & 0.0 & No visible damage \\
\hline $58-2014-0050-0815$ & 0 & 0.0 & No visible damage \\
\hline $54-4003-0030-0254$ & 0 & 0.0 & No visible damage \\
\hline $58-0414-0430-0190$ & 0 & 0.0 & No visible damage \\
\hline $49-3010-0160-0263$ & 0 & 0.0 & No visible damage \\
\hline $54-0235-0120-0094$ & 0 & 0.0 & No visible damage \\
\hline $58-0006-0020-0000$ & 0 & 0.0 & No visible damage \\
\hline $58-0414-0110-0261$ & 0 & 0.0 & No visible damage \\
\hline $58-1026-0040-0304$ & 0 & 0.0 & No visible damage \\
\hline $58-3014-0120-0000$ & 0 & 0.0 & No visible damage \\
\hline $49-4006-0160-0589$ & 0 & 0.0 & No visible damage \\
\hline $58-0414-0540-1036$ & 0 & 0.0 & No visible damage \\
\hline
\end{tabular}




\section{Appendix B (continued)}

\section{Bridges with No Visual Damage (continued)}

\begin{tabular}{|l|r|r|l|}
\hline Bridge & Visual & $\begin{array}{c}\text { V } \\
\text { Sc }\end{array}$ & \\
\hline $54-3012-0080-0000$ & 0 & 0.0 & No visible damage \\
\hline $58-3006-0060-3546$ & 0 & 0.0 & No visible damage \\
\hline $54-2012-0090-0091$ & 0 & 0.0 & No visible damage \\
\hline $49-3011-0010-0238$ & 0 & 0.0 & Minor damages \\
\hline $56-0154-0150-1564$ & 0 & 0.0 & No visible damage \\
\hline $56-4008-0080-0000$ & 0 & 0.0 & No visible damage \\
\hline $49-3003-0020-0645$ & 0 & 0.0 & No visible damage \\
\hline $59-1003-0140-0921$ & 0 & 0.0 & No visible damage \\
\hline $54-2003-0020-0000$ & 0 & 0.0 & Minor local damage \\
\hline $56-4020-0010-0000$ & 0 & 0.0 & No visible damage \\
\hline $56-1010-0030-0980$ & 0 & 0.0 & No visible damage \\
\hline $56-1002-0110-0000$ & 0 & 0.0 & No visible damage \\
\hline $56-1002-0140-0000$ & 0 & 0.0 & No visible damage \\
\hline $49-4020-0010-1014$ & 0 & 0.0 & No visible damage \\
\hline $49-2005-0040-1415$ & 0 & 0.0 & No visible damage \\
\hline $58-1004-0120-1913$ & 0 & 0.0 & No visible damage \\
\hline $54-2004-0020-0000$ & 0 & 0.0 & No visible damage \\
\hline
\end{tabular}

